\title{
COUNTERCURRENT FLOW LIMITATION EXPERIMENTS AND MODELING FOR IMPROVED REACTOR SAFETY
}

\author{
Final Technical Report \\ July 1, 2005 through June 30, 2008
}

Contact and Principal Investigator:

Dr. Karen Vierow

Tel.: 979-458-0600

Email: vierow@ne.tamu.edu

Contributing Authors:

Dr. Isaac Choutapalli, Post Doctoral Associate

Mr. Kevin Hogan, Graduate Research Assistant

Dr. Yehong Liao, former Graduate Research Assistant

Mr. Matthew Solmos, Graduate Research Assistant

Ms. Susan Niki Williams, Graduate Research Assistant

Submitted September 26, 2008

Award Number: DE-FG07-05ID14696

Submitted to:

U. S. Department of Energy

Nuclear Engineering Education Research

DOE Project Manager:

Dr. Nancy Elizondo

DOE HQ Program Manager:

Dr. Michelle Scott

DOE Contracting Officer:

Dr. Elizabeth Dahl

Awardee:

Purdue University

Nuclear Engineering Department

Texas A\&M University

129 Zachry Engineering Center, 3133 TAMU

College Station, TX 77843-3133 


\section{DISCLAIMER}

This report was prepared as an account of work sponsored by an agency of the United States Government. Neither the United States Government nor any agency thereof, nor any of their employees, makes any warranty, express or implied, or assumes any legal liability or responsibility for the accuracy, completeness, or usefulness of any information, apparatus, product, or process disclosed, or represents that its use would not infringe privately owned rights. Reference herein to any specific commercial product, process, or service by trade name, trademark, manufacturer, or otherwise does not necessarily constitute or imply its endorsement, recommendation, or favoring by the United States Government or any agency thereof. The views and opinions of authors expressed herein do not necessarily state or reflect those of the United States Government or any agency thereof. 


\begin{abstract}
This project is investigating countercurrent flow and "flooding" phenomena in light water reactor systems to improve reactor safety of current and future reactors.

To better understand the occurrence of flooding in the surge line geometry of a PWR, two experimental programs were performed. In the first, a test facility with an acrylic test section provided visual data on flooding for air-water systems in large diameter tubes. This test section also allowed for development of techniques to form an annular liquid film along the inner surface of the "surge line" and other techniques which would be difficult to verify in an opaque test section.

Based on experiences in the air-water testing and the improved understanding of flooding phenomena, two series of tests were conducted in a large-diameter, stainless steel test section. Air-water test results and steam-water test results were directly compared to note the effect of condensation. Results indicate that, as for smaller diameter tubes, the flooding phenomena is predominantly driven by the hydrodynamics.

Tests with the test sections inclined were attempted but the annular film was easily disrupted. A theoretical model for steam venting from inclined tubes is proposed herein and validated against air-water data.

Empirical correlations were proposed for air-water and steam-water data. Methods for developing analytical models of the air-water and steam-water systems are discussed, as is the applicability of the current data to the surge line conditions.
\end{abstract}

This report documents the project results from July 1, 2005 through June 30, 2008. 


\section{Table of Contents}

Abstract 3

List of Figures

List of Tables $\ldots$

Executive Summary

1. Introduction

1.1 Motivation for Improved Flooding Models for the Pressurizer Surge Line $\quad 10$

1.2 Occurrence of flooding in Reactor Systems

1.3 Need for Improved flooding Models for the Pressurizer Surge Line $\quad 10$

1.4 Previous Research on flooding

2. Project Objectives and Tasks 15

2.1 Objectives

2.2 Tasks

3. Project Activities $\ldots$

3.1 Air-Water Experiments

3.2 Steam-Water Experiments

3.3 Experiments with Inclined Tubes 87

3.4 Model Development

4. Conclusions

5. References

6. Publications Arising from this Award 


\section{List of Figures}

Figure 3.1 Relationship between liquid flow rate and air flow rate at flooding [7] 19

Figure 3.2 Richter's data for a variety of tube geometries [18] $\ldots 22$

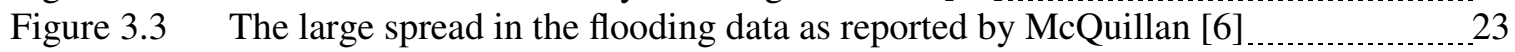

Figure 3.4 Graphical solution for flooding velocities by the drift flux approach [20]............24

Figure 3.5 The frame used to support the test section and the necessary

experimental equipment

Figure 3.6 A schematic view of the experimental setup

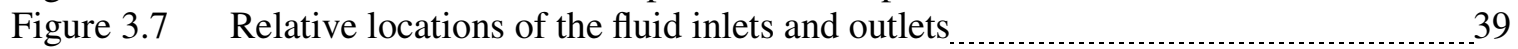

Figure 3.8 The air outlet assembly

Figure 3.9 The upper plenum of the test section 40

Figure 3.10 Pressure vessel for water delivery to the upper pressure transducers and aiding in the purging process 43

Figure 3.11 Rotometers used to control the liquid flow into the system 44

Figure 3.12 Front panel of the LabVIEW program used to collect data $\quad 47$

Figure 3.13 Schematic of the flooding facility 48

Figure 3.14 Valves and lines mentioned for the purging of absolute pressure transducers $\ldots \ldots . . .50$

Figure 3.15 Valves and lines mentioned for the purging of differential pressure transducers $\ldots 52$

Figure 3.16 Test section flow without air injection, showing the annular nature of the liquid film

Figure 3.17 Appearance of wakes in the flow during a liquid only run of the facility

Figure 3.18 Approach to flooding point by incremental steam velocity increases $\ldots . . . . . . . . . . . . . . .58$

Figure 3.19 Typical centerline air velocity for a steady state data run that achieves flooding _...59

Figure 3.20 Sample data point in which flooding appears to occur but soon reverts back to a counter current flow $\quad 60$

Figure 3.21 Pressure drop across the test section and the gas velocity at the onset of flooding ..61

Figure 3.22 Series of pictures capturing the onset of flooding. 62

Figure 3.23 All of the collected data presented at flooding as a function of the Wallis parameters 63

Figure 3.24 Schematic of the entire test facility $\ldots$

Figure 3.25 Test section prior to insulation.

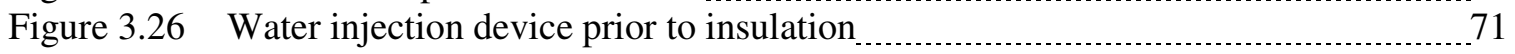

Figure 3.27 Steam generator before insulating 72

Figure 3.28 Steam generator after insulating.

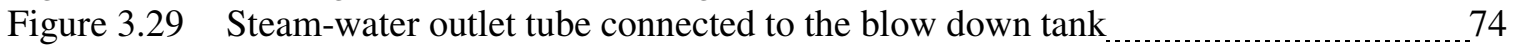

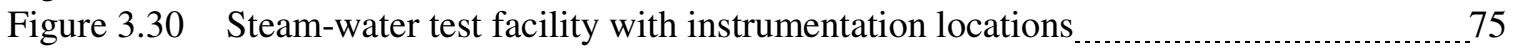

Figure 3.31 Data from all air-water tests 78

Figure 3.32 Differential pressure across the steam-water test section as a function of time 79

Figure 3.33 Absolute pressure in the water exit tank as a function of time $\quad 80$

Figure 3.34 Temperatures across the test section as a function of time _................................ 81

Figure 3.35 Flooding data presented as steam velocity as a function of water flow rate $\quad 82$

Figure 3.36 Flooding data presented as the Wallis parameters $\ldots$

Figure 3.37 The differential pressure drop as a function of water flow rate $\quad 83$

Figure 3.38 Air-water and steam-water data plotted as the Wallis numbers _........................... 84

Figure 3.39 Air-water and corrected steam-water data plotted as the Kutateladze numbers .......85

Figure 3.40 Steam-water data corrected for condensation plotted with 5\% error lines _.............86

Figure 3.41 Schematic of the setup for an inclined test section $\ldots$

Figure 3.42 Wongwises data [53] compared with flow range of the current experimental facility

Figure 3.43 Modified Froude Number vs. Onhesorge Number for Current Experimental Data 91 
Figure 3.44 Comparison of New Correlation against Lacy [44] Data 92

Figure 3.45 Optimum Channel Inclination for Gas Venting in Zapke’s Experiments [15] _.... 94

Figure 3.46 Coordinate System for Countercurrent Flow in a Rectangular Inclined Channel 95

Figure 3.47 Comparison Results: Data Grouped by Experiment Author

99

Figure 3.48 Comparison Results: Data Grouped by Liquid Reynolds Number 100 


\section{List of Tables}

Table 3.1 Parameters of importance during a scaling analysis of the flooding phenomenon 29

Table 3.2 The dimensionless groups arrived at from the Buckingham Pi Theorem _............... 31

Table 3.3 Additional dimensionless numbers used in the analysis of flooding $\quad 32$

Table 3.4 Test matrix for air-water tests

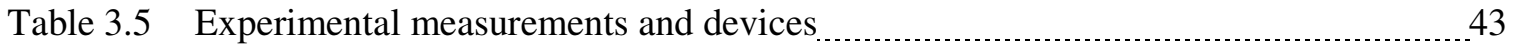

Table 3.6 Parameters for flooding phenomena.

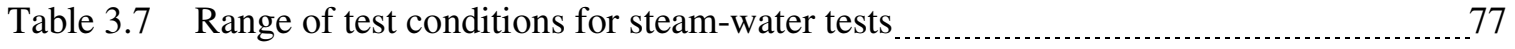

Table $3.8 \quad K u_{\text {crit }}$ as a Function of $\mathrm{D}^{*} \ldots$

Table 3.9 Comparison of Optimum Channel Inclinations in the theory and Zapke's _ 99 


\section{Executive Summary}

This project investigated countercurrent flow and "flooding" phenomena in light water reactor systems to improve reactor safety of current and future reactors. Interest in flooding has recently increased because flooding in the AP600 pressurizer surge line can affect the vessel refill rate following a small break LOCA and because predictions of hypothetical severe accidents with current simplified flooding models show that these models represent the largest uncertainty in analysis of steam generator tube creep rupture. During a hypothetical station blackout without auxiliary feedwater recovery, should the hot leg become voided, the pressurizer liquid will drain to the hot leg and countercurrent flow, or "flooding", may occur in the surge line. Analysis with reactor safety codes shows that the countercurrent flow limitation (CCFL) model heavily influences the pressurizer emptying rate and the potential for surge line structural failure due to overheating and strain.

The aspects which have been better clarified are the effects of condensation and tube inclination on countercurrent flow and flooding. The primary technical goals of the work were to:

1. To experimentally investigate the effects of condensation and tube inclination on countercurrent flow limitation for geometries and conditions applicable to the pressurizer surge line

2. To advance the understanding of flooding mechanisms

3. To develop modeling methods for use in nuclear reactor safety codes

This project consisted of experimental investigations and development of models for incorporation into reactor safety codes such as MELCOR and RELAP. A postdoctoral research associate, three graduate students (one MS thesis completed and another in progress) and several undergraduate students from Texas A\&M University participated in the research. The students acquired experimental experience and received instruction in development of physics models and use of reactor safety codes.

During the first year, an experimental facility was constructed with an adiabatic acrylic test section. The facility is capable of operating at any inclination between vertical and horizontal. Data for flooding characteristics of air-water systems in a vertical tube were obtained. Tests with a tube inclination revealed that a symmetric annular water film is difficult to obtain at more than about $5^{\circ} \mathrm{C}$ from the vertical.

In the second year, the facility was modified for additional instrumentation. Visualization data that provided insights into the falling film wave mechanics was obtained. The design of the steam-water facility was begun.

In the third year, the steam-water facility was constructed and operated. To ensure consistency between the two experimental facilities, the steam-water facility was designed as closely as possible to the air-water facility. Air-water data in the stainless steel test facility revealed that flooding occurred at similar steam and water velocities as in the acrylic test facility. This trend and observations of the steam-water tests in various configurations confirmed that an annular liquid film existed during the tests and that experimental procedures were consistent.

The new data is unique because it was acquired in large diameter test sections that were carefully scaled down from surge line geometries and conditions. The main parameter that could not be preserved was the density ratio between the gas and liquid phase that is expected in the surge line. Steam-water experimental results indicate that, as Wallis found for smaller diameter tubes, the 
flooding phenomenon is predominantly driven by the hydrodynamics. The tests were run with an inlet water subcooling of about $30^{\circ} \mathrm{C}$, compared to the predicted $25^{\circ} \mathrm{C}$ for a station blackout event in a PWR. For certain combinations of liquid flow rate and steam flow rate, flooding was not observed until the test section heated up and the water temperatures reached the saturation temperature. Once saturation was achieved, the steam no longer condensed and flooding was observed. As long as enough condensation occurred to reduce the steam momentum, flooding was not observed.

The three sets of data, air-water in the acrylic facility, air-water in the stainless steel facility, and steam-water in the stainless steel facility, formed the bases for empirical correlations to predict the occurrence of flooding. The correlations are functions of the traditional Wallis parameters, the Kutateladze numbers and dimensionless parameters which better represent the phenomena than the earlier methods of correlating.

The applicability of this data to surge line conditions and geometries is discussed. The test facilities have been scaled down to reproduce most aspects of expected behavior except the fluid density ratio and tube bends. Flooding has been shown by other researchers to occur downstream of tube bends. This aspect of flooding was not studied herein.

The methods for developing a mechanistic model for the onset of flooding are discussed in this report, along with the applicability of the new data under expected surge line conditions.

Tests with the test sections inclined were attempted but the annular film was easily disrupted. In part because the steam-water facility is opaque and minimal data could be obtained, further testing under inclined conditions was not pursued. However, a mechanistic model for gas venting in inclined tubes was proposed and validated against air-water data in smaller diameter tubes.

All of the goals and objectives of the project except for testing at various tube inclinations were successfully completed.

Goals related to the NEER program were also successfully achieved.

1. Support basic research in nuclear engineering: The project resulted in new fundamental data on heat transfer occurring in current and future light water reactor plants and new methods for analytical prediction of the phenomena.

2. Assist in developing nuclear engineering students: The work supported a graduate student for a two-year duration and another for one year. The second student will complete an MS thesis based on experimental work. A third student participated in the project, although not funded by it. This student pursued mechanistic model development. The PI also involved several students as undergraduate researchers during the course of the project.

3. Contribute to strengthening the academic community's nuclear engineering infrastructure: The work assisted a junior professor in continuing an independent research program and will help maintain the nuclear science and engineering capability by the use of nuclear industrial codes and experimental facilities at a major nuclear engineering university department. 


\section{Introduction}

\subsection{Motivation for Improved Flooding Models for the Pressurizer Surge Line}

Flooding is the situation in which the flow of a fluid in one direction is large enough to inhibit, partially or completely, the flow of a second fluid in the opposite direction and possibly cause a transition to unstable or cocurrent flow. Typically, a gas is flowing upward and a liquid is draining downward. The flow limitation is referred to as Countercurrent Flow Limitation (CCFL) and is experienced under a number of reactor conditions. Flooding can prevent sufficient coolant flow into the reactor core or other reactor components. The current project is to improve the level of understanding of flooding mechanisms and to develop an analysis model for more accurate evaluations of flooding in the PWR pressurizer surge line.

\subsection{Occurrence of flooding in Reactor Systems}

Flooding is associated with flow reversal and sometimes a sudden and dramatic change in flow conditions. For the common scenario of a gas/vapor blown upward through the center of an inclined or vertical pipe in which there is a falling film, the gas momentum will exert a shear force on the falling film. For a certain gas flow rate, the shear forces will be large enough to cause large interfacial waves, resulting in a dramatic increase of the gas pressure drop and expelling liquid from the top of the tube. This limit of the stable countercurrent flow is known as flooding.

There are several locations within the reactor cooling system where gravity drainage of liquid can be impeded by upward flowing vapor and potentially result in an undesirable flooding situation. These include the downcomer annulus, the upper core tie plate, the riser section of PWR inverted U-tubes and the pressurizer surge line. In the reactor vessel, flooding can occur during blowdown as Emergency Core Cooling liquid is attempting to fill the downcomer. During reflood, flooding can occur at the tie plate, where the upflow of steam prevents or limits the fallback of liquid ([45, 46]). flooding can also disrupt condensation heat transfer in the riser section of a PWR U-tube during midloop operation and interrupt a mechanism of decay heat removal [47]. The pressurizer surge line is also a potential location for flooding during severe accidents and following a small break LOCA in some advanced reactors.

The current project focuses on flooding in the pressurizer surge line, in which steam enters from the hot leg and water returns from the pressurizer.

\subsection{Need for Improved flooding Models for the Pressurizer Surge Line}

Interest in flooding has recently resurged because flooding in the AP600 pressurizer surge line can affect the vessel refill rate following a small break LOCA [2] and because analysis of hypothetical severe accidents with the current simple flooding models show that these models represent the largest uncertainty in analysis of steam generator tube creep rupture ([48]; [5]).

The safety systems of the AP600 are designed to depressurize the primary system following a small break LOCA is detected. The reactor coolant system pressure is depressurized down to the containment pressure to allow gravity feed of water from the in-containment refueling water storage tank (IRWST). The pressurizer may then be refilled because the top of the pressurizer is connected to the IRWST via depressurization valves. Integral tests were performed at the APEX facility [2] to investigate system performance. Results showed that the pressurizer did not drain until after the final stage of depressurization valves opened. Flooding in the surge line is 
suspected to be the cause of the delayed drainage. The pressure drainage is important because the head put on the downcomer by the pressurizer liquid influences the downcomer pressure, which in turn determines the IRWST coolant injection into the downcomer.

Results of recent severe accident analyses demonstrate the need to model flooding accurately in the pressurizer surge line and the primitive level of current modeling in severe accident analysis codes ([5], [48], [49]). Some of these codes employ the same flooding models as in thermal hydraulic codes such as RELAP5. In analysis of hypothetical severe accidents and the TMI-2 accident by several codes, the predictions of flooding in the pressurizer surge line were shown to include large uncertainty. Flooding results greatly impact the calculated progression of the TMI2 severe accident, and the creep rupture behaviors of the surge line and steam generator tubes as described below.

In the TMI-2 severe accident, there were two locations where countercurrent flow was important. The first location was the pressurizer surge line. Here, the surge line geometry was complicated and flooding influenced the rate at which the pressurizer drained. The second location was the reactor vessel upper plenum, where liquid from the pressurizer was in countercurrent flow with the steam generated by decay heat and fuel cladding-coolant reaction. Specifically, the pressurizer drain rate via the surge line determined the rate at which the core could be cooled and the timing of heatup following the emptying of the pressurizer. Hence flooding predictions greatly impact the progress of TMI-2 severe accident simulations.

There has been concern about steam generator tube creep rupture in hypothetical severe accidents, because it represents a bypass of the containment for radioactive materials to the environment. Best-estimate evaluation of the containment bypass release risk is critical to institute risk-reducing measures. Currently, the Laboratory for Nuclear Heat Transfer Systems at Texas A\&M University is identifying the analysis uncertainties involved in predicting the steam generator creep rupture and has shown flooding in the pressurizer surge line to be one of the largest uncertainties ([5], [47]).

During a station blackout severe accident, coolant vents out of the primary system through the pressurizer power operated relief valves. When the accident progresses to natural circulation cooling of the core, the pressurizer has a large water inventory. The pressurizer pressure is about 160 bar, the liquid draining through the surge line is at its saturation temperature, and the gas flowing up the surge line is superheated, with an average of $25 \mathrm{~K}$ above its saturated temperature. The draining of the pressurizer water to the hot leg affects the temperature rate of increase in the surge line, which impacts the surge line creep rupture behavior. The creep rupture failure timing of the surge line determines whether the surge line fails by creep rupture before the steam generator tubes fail. If the steam generator tube failure happens first, radioactive material may be released directly to the environment. Therefore the flooding application in the surge line is important in realistic prediction of containment bypass release probability of radioactive materials.

Since no satisfactory mechanistic flooding models exist yet, current safety analysis codes employ empirical flooding correlations to predict the onset of flooding. With their default flooding models, the SCDAP/RELAP5, MELCOR and MAAP severe accident codes predict significant discrepancy in flooding taking place in the surge line in a hypothetical station black severe accident [48]. The goal of this work is to obtain a better understanding of the phenomena and develop models that will address the safety analysis needs for current and future reactor designs.

\subsection{Previous Research on Flooding}


Although a great deal of work has been carried out in the past few decades, there is still considerable uncertainty concerning the mechanisms causing flooding as well as the most appropriate correlations for practical applications. Several factors impact the onset of flooding, including: the tube diameter, tube inlet and outlet configuration, tube inclination and heat transfer, to name a few. The tube diameter effect diminishes as the size of the tube increases. Since the surge line diameter is large, the tube diameter effect is relatively small and will not be studied herein. Great care is being taken with respect to the tube inlet and outlet configurations so that the water and gas-phase injections are well-understood. Primary focus is placed on the tube inclination and the heat transfer aspects, for which there are large inconsistencies in reported data. Past experimental and analytical investigations are reported below.

Generally, there are two approaches to setting up a flooding model. One is an empirical correlation based on correlated experimental data. Another is a mechanistic model based on simplifying assumptions for the flooding physical mechanisms. Due to the large number of influencing factors and the complexity of the mechanisms involved, an empirical correlation is an efficient approach to predict the onset of flooding under a given situation. However, empirical correlations are limited to the test conditions ranges. On the other hand, no mechanistic models have been shown satisfactory in predicting the onset of flooding for a variety of nuclear piping systems. A comparison of the performance of several empirical and semi-empirical correlations is presented by McQuillan [6] Comprehensive surveys on flooding literature are presented by Bankoff [17] and Hewitt [50]. Empirical and mechanistic models are reviewed below.

\subsubsection{Tube inclination effects}

Flooding prediction in inclined tubes such as the pressurizer surge line is less conclusive than that in vertical tubes. In some studies $([51,52])$ the effect of inclination angles was incorporated into their correlations but the trend of flooding velocity depending on inclination angles has not been clearly pointed out.

To study the effects of inclination angles and upper end conditions on the onset of flooding, experiments showed that for an upper-open end system, with increasing inclination angles from the vertical, the flooding curves shift to lower gas velocities. For an upper-closed end system, the onset of flooding is nearly the same for all inclination angles ([53]). For steam-water countercurrent flow in an inclined channel ([54]), the flooding steam velocity was the lowest for the smaller inclination angles and increased with an increase in inclination angle up to approximately $30^{\circ}$. For $31^{\circ}$ and $87^{\circ}$ inclinations, the flooding steam velocities were approximately equal.

In a study on air-water countercurrent flow in a $51 \mathrm{~mm}$ tube for a wide range of inclination angles $\left(1^{\circ}-90^{\circ}\right.$ from horizontal) ([30]), it was pointed out that the critical flooding velocity tends to increase and then decrease as the inclination angle is changed from horizontal to vertical. Comparing the limiting velocity in vertical tubes and inclined tubes ([2]), the counter-current flow in the vertical section limits the liquid downflow more than in the inclined section; flooding becomes less limiting with increasing inclination below $45^{\circ}$, and becomes more limiting with increasing inclination above $45^{\circ}$. In a nearly horizontal pipe with inclination angle less that $1^{\circ}$ ([55]), the transition criterion for the onset of flooding is very sensitive to the inclination angle; a slight increase in the inclination angle has a great effect on the location where flooding occurs and on the flow patterns.

\subsubsection{Condensation effects}


Condensation effects on flooding have been studied in vertical tubes and one study is known for tests at a nearly horizontal angle ([17]). Condensation effects were shown to cause a negative pressure loss due to loss of the vapor phase momentum. The effect was a function of distance along the tube. Once the liquid became saturated, flooding reverted to being driven by hydrodynamic forces ([19]).

Visualization studies on flooding for a liquid/condensing gas mixture were reported by Girard et al., [56]. Girard observed steam/water flooding in a glass test section for imposed pressure drops across the tube at near atmospheric pressure.

Reflux condensation in a vertical tube with flooding has been studied by the PI to obtain local heat transfer coefficients (47). In these experiments, steam was injected into the bottom of a stainless steel condenser tube and the conditions under which condensate could not return downward were recorded. Since flooding investigations were not the target of the study, critical information such as the conditions at onset of flooding was not pursued and flooding models were not developed.

\subsubsection{Empirical Correlations}

Under the simple geometry of a vertical tube and atmospheric temperature and pressure conditions, the Wallis and Kutateladze correlations are the most well-established empirical correlations. The Wallis correlation considers the inertial and gravitational forces in equations (1), while the Kutateladze-type correlation considers the inertial and interfacial forces in equations (2).

$$
\sqrt{j_{g}^{*}}+m \sqrt{j_{f}^{*}}=c
$$

Wallis:

$$
\begin{aligned}
& j_{g}^{*}=\frac{j_{g}}{\sqrt{g D\left(\rho_{f}-\rho_{g}\right) / \rho_{g}}}, j_{f}^{*}=\frac{j_{f}}{\sqrt{g D\left(\rho_{f}-\rho_{g}\right) / \rho_{f}}} \\
& \sqrt{K u_{g}^{*}}+m \sqrt{K u_{f}^{*}}=c
\end{aligned}
$$

Kutateladze-type:

$$
K u_{g}=\frac{j_{g}}{\sqrt[4]{g \sigma\left(\rho_{f}-\rho_{g}\right) / \rho_{g}^{2}}}, K u_{f}=\frac{j_{f}}{\sqrt[4]{g \sigma\left(\rho_{f}-\rho_{g}\right) / \rho_{f}^{2}}}
$$

In equations (1) and (2), $j_{g}$ and $j_{f}$ are the volumetric flux of the gas and liquid phase, respectively; $m$ and $c$ depend on tube geometry and inlet/outlet configuration and are coefficients correlated from experiment data ([21]). It has been argued that $m$ and $c$ could be derived as variables explicitly dependent on tube geometry and inlet/outlet configuration $([57,58])$.

The Wallis correlation explicitly considers the effect of tube diameter, whereas the Kutateladze correlation uses the capillary length as the characteristic length. The Wallis correlation is more applicable to small diameter tubes, while the Kutateladze correlation is appropriate for large diameter tubes where the diameter effect is less than the surface tension effect on interfacial surface behavior and flooding occurrence ([35]).

These correlations do not account for the effects of condensation or tube inclination. The correlations that describe tube inclination effects are similar in format to the Wallis correlation but they include an additional factor that depends on tube inclination ([39]). 
From the above literature review, it was observed that no flooding model is generally applicable to a variety of conditions, especially in the pressurizer surge line with inclined tube sections and condensation heat transfer.

\subsubsection{Mechanistic Models}

In vertical tubes, most mechanistic models to predict flooding conditions are either film models or interfacial wave models.

Flooding in film models is predicted to occur when the interfacial shear is large enough to cause an upward flow in the liquid film. Film models are obtained based on the steady-state solutions of a one-dimensional laminar film flow subjected to interfacial shear stress ([28]) where the interfacial shear stress is derived from a constitutive relation that may involve large uncertainties. To overcome this shortage, a 2-dimensional numerical simulation was conducted to calculate the reasonable values of the interfacial shear stress ([44]). The idea behind the interfacial wave models is that at the onset of flooding, waves grow large enough in amplitude to block the tube, or flooding is initiated by the upward propagation of a wave and the accumulation of other waves falling onto the initial one.

Interfacial wave models are based on flow instability. Kinematic wave theory has been successfully employed to establish such a model ([13]), which can be generalized to Wallis or Kutateladze type correlations under certain approximations. However, none of these models are in general agreement with the experimental data over a wide range of operating conditions.

Though there is less understanding of flooding mechanism in nearly horizontally-inclined tubes than that in vertical tubes, the mechanistic models are based on similar theories. As examples, Hewitt [50] and Barnea [30] reported models based on a film theory in which the interfacial shear is used to predict the flooding limits in inclined pipes over the entire range of inclinations. The wave theory of Kelvin-Helmholtz critical condition was applied to derive flooding criterion in a slightly inclined pipe ([2]). The flow regime transition theory [55] was applied to predict the onset of flooding in a nearly horizontal pipe. 


\section{Project Objectives and Tasks}

\subsection{Objectives}

The primary technical goals of the work are:

- to investigate the effects of condensation and tube inclination on countercurrent flow limitation for geometries and conditions applicable to the pressurizer surge line

- to advance the understanding of flooding mechanisms

- to develop modeling methods for use in nuclear reactor safety codes

The significance of the research into flooding mechanisms lies in the contributions towards improved safety and reliability of current and future LWR's. The phenomena investigated in this work will be present in current and future reactors.

The significance of the flooding investigation lies in clarification of a basic phenomenon that occurs in several nuclear and non-nuclear applications.

The modeling methods that result from this study will provide a tool for evaluating system performance and will be necessary for the reactor design and licensing processes. The analysis models will be made compatible with a variety of reactor safety codes

\section{$2.2 \quad$ Tasks}

The specific tasks to accomplish these objectives are to:

- construct an experimental facilities for air-water system

- obtain fundamental data for flooding, i.e. water and air flow rates and differential pressure measurements

- construct an experimental facility for steam-water system

- obtain data for flooding, i.e. water and steam flow rates and pressure drop measurements

- develop correlations and analytical model for both air-water and steam-water systems for implementation into a reactor safety code

- incorporate the analytical model into a reactor safety code and verify the model 


\section{Project Activities}

\subsection{Air-Water Experiments}

\subsubsection{Introduction}

In the case of two-phase flow, there exist several important and as of yet still unclarified phenomena. These phenomena affect many aspects of engineering design from calculations of pressure drops to the analysis of heat transfer characteristics. One such phenomena is known as the countercurrent flow limitation, or CCFL, and its appearances are many, its effects, legion. Flooding affects a great variety of systems both within the nuclear industry and beyond. This section documents a research study into the basic physical mechanisms and associated effects of flooding in a large-diameter round duct under adiabatic conditions. An experimental program will be presented that reveals new insights into the occurrence of flooding. From the experimental database, an empirical correlation was obtained for incorporation into reactor safety codes. Thus, it is necessary to give a brief description of flooding and its importance to the nuclear industry.

\subsubsection{Relevance}

The study of flooding is of great importance to designers of both physical equipment and thermal hydraulic analysis computer codes. Phenomenon based models will allow the designers to provide the nuclear power industry with the tools to better protect both equipment and the public from harm. Reactor safety codes such as MELCOR, MAAP, and SCDAP/RELAP5, when modeling a design basis accident will call a number of correlations to the problem for reactor safety analysis. One such situation involves the flow regime and heat transfer characteristics of the surge line on a Pressurized Water Reactor pressurizer. The large diameter pipe that constitutes the surge line contains changes in inclination between the pressurizer and the hot leg.

Previous analyses of the flow characteristics in this section of the system have yielded contradictory and inconclusive results [1] [2]. To better understand the phenomena associated with this accident scenario, the research presented here was undertaken to gain more insight into the physics of the situation and to supply a more appropriate correlation than currently available. The correlation presented here is suitable for use in all large diameter counter current flow limitation problems and care has been taken to ensure the quality of both the data taken and the derivation of the correlation.

The surge line of a PWR is a connection between the hot leg of the primary system and a large, pressurized container [3]. The pressurizer serves the purpose of maintaining the pressure in the PWR system by acting as a pressure control mechanism. Since water is essentially incompressible, the pressurizer either heats water making steam to maintain system pressure (and thus increase the volume of water in the system) or condenses steam to accommodate water expansion [4]. In the case of a hypothetical station black out severe accident, where a steam generator pressure relief valve is stuck in the open position, the surge line would be subjected to high pressures. This could result in an increase in system pressure and ultimately a creep-rupture failure in the steam generator tubes or other primary side components. It is desirable to calculate accurately the distribution of temperature along these tubes for a better understanding of the creep-rupture failure mode. This mode is affected by flooding in the pressurizer surge line. This situation was studied by Liao [5] who came to the conclusion that MELCOR's flooding models were inadequate in defining the flooding limit for the pressurizer surge line. This is but one example of how flooding is of the utmost importance to the safety analysis engineer, and the safety codes they use. 


\subsubsection{Countercurrent Flow Limitation}

Countercurrent flow is defined as the two-phase flow regime in which the working fluids of a system flow with velocities of opposite signs; that is, fluids flowing in opposite directions. A simplified example of such a flow would be the downward flow of milk leaving a bottle with the upwards flow of air replacing the subsequent void. As the liquid leaves the bottle, the remaining volume must be replaced by some fluid, in this case air. Thus, there exists a countercurrent flow situation in which milk is flowing with the aid of gravity into a pint glass and air is flowing in the opposite direction due to a pressure difference. Furthermore, if the milk is poured too quickly, a violent and chaotic situation arises: flooding. If the rate at which the liquid leaves the vessel is great enough that the associated air flowing into the vessel inhibits the flow of both, flooding is said to have been achieved. While this is but a simple example, the physics are essentially the same as in a Pressurized Water Reactor surge line during an accident scenario. This example illustrates that there must be a point at which the velocities of two fluids differ in such a way that normal, steady flow is interrupted.

It is also necessary to introduce the term "flooding". In much of the literature, the term flooding is synonymous with CCFL. While CCFL and flooding both refer to essentially the same phenomenon, CCFL is defined as the point at which the relative velocities of two fluids results in a change in the direction of a portion of the liquid phase. The key word in the definition is point; that is, an instant when the phenomenon occurs which is different than the continuous nature of "flooding". Flooding is the situation associated with the system when at least a measurable portion of the liquid phase is flowing in the direction of the gaseous phase. This study deals with the onset of flooding, and not the characteristics of a system during the flooding stage.

Since there exists such a large range of experimental studies devoted to flooding, it is difficult to determine which aspects need to be examined in detail. These experiments focus on large diameter ducts of a circular cross section. Large diameter tubes closely model the surge lines of PWR pressurizers as opposed to small diameter tubes. The distinction between the sizes reiterates the complex nature of flooding. The conditions for which the experiments are run are also well defined which add to the reliability of the data collected. The large diameter test section is unique in that it models a specific component while it also generates a general set of flooding data. This investigation is also a preliminary step in a large scheme. The next step is to experimentally examine the same phenomenon under similar conditions using water and steam as the working fluids.

\subsubsection{Objective and Scope of Air-Water Experiments}

The objectives of this work are given below.

- To design and conduct experiments regarding flooding in a large diameter, round duct using air and water as the working fluids under adiabatic conditions.

- To better clarify the phenomena related to the onset of flooding.

- To correlate the data and develope a correlation that may be used in reactor safety analysis to predict flooding.

In order to further the field of two-phase fluid dynamics as it relates to the nuclear power generation industry, this research will investigate the phenomenon known as the countercurrent flow limitation. A better understanding of flooding will lead to more accurate and more reliable reactor safety codes. While a great many experimental studies have been conducted on the topic of flooding, this investigation will shed light on unexplained aspects associated with the phenomenon. Over 25 independent experimental investigations into flooding have been 
conducted [6], each of which has its merits as well as its limitations. This investigation has been undertaken to reduce discrepancies and errors and to provide accurate and precise data. Finally, a new correlation that can be used to predict flooding in large diameter round ducts will be proposed.

The air-water experiments are presented in several sections.

- Section 3.1.3 consists of a literature survey of available papers and texts on the flooding phenomenon as they relate to the experiments conducted. This survey contains information needed to explain the techniques, methods, and rationale behind the design of the experiments. Furthermore, the survey also provides the methods for analysis of the new data to obtain the aforementioned correlation.

- Section 3.1.4 presents a scaling analysis that was performed in order to properly define the necessary parameters and properties which are believed to affect flooding. Also provided is a detailed explanation as to how the final test matrix was determined.

- Section 3.1.5 describes the test matrix.

- Section 3.1.6 provides a detailed explanation and description of the experimental facility with an emphasis on the design process and equipment used for the experiments conducted. This Section will also address the decisions made with respect to instrumentation and data collection. Many of the choices made regarding equipment design have an effect on the flooding point, so the rationale for each is given.

- Section 3.1.7 describes the instrumentation, data acquisition and data reduction procedures.

- In Section 3.1.8, a detailed operating procedure is given to provide the reader with a more succinct understanding of the data and where it comes from. Emphasis is placed on the start up procedures due to the fact that the apparatus must be placed in a consistent starting position before each test is conducted.

- The results of the experiments run are provided in Section 3.1.9 with analysis and discussion. The many characterization tests, or shake down tests, that were conducted to ensure the best possible data collection are explored first. Sample test runs are compared next which provide the reader with an understanding of the remainder of the experimental runs. The final correlation is presented in its final state along with justifications.

- Section 3.1.10 provides conclusions that have been drawn from the experiments and the associated analyses.

\subsubsection{Literature Survey}

There is a wealth of information in the journals and texts regarding the phenomenon of the flooding. The literature can be broken down into two categories: theoretical treatments and experimental investigation. Since efforts are being taken to experimentally investigate flooding, the majority of the review focused on the experimental papers available. Presented here is a review of the literature discussing flooding, its theory, experiments examining it, and correlations for predicting flooding.

The organization of the literature review is as follows. A historical overview of the experiments and correlations resulting from them is given. This includes the derivation of several of the correlations and a discussion of the experimental procedures used to develop them. Next are disclosed the various mechanisms proposed to describe flooding and CCFL. This will include classifying the mechanisms into three groups. After this, a section will be included on the theory of flooding experiment designs which should add to the understanding of the design choices made while designing the experiment used for this research. Also in this section is a discussion on the 
role of tube diameter, which will play a very large role in the discussions to follow. Finally, a review of phenomenon related to the final correlation will be given. This section will provide all adequate information needed to derive the a flooding correlation presented herein.

\subsubsection{Historical Background}

The study of flooding and CCFL resulted in numerous correlations for predicting flooding and experimental investigations. The pioneering work of Wallis and Kutateladze served as a foundation for all subsequent work concerning the development of correlations. The foundations of this work were developed for flooding in packed beds [7]. These findings include the early work of Sherwood in correctly identifying the effect that velocity plays on the phenomenon [8]. One of the most important findings of these early studies is the inverse dependence of the onset of flooding on the relative velocity of the working fluids. This effect can be seen from one of Wallis' early investigations in figure 3.1 .

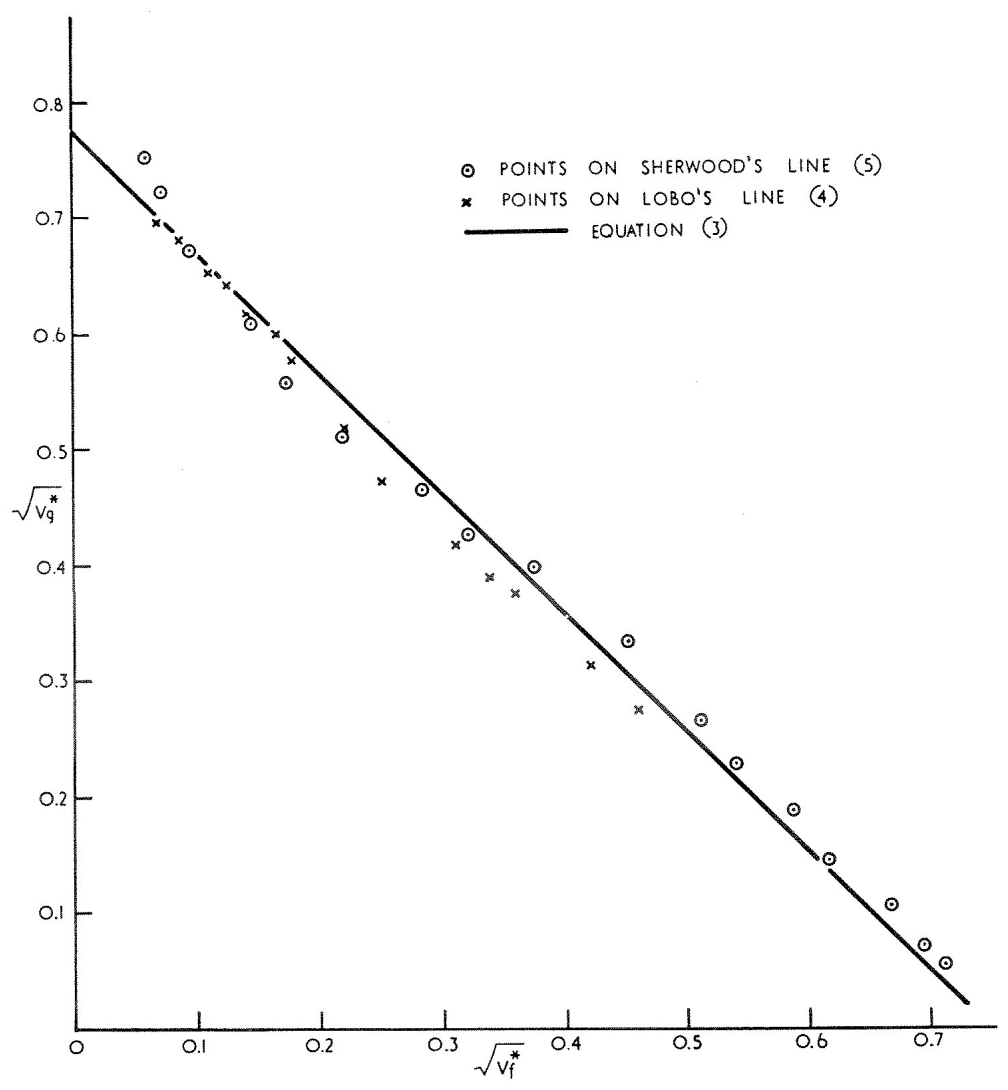

Figure 3.1 Relationship between liquid flow rate and air flow rate at flooding [7]

As the liquid phase superficial velocity increases, the gaseous phase superficial velocity required to induce flooding decreases. This trend appears in all of the flooding data and should be considered a first principle upon which all other statements are built. The most widely accepted data and analysis comes from the aforementioned pioneering work of Wallis in the sixties. Wallis however does not fully define the phenomena when he derives the first accepted correlation and it is restricted to small diameter tubes [7]. In this study, he also defines what will become the hallmark for dimensionless studies on flooding, the Wallis parameter, which is essentially a dimensionless velocity. 


$$
j_{f}^{*}=j_{f} \sqrt{\frac{\rho_{f}}{g D\left(\rho_{f}-\rho_{g}\right)}}
$$

and

$$
j_{g}^{*}=j_{g} \sqrt{\frac{\rho_{g}}{g D\left(\rho_{f}-\rho_{g}\right)}}
$$

With this velocity, Wallis proceeds to formulate the Wallis-type flooding correlation. In it he concludes that the sum of the square root of these two dimensionless velocities is equal to a constant [7].

$$
\left(j_{g}^{*}\right)^{1 / 2}+m\left(j_{f}^{*}\right)^{1 / 2}=C
$$

Clift [9] in his experimental study claims that the Wallis parameter is a suitable correlation to predict flooding but concedes that his results work well due to the similarity in experimental apparati. This form of a flooding correlation only considers the diameter and the gravity term in addition to the volumetric fluxes. These are the three determining factors that Wallis is suggesting affect flooding. However, this is explained by the fact that he considered only small diameter pipes when conducting his experiments. It will be shown later that there is indeed a difference in "large" and "small" diameter pipes when flooding is considered [10], [11]. For the present, though, the small diameter constraint instituted by Wallis is taken care of by the second major flooding correlation, the Kutelatadze correlation [12] [13].

The so-called Kutelatadze correlation was first put forth by Pushkina and Sorokin [14] in their experimental work involving water, glycerin and ethyl alcohol. They define the Kutateladze criteria thus.

$$
K_{g} \equiv \frac{\rho_{g}^{1 / 2} j_{g}}{\left[g \sigma\left(\rho_{f}-\rho_{g}\right)\right]}=3.2
$$

The result of these criteria is that it assumes that the liquid flow rate is inconsequential to the flooding phenomenon. This is due mainly to the fact that the model created was one involving vapor generation from boiling [12], and that the driving force of both flows was vapor generation. That is, the liquid phase was not moving under any forces other than buoyancy. Another unique part of this correlation is its neglect of a diameter dependence. Pushkina contends that because none of his data appeared to depend on the diameters he tested, there should be no diameter dependence on the flooding point [14]. The stated cause for this neglect is that the occurence of flooding is found to be more dependent on the formation of "crests" on the liquid phases and furthermore that these crests have no dependence on the tube diameter. The final statement from this investigation is that the amount and profile shape of the momentum of the vapor phase must be the contributing factor which leads to flooding. However, the Kutateladze correlations as it is used today was defined neither by Kutateladze himself nor Pushkina et al. but by Tien in 1977 [13]. Using a Wallis type correlation as an analogous entity, Tien defined the criteria for flooding to be: 


$$
\sqrt{K u_{g}}+\sqrt{K u_{f}}=c_{k}
$$

Where Tien uses the original formulation for $K u_{g}$ but adds the term:

$$
K u_{f}=\frac{\rho_{f}^{1 / 2} j_{f}}{\left[g \sigma\left(\rho_{f}-\rho_{g}\right)\right]^{1 / 4}}
$$

Tien further states that the constant value, ck, is equal to $\sqrt{3} 3.2$, similar to the original Kutateladze criteria. Another interesting point brought up by Tien is the dependence of flooding on the Bond number, Bo. The Bond number is a dimensionless diameter defined by:

$$
B o=\frac{\rho g D^{2}}{\sigma}
$$

Tien claims that such dimensionless diameters must be large, greater then 30 , for most flooding situations in order to assume that the curvature effect of the tube is insignificant. He bases this suggestions on the results of Pushkina and Wallis [13]. A more in-depth look at the Bond number dependence is given below as it describes the effect that tube diameter has on flooding and how to decide upon which correlation to use.

A more recent suggestion by Zapke is that the Kutateladze correlation is not su $\square$ cient to correlate data due to a lack of attention to the length of the tube [15]. While this study focuses mainly on rectangular ducts, its conclusions are reduced to general flow situations and thus should be considered here. Zapke defines two dimensionless numbers new to the realm of flooding namely, the Froude and Ohnesorge numbers. The Froude number for this correlation is defined as the densimetric liquid Froude number, or:

$$
F r_{D L}=\frac{\rho_{f} V_{f}^{2}}{\left[g D_{h}\left(\rho_{f}-\rho_{g}\right)\right]}
$$

Also defined is the liquid phase Ohnesorge number:

$$
O h_{f}=\sqrt{\frac{\mu_{f}^{2}}{\rho_{f} D_{h} \sigma}}
$$

Zapke claims that the Froude number is representative of the ratio of the drag force exerted by the gas on the liquid phase and the weight of the liquid film [15]. This would imply that the drag force must exceed the body forces on the liquid phase for flooding to occur. The Ohnesorge number is used in this correlation to relate the liquid properties to the flooding gas velocity [16].

Since such a large number of experimental studies have been conducted with respect to flooding, there needs to be a standard manner of reporting the data [17]. Shown below in figure 3.2 is a standard plot of the data reported by Richter [18]. The use of the Wallis parameter as a plotting mechanism is seen throughout the experimental studies [17]. 


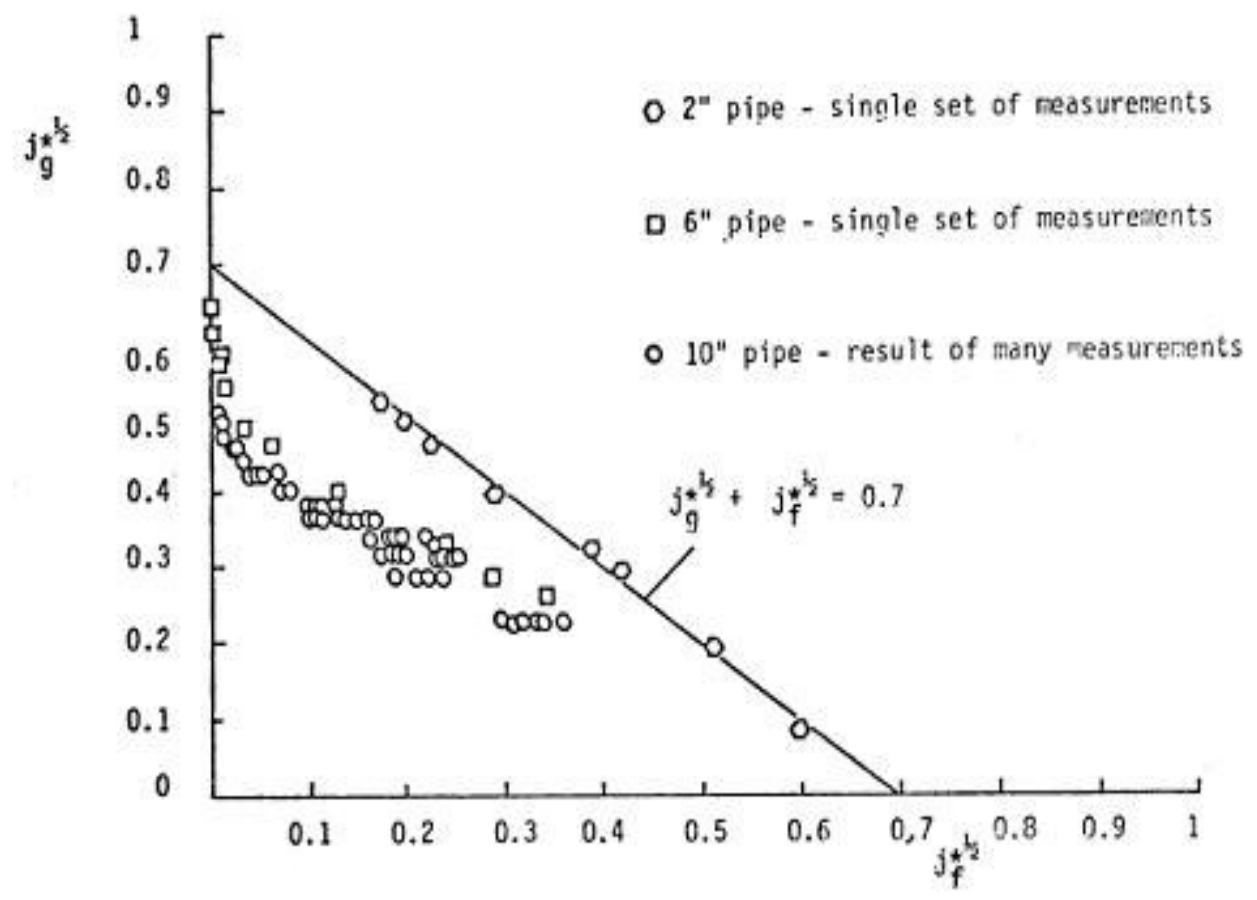

Figure 3.2 Richter's data for a variety of tube geometries [18]

The spread in the flooding data is also of interest. McQuillan [6] has made the observation that the most of the correlations discovered only predict the data from which they were derived. Figure 3.3 illustrates this point by showing the results from 24 investigations and the large spread these points take.

\subsubsection{Flooding Mechanisms}

The mechanisms proposed to explain flooding and CCFL are discussed here. Throughout the literature theories have been proposed to explain under what conditions flooding will occur. It has been suggested that all of these theoretical mechanisms can be reduced to three broad categories [19] [20]. All other theories are considered to be variations on these three themes. As such, these mechanisms provide a comprehensive view of the factors which may or may not contribute to flooding. The three major categories are:

- Kinematic Waves

- Upward Liquid Film Flow

- Droplet Entrainment 


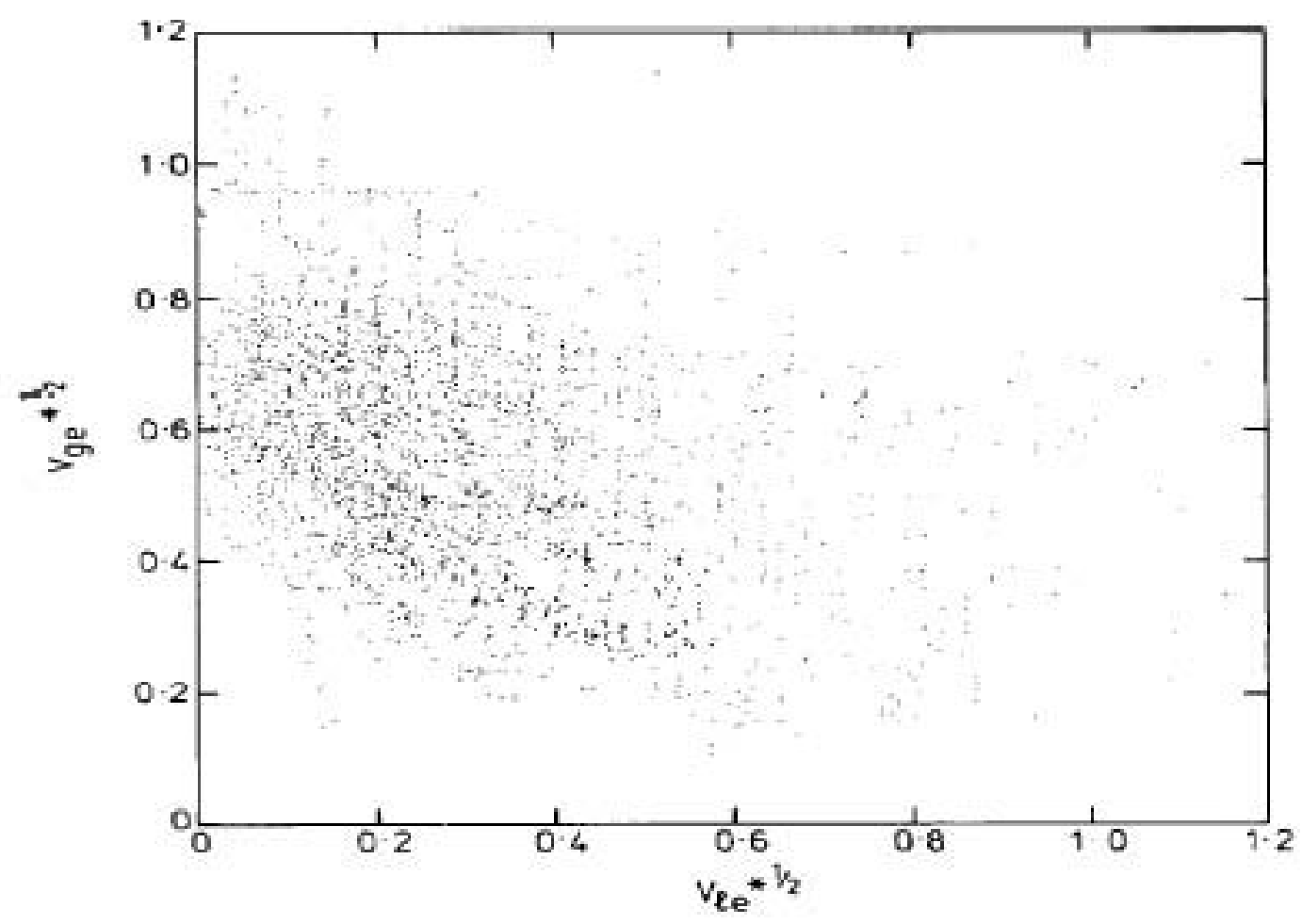

Figure 3.3 The large spread in the flooding data as reported by McQuillan [6]

\section{a) Kinematic Waves}

The kinematic wave mechanism comes directly from the drift flux model of two phase flow [20]. Wallis was the first to assign a drift flux solution to the flooding problem by examining the relative velocity of the phases to the drift flux. This model stipulates that the shear forces at the interface are negligible when compared to the gravity forces acting on the liquid phase. Kinematic waves are formed only by density differences and thus depend only on the continuity equation by definition [20], and as such do not depend on the momentum equation. As a result, acceleration and frictional pressure losses are also neglected from the analysis. What is left is the drift flux relationship as Wallis defines it [21]. Ohkawa and Lahey have derived two terms that can be used to predict flooding [22].

$$
\overline{j_{g}}=\left(C_{0} \bar{j}+\overline{U_{g j}}\right) \bar{\alpha}
$$

Where $\alpha$ is the average gas volume fraction. If the drift velocity, $\mathrm{U}_{\mathrm{g} j}$, is only a function of physical properties and the average void fraction, we arrive at the following relationship for the drift flux:

$$
\overline{j_{g f}}=\bar{\alpha}\left(\overline{u_{g}}-\bar{j}\right)
$$

Shown in figure 3.4, the drift flux, $\mathrm{j}_{\mathrm{gf}}$, is dependent only on the void fraction if the velocities of the two fluid are known.

The lines numbered one through four correspond to different values for the volume flux as indicated on the axes [20]. The meanings of the lines are given below. 
1. Represents concurrent flow, from the figure it is obvious that the values for jf and jg are such that they maintain the same sign and thus are moving in the same direction.

2. Represents countercurrent flow without flooding. Again, the magnitude and direction of the terminus points of the line should indicate the directions of the fluid flows.

3. Represents CCFL. Line 3 is tangent to the curve and as such it is the only solution that results in a singular value for the drift flux.

4. There is no intersection with the curve, physically impossible.

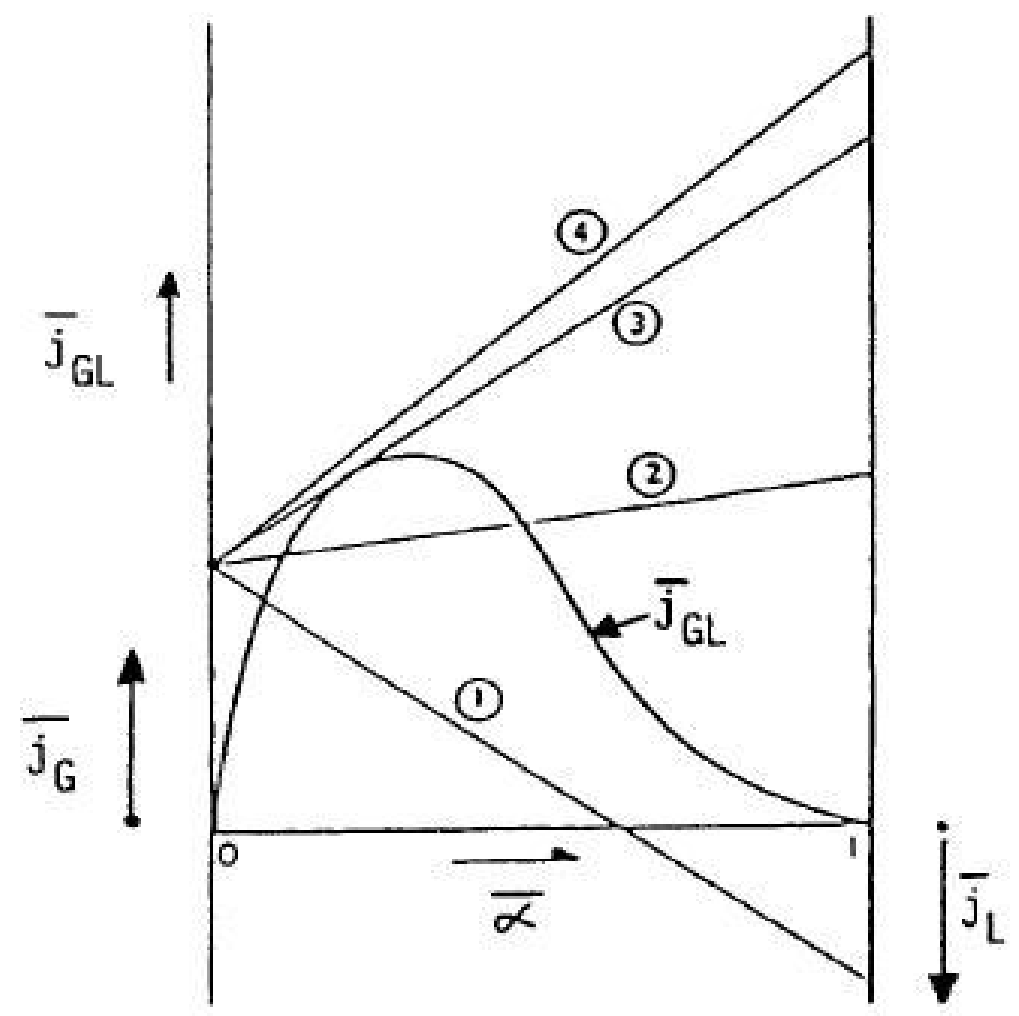

Figure 3.4 Graphical solution for flooding velocities by the drift flux approach [20]

While this analysis does yield a very good approximation to the flooding problem, the curve shown above can only be constructed from experimentally gathered data. This is because there are three unknowns; jf, jg, and $\alpha$. As such, a fully deterministic prediction of flooding is not possible [20] and this solution only provides a qualitative picture of CCFL.

The experiments and studies done to further the kinematic wave theory are numerous. Starting with Wallis in 1961 [7], and continuing through the decades, [23] [24] [25], there has been a host of agreements. However, as prevalent as kinematic waves are, over half of the experimental investigations have be conducted on small diameter pipes.

\section{b) Upward Liquid Film Flow}

The upward liquid film model makes use of dynamic waves as opposed to kinematic ones. Imura [23] states that a change in the wave amplitude on the surface of the fluid leads to bridging, which in turn leads to flooding. This theory is based on the belief that the process of flooding comes from the bridging of liquid across the cross section of the channel. This is also dependent, unlike the kinematic wave model, on the shear stresses acting on the interface between the gas and liquid phases [26]. Cetinbudaklar [27] makes the case that the shear forces on the liquid interface can 
only be considered if the wave propagation is moving in the same direction as the gas flow due to the magnitude of the velocity.

Chung admits that due to the rather complex nature of this analysis, the liquid film flow model lacks the acceptance of the Wallis and Kutetaladze correlations [26]. Taitel et al. [28] make the case that if the interfacial shear terms are known or can be calculated, then characteristics of the flooding process can be found. They add that any entrance effects can be attributed to their effect on the interfacial shear, and thus on flooding. This analysis was followed by an experimental investigation of Dukler concerning liquid film movement in vertical pipes [29]. The claim is made that the upward shear on the liquid from the gaseous phase is suffcient to lift a liquid film upwards. The Reynolds number of the liquid film affects flooding by contributing to a friction factor at the interface. Furthermore, this friction factor is related to the ratio of the film thickness and the tube diameter. Work by Barnea has suggested physical agreement with this theory [30].

\section{c) Droplet Entrainment}

The droplet entrainment model was first mentioned by Dukler with respect to the momentum transfer of entrained droplets of liquid in the gaseous flow. It has been suggested that the small drops that are seen to be ripped from the surface of the fluid just before flooding occurs may lead to flooding [31]. The occurrence of flooding then becomes linked to a gas velocity that is capable of suspending the largest stable drop of water. This analysis is performed by conducting a force balance between the drag forces on a drop of water and the gravity forces acting on it as well. Moalem [31] claims that this velocity can be found by means of the critical Weber number, $\mathrm{W}_{\mathrm{ec}}$, and the drag coeffcient of the drop, $\mathrm{C}_{\mathrm{d}}$.

$$
U_{g}=\left(\frac{4 W e_{c}}{3 C_{d}}\right)^{1 / 4}\left[\frac{\sigma g\left(\rho_{f}-\rho_{g}\right)}{\rho_{g}{ }^{2}}\right]^{1 / 4}
$$

Moalem further asserts that the results of such an analysis match the flooding correlation given by Sorokin et al [14] [31]. From these conclusions, the entrained droplet model does seem to offer a good approximation to the flooding problem. However, there are conditions that need to be met for this to be true. First, the interfacial waves must be small in order to keep the air volume fraction high.

\subsubsection{Geometric Dependencies}

The majority of geometric considerations concerning flooding deal with the entrance configuration and flow mechnism of the liquid phase. These so-called "entrance effects" will undoubtedly contribute to a great deal of the issues facing the flooding experimenter. Wallis was the first to recognize that such effects will change the conditions inside the test section [7]. He discovered that flooding would occur more readily for a "smooth" entrance than for a "sharp" entrance. The smooth and sharp differentiation is with respect to the location where the liquid is entering the test section; that is, smooth indicates that the entrance ports were rounded flanges whereas sharp indicates a stepped flange entrance.

The geometry effect is further examined in detail by Chung [26] in which he concludes that the entrance and exit disturbances have an effect on the diameter dependence of the system. The result is that the constant values used in the Wallis correlation must be altered to allow for agreement. For the experiments he used, Chung suggests the Kutateladze constants $m$ and $C_{k}$ from equation (3.5) be adjusted according to the geometry. However, Chung ultimately concludes that as the diameter of the test section increases the effect of entry conditions decreases. Finally, it has 
been suggested that much of the disagreement in the flooding data is a direct result of these separate entrance conditions [6].

The second important geometrical consideration is the actual test section diameter. The distinction between large and small diameter pipes with respect to flooding was first made by Wallis. Wallis discovered that there does exist a dependence on diameter for the flooding point [7]. This is most clearly illustrated by the definition of the Wallis dimensionless velocity which contains the pipe diameter as the characteristic length. This dependence on geometry is not specific to the transition from countercurrent flow to cocurrent flow but between all flow regimes [32]. The Pushkina study [14] claims that there is no diameter dependence on the actual flooding point other than the Bond number limit. Numerous experimental investigation and analytical studies were conducted with respect to the accuracy of each correlation under separate diameters [18] [23] [33] [6] [34]. It remains unclear as to what diameter should be used as a cutoff point between the two correlations. Richter [33] suggests the following cutoffs: for pipes with an inner diameter up $50.8 \mathrm{~mm}$, the Wallis parameter should be used; for diameters greater than $152 \mathrm{~mm}$, the Kutateladze should be used instead. It is obvious that based on this criterion there is a large gap of applicable diameters. Jayanti [35] claims the diameter dependence is limited to its effect on the two mechanisms for flooding; droplet entrainment and wave transport. The argument is that as the diameter of the pipe increases, the velocity of gas required to deliver liquid drops out of the test section is less than the gas velocity required to move a wave up the test section. There is no actual size given for this transition to take place. Vijayan [10] attempted to reconcile this discrepancy by conducting similar experiments on several different pipe diameters. The final result of the study was that in tube diameters above $67 \mathrm{~mm}$ only the Kutetaladze correlation should be used. Furthermore, Bankoff establishes that the diameter plays no part in the magnitude of the gas velocity if the dimensionless diameter, $\mathrm{D}^{*}$, also described as the square root of the Bond number, is above 30 [19].

$$
D^{*}=D\left[\frac{g\left(\rho_{f}-\rho_{g}\right)}{\sigma}\right]^{1 / 2}
$$

Based on this wealth of knowledge on the topic of tube diameter and its relationship to flooding, it is concluded that the large diameter supposition is valid based on the findings of the abovementioned articles and the lack of any known contradictory data.

\subsubsection{Other Considerations}

The are other aspects of flooding which will play a role in the development of a correlation. Presented in this section is a review of these phenomena.

\section{a) Annular Flow}

From the above definition and examples of countercurrent flow, it stands to reason that the results of such a scenario depend on or result in a change in flow regime. The field of two phase flow depends heavily on the concept of two phase flow regimes. Of importance to this study is the annular regime. Such a flow regime is characterized by the liquid phase flowing down the walls of the duct in a thin film with a stagnant, cocurrent, or countercurrent gas core taking up the center [21]. This flow regime is of interest to the current investigation because of its occurence in the PWR Pressurizer surge line. It is desirable in an accident scenario to have the water in the pressurizer drain into the coolant loop. Under certain conditions the flow regime in the surge line would be annular in a vertical section with the working fluids being steam and water. Thus, in order to closely model the prototypical situation, an annular film flow is chosen. 


\section{b) Liquid Film Thickness}

Dimensionless numbers can be used to identify parameters upon which a phenomenon depends. This is necessary for both scaling purposes and to properly generalize the situation. During the course of the research performed for this investigation, a dimensional analysis was conducted. Using the Buckingham Pi theorem, several dimensionless groups were defined as being descriptive of the flooding scenario. There exists some contention as to the validity or choice of a representitive length scale. In most fluid dynamic systems where ducts or pipes are of primary interest, the hydraulic diameter is most frequently used [19]. Due to the nature of the phenomenon, the choice of length scale is not well defined. First, since the flow regime of study is annular flow in a large diameter pipe, the geometric description of the liquid phase of the flow is much more dependent on the film thickness than the diameter. That is, due to the symmetric nature of the flow regime, the film thickness is more characteristic of the flow than the fixed diameter. Second, due to the fact that the diameter of the present study's test section is above the "large diameter" cutoff [10], the flow system itself can be assumed to closely model a flat plate as opposed to a round duct. It is intuitively obvious from this assumption that the diameter is being ignored and as such it would not be sound to use it as a characteristic length. Finally, the film thickness itself is closely related to the void fraction [21]. In fact, void fraction is tightly coupled to the film thickness in that it can be used to describe the surface of the liquid-vapor interface.

All the correlations found to date rely on first defining a dimensionless film thickness parameter and then backing out a reasonable film thickness from this value [36] [3] [19]. In order to accomplish this, a Reynolds number must be assigned. The Reynolds number used in the following correlations is not a descriptive number for the system or for the flooding phenomenon. A liquid Reynolds number of the form [3]:

$$
\operatorname{Re}_{f}=\frac{4 Q_{p}}{D \cdot \mu_{f}}
$$

Where $Q_{p}$ is the liquid volume flow rate per unit perimeter. This definition of a Reynolds number assumes that the entirety of the flow is in the liquid phase. For vertical falling film thickness, Belkin et al. [36] was the first to formulate the dimensionless film thickness under laminar flow conditions. This model was further expanded to turbulent regimes by the work of Wallis [21]. However, under most of these uses was the assumption that the correlation was only valid for flows of liquid down a vertical surface without gas flow. It would, therefore, be inappropriate to use such a correlation to reduce the data set acquired from the current set of experiments in which there is a countercurrent gas flow. There have been studies into whether or not such a correlation is applicable to systems in which there is an appreciable gas flow. Guedes de Carvalho has stated that such a correlation can be used in the case of countercurrent gas flow on a falling film up to the point of flooding [37]. While he makes the point that the phenomenon itself will affect the film thickness, it does not pose a great enough modifying effect so as to render the correlation unusable. The film thickness can be calculated by using the following relationships. By beginning with calculating the liquid film Reynolds number, Ref, the dimensionless film thickness, $\delta^{*}$, can be found from the Belkin correlations [36]:

$$
\delta^{*}=0.304 \operatorname{Re}_{f}^{7 / 12}
$$

This characteristic film thickness is then used to find the actual film thickness which will be used as the characteristic length for the system. This relationship was first derived by Nusselt [36] as the definition of such a dimensionless film thickness: 


$$
\delta=\delta^{*}\left[\frac{v_{f}^{2}}{g\left(1-\frac{\rho_{g}}{\rho_{f}}\right)}\right]^{1 / 3}
$$

This film thickness is the characteristic length used both in further dimensionless groups and in the calculations of the actual phase velocities of the fluids. These velocities are the bases upon which the correlating factors have been defined. They are arrived at because of the fact that the void fraction in the test section can now be defined from the film thickness by a simple geometric analysis and the definition of the void fraction, $\alpha$.

$$
\alpha \equiv \frac{A_{\text {gas }}}{A_{\text {total }}}=\left(1-2 \frac{\delta}{D}\right)
$$

This definition of alpha is dependent only on the known diameter of the test section and the film thickness above defined. Thus, the velocities of the fluids, as found from the volumetric fluxes, are known and as such used to describe the system. If fact, these velocities are instrumental in the definition of the correlation here presented. These velocities are found by the following relationships [21].

$$
\begin{gathered}
v_{f}=\frac{j_{f}}{1-\alpha} \\
v_{g}=\frac{j_{g}}{\alpha}
\end{gathered}
$$

\section{c) The Froude and Ohnesorge Numbers}

The final segment of the correlation deals with two dimensionless parameters that were found from a similarity study conducted on the flooding experiment. A detailed description of this analysis can be found in the self-titled section along with a discussion of the dimensional dependence of other parameters. The result of this dimensional analysis was the discovery that the gravity, surface tension, viscous, and inertia forces can all be related to the flooding phenomenon. Namely, the Froude number, Fr, and the Ohnesorge number, Oh, are both dimensionally linked to the flooding experiment. The relationships of these numbers to flooding have been seen before. Zapke and Kroger [15] have made the case that the Froude number is merely an alteration to the Kutateladze number by pointing out that if the length scale used in the Froude number is altered to include a gravity term the Kutateladze factor is obtained.

Mouza also makes the claim that both the Froude number and the Ohnesorge number are important factors in flooding [25]. He suggests that the Froude number successfully captures the interactions of the physical properties of the system and the liquid layer thickness. His definition of Fr for vertical flows takes the form of 


$$
F r=\frac{\left\langle U_{f}\right\rangle^{2}}{D_{h} g}
$$

where $<\mathrm{U}_{\mathrm{f}}>$ is the mean liquid layer velocity given by:

$$
\left\langle U_{f}\right\rangle=\frac{Q_{f}}{A_{f}}
$$

This is similar to Zapke's definition from equation (3.8) but lacks the densimetric term. Mouza only used density to calculate his values for liquid flow rates and does not use them in his correlating terms. He claims that due to the forces acting on the interface, the viscosity and surface tension are much more important than density. This is a result of Mouza assuming that the surface and line forces, i.e. the interface, are responsible for flooding.

\subsubsection{Scaling Analysis and Test Matrix}

Presented in this section is the scaling analysis to identify the primary dimensional dependencies of the phenomenon and the parameters of interest for both the experiment and the final analysis as they relate to the prototype. A dimensional analysis was done according to the Buckingham Pi theorem as explained in [38]. This approach determines the dependence of physical parameters on each other so that a functional relationship between such parameters may be found. Also known as a scaling analysis, this technique will highlight the characteristics of the system which should lead to flooding. Also included in this section is a brief description of the test matrix used to conduct the experiments. This will include an explanation of the entire global set of values for which the test was run.

\subsubsection{Scaling Analysis}

The purpose of this analysis is to determine which parameters need to be scaled to the proper dimensions and magnitudes to best represent the prototype PWR pressurizer surge line. The first step is to address which parameters are important to the flooding phenomenon and compare them to the available properties and hardware characteristics in the lab, this is shown in Table 3.1.

Table 3.1 Parameters of importance during a scaling analysis of the flooding phenomenon

\begin{tabular}{|l|l|l|}
\hline Parameter & Effect & Reference \\
\hline Density ratio & $\begin{array}{l}\text { Disturbance and instability } \\
\text { effects, very important }\end{array}$ & Zapke [39] \\
\hline Tube diameter & Many aspects, very important & Vijayan [10], Jayanti [35] \\
\hline Tube length & Location of flooding & Jeong [40] \\
\hline Surface tension & $\begin{array}{l}\text { Slight stabilizing effect on } \\
\text { flooding }\end{array}$ & Deedarlianto [41] \\
\hline Liquid viscosity & Interface instability & Chung [26] \\
\hline Gas viscosity & None & Zapke [39] \\
\hline Gas Re & Independent of flooding & Zapke [39] \\
\hline Liquid Re & Film thickness & Carvalho [42] \\
\hline
\end{tabular}


Tube diameter is a primary factor in determining the scale of the experiment. As stated previously in the literature survey, there are two main groups of tube diameters, large and small. Since the prototype PWR pressurizer surge line diameter is 10 inches, this falls well within the bounds of the large tube diameter classification. The cutoff as suggested by Vijayan [10] based on his experiments is $67 \mathrm{~mm}$, or approximately 2.6 inches. Furthermore, Vijayan's conclusions are that any diameter above this threshold will reach flooding under similar conditions. That is, above 67 $\mathrm{mm}$, tube diameter no longer affects the flooding point. Therefore, any tube diameter over 2.6 inches will act similarly to any other tube with a diameter over 2.6 inches. To keep the tube diameter to a value for which the existing facilities can accomodate flow rates of the fluids to induce flooding, the scale of the experiment, geometrically speaking, is set to a three inch inner diameter.

According to Zapke, the gas phase Reynolds number is independent of the flooding phenomenon. Thus, it is not a good indicator nor should it be used to scale the experiment and its working fluid parameters. The implication is that if the gas phase Reynolds number is insignicant, so is the gas velocity. This result would neglect the affect that the viscous forces have on the Reynolds number. The real meaning behind Zapke's conclusion is that the gas Reynolds number should not be used for correlating flooding data. The liquid phase Reynolds number would require velocities which are well outside the bounds of a laboratory. This is shown by looking at the prescribed prototype conditions as mentioned by Liao [5]. The Re value for the prototype is approximately 218,000 . This number is based on a liquid volume flux, jf , of $0.1 \mathrm{~m} / \mathrm{s}$ and liquid water and steam at $160 \mathrm{bar}$ and $630 \mathrm{~K}$. If this Re was to be matched by an experiment with a 3 in diameter tube, the resulting jg would be $21 \mathrm{~m} / \mathrm{s}$. While this seems reasonable, the corresponding air velocity in a one and a half inch approach tube would be greater than $100 \mathrm{~m} / \mathrm{s}$.

A better scaling parameter would be the liquid Froude number. This number appears in a dimensional analysis for the phenomenon and can be considred to be a descriptive and characteristic number. For the prototype, the Froude number for the liquid phase is found to be 4 $\times 10^{-4}$. At the same Froude number, an air and water facility would have to have a value for jf of $0.055 \mathrm{~m} / \mathrm{s}$. This would require an inlet water volumetric flow rate of $4.2 \mathrm{GPM}$ which is well within the bounds of the present experimental limits.

Since the working fluids of the prototype and the experiment are dissimilar, the density ratio parameter is not likely to be closely scaled. For water and air, the ratio $\left(\varrho_{\mathrm{g}} / \rho_{\mathrm{f}}\right)$ is essentially zero, indicating that the density ratio is particularly skewed. For the prototype situation, the same ratio is approximately equal to 0.154 , suggesting that this will affect the final gas velocity to induce flooding. The ratio of densities is also an important property to consider according to Zapke [39], where he states that the densities of the fluids are proportional to the gas velocity needed to induce flooding. This proportionality is shown in equation (3.1).

$$
j_{g} \propto \frac{D^{0.55} g^{0.5} \rho_{f}^{0.55} \sigma 0.05}{\rho_{g}^{0.5} \mu_{f}^{0.1}}
$$

It should be noted that this result was derived by assuming that $(\rho f-\rho g$ ) $\approx \rho f$ and solving a modified Wallis correlation for jg. Since for the prototype condition there is only 15\% disagreement between the phase densities, this assumption, while not perfect, is at least allowable. The density ratio scaling will be partially addressed in the steam-water tests on a separate facility. 


\subsubsection{Dimensional Analysis}

In order to properly assess the parameters that govern flooding, a scaling analysis must be completed to determine which physical properties of the system are linked are independent. This is accomplished by first conducting a Buckingham Pi Theorem analysis on the system. The parameters of importance were chosen to be the densities of the working fluids, their viscosities, their relative velocity, surface tension, film thickness, diameter, and gravity:

$$
f\left(\rho_{f}, \rho_{g}, \mu_{f}, \mu_{g}, v_{r}, \sigma, \delta, D, g\right)
$$

For the purposes of the analysis, mass $(\mathrm{m})$, time $(\mathrm{t})$, and length $(\mathrm{L})$ were chosen as the primary dimensions. From this, it is obvious that there must be 9-3, or 6, dimensionless groups. After completing the Pi theorem analysis, the groups shown in Table 3.2 appear.

Table 3.2 The dimensionless groups arrived at from the Buckingham Pi Theorem

\begin{tabular}{|c|c|}
\hline Pi Group & Parameters \\
\hline$\Pi_{1}$ & $\frac{\rho_{g}}{\rho_{f}}$ \\
\hline$\Pi_{2}$ & $\frac{\mu_{f}}{v_{r} \rho_{f} D}$ \\
\hline$\Pi_{3}$ & $\frac{\mu_{g}}{v_{r} \rho_{f} D}$ \\
\hline$\Pi_{4}$ & $\frac{\sigma}{v_{r}^{2} \rho_{f} D}$ \\
\hline$\Pi_{5}$ & $\frac{D g}{v_{r}^{2}}$ \\
\hline$\Pi_{6}$ & $\frac{\delta}{D}$ \\
\hline
\end{tabular}

The $\Pi_{5}$ group is essentially the Froude number. As stated above in the literature survey, the Froude number relates the kinematic forces in the flow to the gravity force. This indicates that this relationship is of importance to the flooding phenomenon. In order to include the film thickness in the Froude number, the Pi groups can be rearranged in the following manner:

$$
F r=\frac{v_{r}^{2}}{g \delta}=\frac{1}{\prod_{5} \prod_{6}}
$$

Another interesting result of this analysis is $\Pi_{6}$, which is the ratio of the film thickness to the test section diameter. This number characterizes the system in a way which takes tube diameter into account. Based on this analysis, all of the parameters upon which flooding depends are well defined. In addition to these groups, there are several other dimensionless numbers that are widely used in the study of flooding, shown below in Table 3.3. Most of these have been covered in the literature survey; however, they deserve to be revisited. 
Table 3.3 Additional dimensionless numbers used in the analysis of flooding

\begin{tabular}{|c|c|c|}
\hline Dimensionless Number & Symbol & Definition \\
\hline Ohnesorge Number & Oh & $\frac{\mu_{f}}{\sqrt{\rho_{f} \sigma \delta}}$ \\
\hline Bond Number & Bo & $\frac{j_{f} \mu_{f}}{\rho_{f} D^{3}}$ \\
\hline Wallis Parameter & $j^{*}$ & $j^{*}=j \sqrt{\frac{\rho}{g D\left(\rho_{f}-\rho_{g}\right)}}$ \\
\hline Kuteteladze Parameter & $\mathrm{Ku}$ & $K u=\frac{\rho^{1 / 2} j}{\left[g \sigma\left(\rho_{f}-\rho_{g}\right)\right]^{1 / 4}}$ \\
\hline
\end{tabular}

The Ohnesorge number relates the viscous forces to the surface tension forces. This ratio will play an important role in correlating the data taken and provides another means of accounting for the forces involved. Furthermore, the Ohnesorge can be found from the Pi groups by the following relationship:

$$
O h=\left[\frac{\Pi_{2}^{2}}{\prod_{4} \Pi_{6}}\right]^{1 / 2}
$$

Also, the Bond number has been referred to as a dimensionless diameter [13]. As such, this parameter is also a good characterization of the system and usually is used as a term for validating the use of the Kutelatadze correlation. In addition to these, there are, of course, the Kutetaladze and Wallis numbers which have been used for the prediction of flooding in many studies and examples.

\subsubsection{Test Matrix}

The largest restriction on the test matrix with the flooding rig is the physical limits to the flow rates achievable. That is, there was a limited range of both liquid and air flow rates that could be used for the experiments. The liquid flow rate is bound on both sides by the supply of water coming from the water main in the laboaratory and the available air flow rates achievable by the blower. The upper limit of water flow rates was found to be approximately 7.2 GPM as delivered from the water main. Attempts were made to increase this flow rate by means of a AMT1900 pump. However, the physical restrictions of the flow loop itself, i.e. pressure drops across the system, were too great for this pump to overcome. As a result, the pump had no effect on boosting the possible flowrates of the liquid phases. On the lower bound of liquid flow rates, the obvious answer is that there were no physical limits as the flow rate of water, controlled by the rotometer pair, could be reduced to zero and thus any value in between this and the max value. The air flow rate, then, becomes the limiting factor in the lower water flow rate scenario.

The air flow rate limits of the test matrix are now defined in order to more completely characterize the system and define the working test matrix. Again, as previously stated above, there exists no lower limit to the air flow rate by physical logic. However, due to the method of flow control mentioned in the facility description section above, the bypass control valve restricted flow in such a way that the minimum controllable air velocity was found to be $24.4 \mathrm{~m} / \mathrm{s}$ 
centerline maximum velocity in the air approach line. This value corresponds to a volume flow rate, $\mathrm{Qg}$, of approximately $2.14 \times 10^{-2} \mathrm{~m} / \mathrm{s}$. The maximum flow rate of the air is determined again as with the water flow rate case by the physical pressure drops in the system that the air phase experiences. These are due to the geometric factors in the design as built and cannot be altered. The final configuration of the system results in a maximum air flow rate of approximately $39.0 \mathrm{~m} / \mathrm{s}$, or $3.41 \times 10^{-2} \mathrm{~m} / \mathrm{s}$. With this information it now becomes possible to define the test matrix for the experiment by which the most $\mathrm{e} \square$ cient and concise method of collecting the necessary data can be arrived at. By using a Kutelatdze type correlation to approximate the flooding velocity of water given the maximum air flow rate attainable, the lowest water flow rate becomes 3.90 GPM. If it is assumed that air flooding flow rate will decrease as liquid flooding flow rate increases, this yields a range of liquid flow rates at which the blower can supply the requisite amount of air of 3.90 GPM to 7.20 GPM. The test matrix can be found in Table 3.4.

Table 3.4 Test matrix for air-water tests

\begin{tabular}{|c|c|c|}
\hline Working Fluid & Water & Air \\
\hline Upper Limit & $7.10 \mathrm{GPM}$ & $40.0 \mathrm{~m} / \mathrm{s}$ \\
\hline & 6.70 & \\
& 6.30 & \\
& 5.90 & \\
& 5.5 & \\
& 5.1 & \\
\hline Region of Interest & 4.70 & \\
& 4.30 & $32.4 \mathrm{~m} / \mathrm{s}$ \\
\hline Lower Limit & $3.90 \mathrm{GPM}$ & \\
\hline
\end{tabular}

The region of interest is the section of the test matrix that is closest to the scaled values. For this investigation, $\mathrm{a} \mathrm{j}_{\mathrm{f}}$ of $0.055 \mathrm{~m} / \mathrm{s}$ was found to be the lowest obtainable liquid flowrate. This corresponds to a liquid flow rate of $4.2 \mathrm{GPM}$, which represents the bottom portion of the test matrix. The remainder of the test matrix is devoted to acquiring a large enough range of data for the development of the correlation.

It should finally be noted that the increments taken for each liquid flow rate were determined by the accuracy of the liquid flow magnetic flow meter. Since the available incremental steps are at a minimum of $0.1 \mathrm{GPM}$, care was taken to evenly distribute test runs at small multiples of this value.

\subsubsection{Facility Description}

This section details all structural and physical components of the experiment and provides both an explanation of the facility and an outline of the rationale for each component. This section is divided into several sections. First, the physical support structure, referred to as the "frame" is described, followed by an explanation of the structure holding the test section, referred to as the "cage". The next section is concerned primarily with the test section and all of its attachments and physical attributes. This section will deal with all parts of the experimental facility that are made from optically clear acrylic. Finally, the third major section deals with the instrumentation and the data acquisition system. This section details all data gathering instruments and equipment including but not limited to electronic instruments (pressure cells, thermocouple, etc.) and manual equipment (rotometers). A final section explains how the data is reduced; the final LabVIEW data acquisition program and arrangement will be explained and the rationale provided, followed by a description of the integral experimental system. 


\subsubsection{The Frame}

The "ground level" system upon which all other equipment is ultimately supported is the structural frame. This large structure provides both the physical grounding for the test section and instrumentation and also provides the rigidity needed for both stable operation and safety. This structure is a ten foot long by two foot wide by ten foot high steel box made from $1-5 / 8$ inch slotted steel channel. The frame is shown in figure 3.5. The standard trade name for the construction material is "single channel slotted Unistrut (TM)". Standard fittings were used to connect all components and the structure is anchored to the concrete floor of the lab using standard half inch concrete anchors on all six uprights.

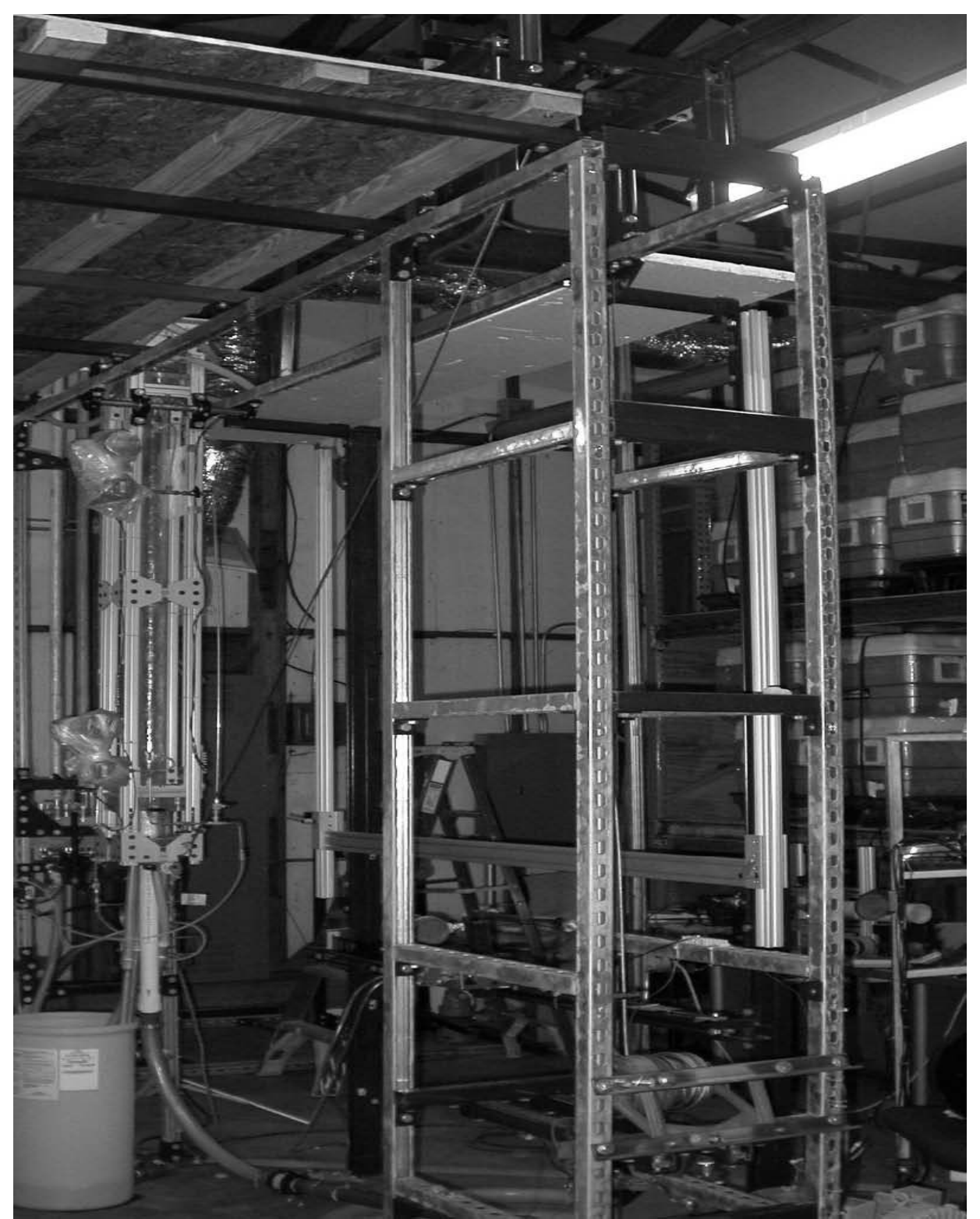

Figure 3.5 The frame used to support the test section and the necessary experimental equipment

\subsubsection{Design Details}

The slotted channels allow for the attachment of other structural and nonstructural components to the frame from two sides of the channel as opposed to only one side of the channel where standard single channel strut was used. For most fittings and junctions, the standard side of the 
channel was used. The size of the major sections of the frame were decided by the design size of test section and cage and the fact that it was most convenient to use the standard ten-foot length. Ten-foot lengths for the uprights allow for the cage to rotate a full 90 degrees without being impeded either at the top or the bottom. Since drains, exhausts, and fluid inlets are needed at the top and the bottom of the cage, flexibility was of utmost importance. This dimensional decision allows for the cage to be in essentially the same orientation when situated at a horizontal configuration as in a vertical one. That is, the associated instrumentation and fluid connection systems migrate less as a result.

The cage is located at the "near" end of the frame. This convention is arbitrary and will be used for easy reference. Also located at the near end of the frame is the water delivery system, the details of which will be given in the instrumentation section. Finally, a torque induction system involving two springs is also located at the near end to secure the test section into position. Conversely, the far end of the frame is composed of the winch system and the air supply or blower system. A schematic of the test facility is shown in Figure 3.6.

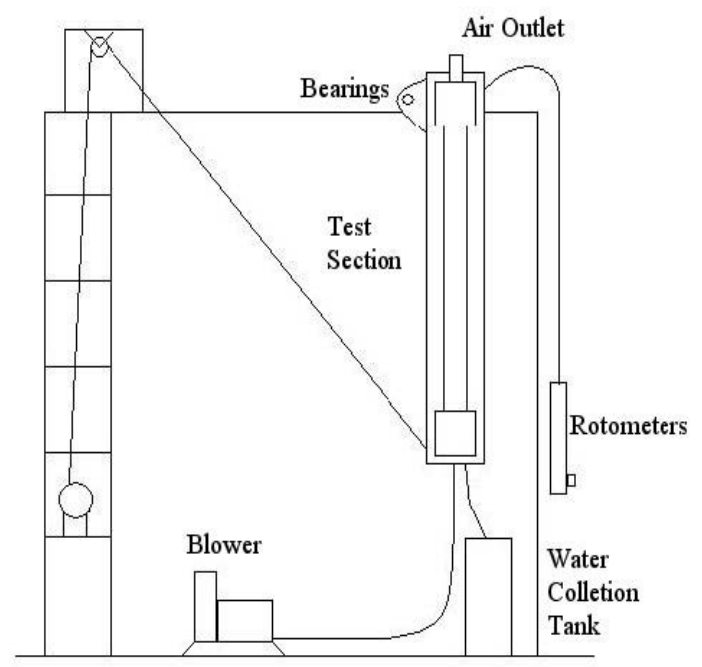

Figure 3.6 A schematic view of the experimental setup

\section{a) The Frame Near End}

The near end of the frame consists of the cage rotation bearings, water delivery system, and the torque supply system. The cage bearings are located on the upper cross beams approximately 18 inches from the end of the channels. The bearings are standard sealed one-inch bearing assemblies mounted to the cross beams with $3 / 8$ " bolts. Additionally, they are isolated from vibrations in the frame by means of vibration damping pads in order to minimize the effect of vibration on the test section. The size of a one-inch rotational rod was struck upon after estimating the greatest possible mass that the cage could theoretically exhibit. That is, if it is assumed that the test section and plenums are full of water, what is the maximum weight of the test facility including aluminum cage, acrylic test section, and water. After performing a material mechanics analysis using this mass, it was found that a one-inch round steel shaft would support the cage with an acceptable factor of safety and would not deflect by an appreciable amount.

The water delivery system is also located at the near end of the frame. This system includes the magnetic flow meter, the two manual control rotometers, and all associated piping and tubing. The location of the water delivery system minimizes the distance to the upper plenum of the test section for all inclination angles. All water is supplied by the building water main and feeds 
directly into the magnetic flow meter by way of a nominal one-half inch pipe. From the flow meter, the water approaches the rotometers and is split in such a way that the flow meters receive an equal amount of water flow. Thus, the magnetic flow meter will provide all necessary flow data while the rotometers will allow for fine control. After the rotometers, one-inch standard pipe traverses the height of the frame and is then connected to flexible hosing. The hosing allows for the water to enter the upper plenum without being affected by the inclination of the cage. If rigid plumbing where implemented, the cage would not be easily rotated.

Finally, the torque system is a correction system resulting from the physical nature of the test section cage. The cage is hung in such a way that its center of mass is not located directly under the bearing when the test section is fully vertical. When the cage is allowed to hang free, the test section rests at an inclination angle of approximately 10 degrees from vertical. Thus, it was necessary to design a system which would alter the inclination of the system when measurements less than 10 degrees are desired. Two long springs were attached to the cage at its lowest point, thus ensuring the greatest moment arm, and attached to the near end of the frame. Before their final terminus, the springs are routed upwards by way of spring pulleys in order to allow adjustments to the tension supplied. This is accomplished by adjusting the j-bolts connecting the end of the springs to the rigid frame. The springs supply enough torque to keep the cage at the desired angle for the experimental range, thus compensating for the discrepancy caused by the location of the center of mass.

\section{b) The Frame Far End}

The far end of the frame is primarily for the location of the winch. It also consists of the air supply, or blower system and instrumentation. The winch was outfitted with new, 3/16-inch aircraft cable specified mainly by the aforementioned maximum theoretical cage weight. The newly cabled winch provides 3 inches of linear cable movement per one full rotation of the control boss. This relates to approximately 0.5 degrees of inclination angle per one full rotation of the control boss. This fine control is extremely useful when considering the inclination angle affect on flooding.

The winch is mounted on the frame in such a way that the control boss' plane of rotation is parallel with the ground. This was accomplished by means of a fabricated mounting system. The cable leaves the winch and travels vertically up the frame freely until it encounters a hard mounted pulley attached to the upper portion of the far end of the frame. From the pulley, the cable travels back to the lower end of the cage and attaches there by means of a hook and eye configuration. Thus, the winch can control the inclination angle of the cage easily due to the large moment arm created by the location of the eye hook. Although the test facility was constructed with the capacity to run tests at $0-90^{\circ}$ inclination angles, inclined tests will be run as part of future test programs.

The far end of the frame is also home to the air supply system. The blower is located past the near end of the frame with the air supply pipe being attached directly to the uprights. This section of the blower system was designed to allow for the air leaving the blower to become fully developed before encountering the pitot tube air velocity meter. It is also necessary that this section of piping be rigid and stable to ensure fully developed flow of the air.

\section{c) The Cage}

The test section is situated inside a rigid aluminum structure referred to as the "cage". The cage was designed to give a structural rigidity to the test section and to allow for instrumentation to be attached near the test section, eliminating the need for long, error inducing approach tubes. This is 
of increasing importance when the test section is inclined. The decision to use the aluminum structural material, as opposed to more steel channel, was made based on several factors. The first factor was weight. In order to make the system safe, it was determined that the lighter a facility was, the less chance there was of encountering a design limit on hardware. That is, it was necessary to design a facility that would remain rigid during operation, but would not prove too heavy to move via the winch, or that would compromise the tensile strength of the aircraft cable. Aluminum structural material is half as massive as equivalent steel channel, but is comparatively strong.

Another reason for choosing the aluminum structural material has to do with the availability of "attachable sides". That is, all four sides of the aluminum strut are capable of receiving t-bolts, thus components (fittings, mounting hardware, etc.) can be attached to any open section of the material. This allowed for a more rigid design of the cage with respect to the attachment of the test section and a more convenient locating of instrumentation. This fact is highlighted in the instrumentation section regarding the pressure transducers below.

Yet another factor in choosing the aluminum material for the cage follows from the previous convenience; that being the ability to change out components while the cage is hung. Due to the nature of the t-slotted aluminum framing system, it is possible to change out parts of the acrylic test section assembly while the cage is attached to the frame. This also eliminates the time consuming procedure of taking the cage down and putting it back up.

Most of the reasons for the design choices about the cage come directly from the design of the test section. However, some of the test section design choices were in turn decided upon because of the cage design. The cage assembly rotates about a set of enclosed bearing units. These bearings also attach directly to the cage approximately 10 inches from the end of the cage. The bearing attaches directly below the second set of cross members. The members that the bearings attach to are the longest continuous pieces of aluminum and measure 86 inches in length. This length encompasses the entire length of the test section and associated plenums, flanges, and outlet components.

The cross members measure five inches in length and are used both for structural support of the cage, and as an attachment point for the test section flanges. Since the aluminum strut cross section is a 1.5 inch square, the cage, when fully assembled, exhibits a square cross section of 8 inches. The cage is assembled by means of commercially available fittings of both angled, 90 degree braces and flat mending plates. This means of construction allows for unparalleled rigidity which results in safety and structural reliability.

\section{d) Acrylic Components}

All parts of the experiment constructed with optically clear acrylic or those attaching to said acrylic are referred to as the test section. This distinction is necessary due to the fact that the actual "test section" is a 3-inch inner diameter, 72 inch long acrylic tube in which flooding occurs. However, for ease of description, the convention in this section is to refer to all components directly attached or affected by this tube as the test section. It is necessary to briefly state all components which compose the test section and present a schematic view of the test section, shown in figure 4.3. Starting from the "top", i.e. those components located highest on the test section when it sits in a vertical position, there are: the air outlet assembly and flange, the upper plenum and flanges (which include all the water inlet ports and tubing), the test section tube (with associated flanges and pressure ports), the lower plenum and flanges, and the air inlet assembly (with associated fittings). The following subsections will detail the design of each listed component. 


\section{e) The Air Outlet}

The uppermost component of the test section is the air outlet. This component provides the air (and entrained water) a method of leaving the test section. Furthermore, the air outlet is also responsible for inducing an annular flow within the test section by creating a constant $1 / 8$-inch gap for the water entering the test section to flow through. The air outlet consists of two parts, the outlet body and a flange. A construction picture is provided in figure 4.4.

The outlet body is a cast acrylic tube of 1/4-inch thickness and 2.75 inch outer diameter. The end of the tube that lies inside of the test section has a 30 degree bevel on the inner surface. This bevel was added in order to reduce the flow resistance that the air would see as it leaves the test section. The first design of this part had a flat, 90 degree end which was observed to create unwanted turbulent vortices and disturb the incoming water to a large degree. With the implementation of this design, such vortices have not been observed. On the other end of the tube, a small relief has been machined in to allow for the future attachment of an outlet fitting. This differs from the original design which contained a reducer at this end of the tube. This reducer took the diameter of the tube from its 2.25 inch inner diameter to a $3 / 4$ inch NPT female thread over approximately 3 inches. The resulting pressure drop across this reducer proved to be too great during initial shake down tests and required removal. It is at this point in the design process that the issue of pressure drops became important. The pressure drop across this reducer was large enough to affect the flow through the entire experimental facility. The drop caused the test section to become pressurized and reduced the air flow through the system to a point where flooding was no longer achievable.

Finally, a mounting flange is attached to the air outlet 8 inches from the beveled end of the tube by using acrylic solvent weld. This flange mounts to the upper plenum and the uppermost stringers of the cage. For the experiments conducted herein, the upper end of the air outlet was left open to the environment. This allows for the working fluids to exit the test section with a minimum of flow friction and acceleration pressure losses. The only friction seen by the fluids as they exit are wall friction and a slight reduction in flow diameter. This reduction in flow diameter, though, is small and does not contribute greatly to any inherent pressure drop. As a result, this component should not induce a significant pressurization of the test section. Thus, the pressure inside the test section can be assumed to be at atmospheric. The second purpose of the air outlet is to aid in the formation of annular flow. Since the air outlet tube rests inside of the test section, the end of which is situated below the holes which allow water into the test section, an annular film is formed within the test section. 


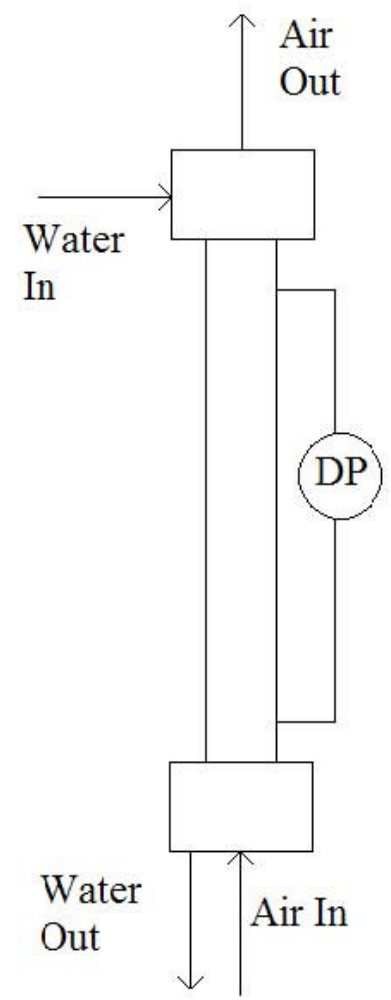

Figure 3.7 Relative locations of the fluid inlets and outlets

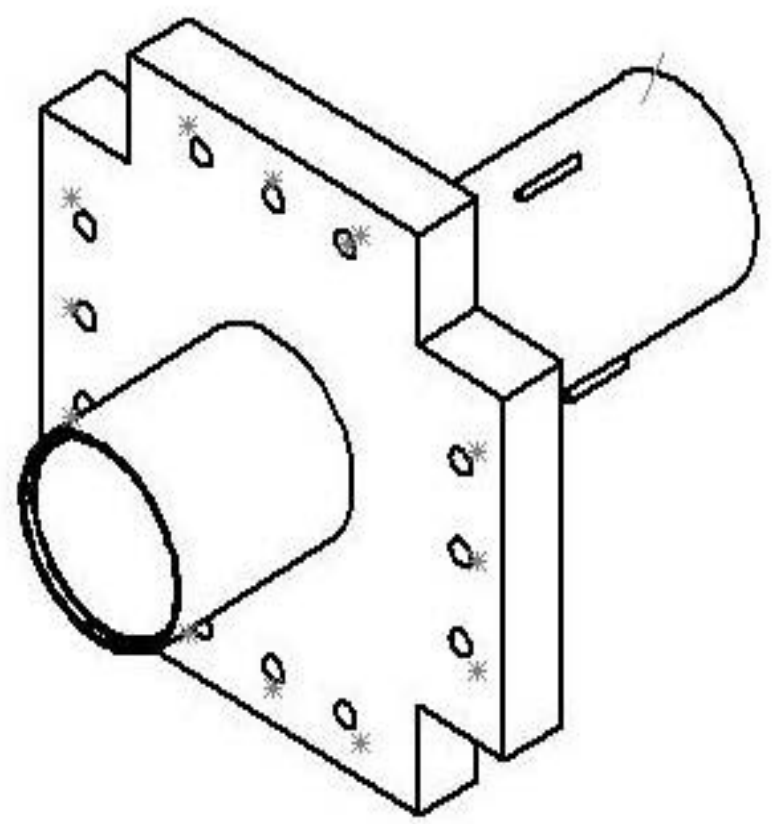

Figure 3.8 The air outlet assembly

\section{f) Upper Plenum}

The upper plenum of the test section provides the means by which the water enters the test 
section. The plenum consists of three pieces, the plenum body and two flanges. The plenum body is a 5-inch inner diameter cast acrylic tube of 6-inch length. Into this tube, four 1-inch holes have been milled to allow for water to enter the plenum. Attached to the outside of these holes are threaded acrylic blocks into which hose fittings are inserted as shown in figure 4.5. These fittings accept hoses from the water supply system. At each end of the plenum a flange has been solvent welded which will attach to the air supply flange or the test section flange. Each of these plenum flanges has an o-ring grove that seats a 232-3 o-ring which seals the plenum from the outside environment.

As stated above, the upper plenum provides the water pre-injection system for the test section. That is, water enters the plenum via the one-inch holes, referred to as "injection ports", and comes to a relative fluid equilibrium, i.e. fixed gravity head and a fixed stagnation pressure. This results in the upper plenum acting as a stagnation chamber, allowing for the flow entering the test section holes to do so at relatively the same conditions. The plenum contains four injection ports; however, only two of them are actually used for the experimental runs considered in the runs analyzed. These ports are situated on the top and bottom of the plenum were it to sit in a horizontal position. These two ports create an equal distribution of volumetric flow entering the upper plenum. In the first design, only one port was included and it was observed that the

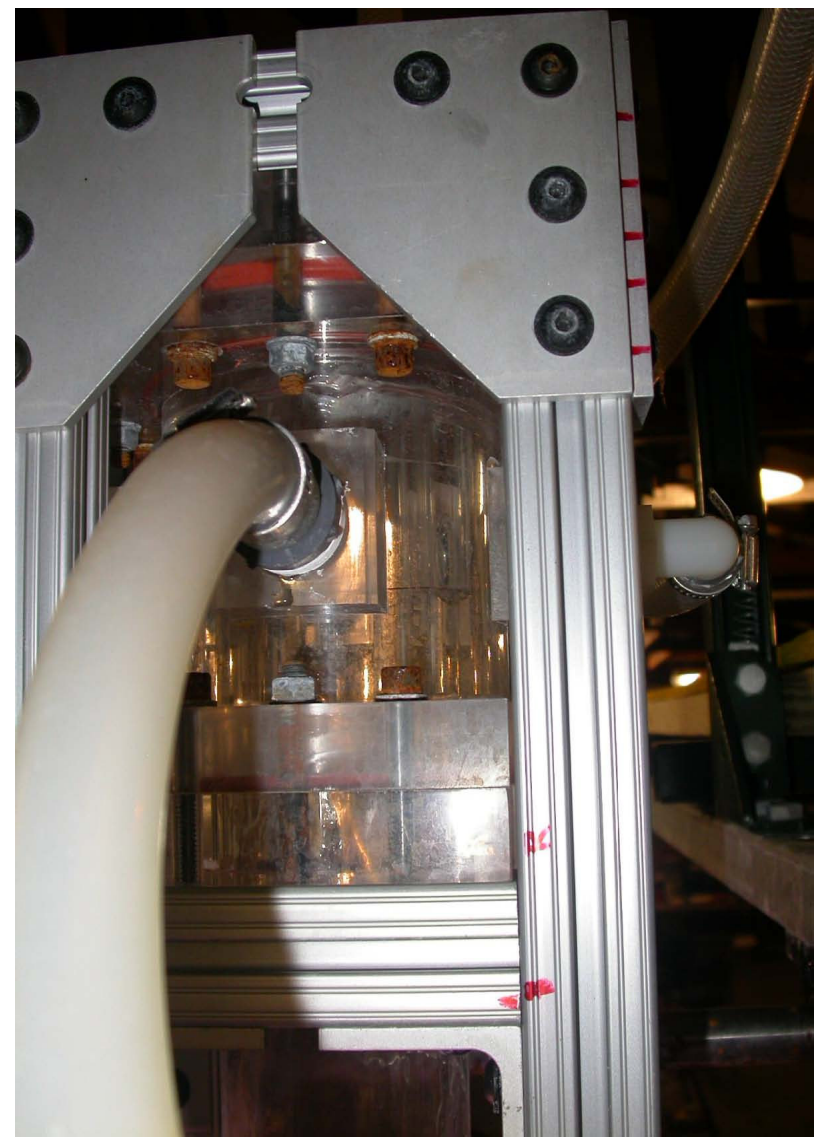

Figure 3.9 The upper plenum of the test section

water level in the plenum at the port was markedly higher than on the opposite side. This discrepancy in water level would produce an unequal gravity head and disturb the annular flow created in the test section. The addition of a second port negated this unevenness and a uniform 
water level has been seen to result. The second two ports were added as options so future investigations would benefit from the added control over inlet water flow rate.

\section{g) Test Section}

The test section is the clear acrylic tube in which flooding is observed to occur. The test section used for this experiment measures 72 inches in length and has a nominal inner diameter of 3 inches. The wall thickness of the test section is one quarter of an inch. Four pressure ports have been added, two on each side, to accommodate a differential pressure transducer and two absolute pressure transducers. On the upper end of the test section, inside of the upper plenum, the water enters the test section through a series of 12 evenly spaced 1/4-inch holes. These holes are placed at the same axial plane and are radially symmetric. The air outlet pipe extends into the test section and terminates approximately two inches below these water inlet holes. This has the effect of forming the annular flow regime within the test section. The lower end of the test section descends into the lower plenum and extends about 4 inches below the air inlet pipe.

The water inlet of the test section directs the flow into an annular regime, alleviating many of the entrance effect problems encountered by previous experiments [23]. This water inlet configuration also allows for the symmetric entry of water into the test section. By separating the flow into 12 distinct flow paths, the flow is evenly distributed around the test section. If, instead, the flow were allowed to enter the test section via slits cut into the tube, any flow disturbances induced by the water entering the upper plenum would be compounded and annular flow would not be maintained. The pressure ports are situated such that the differential pressure ports are located 52 inches apart on the "bottom" side of the test section. The bottom side refers to the side of the tube that would be under the rest of the test section if the cage where held in a horizontal position. This is due to the fact that for increased inclination angles, the annular flow regime breaks down and a stratified flow regime takes over. For these situations it would still be necessary to record differential pressure data and since the pressure transducer water lines would drain in the absence of a liquid level, the ports needed to be placed on the bottom side of the test section. The absolute pressure measurements are of lesser importance to the experiments at hand. They are needed only to gain a basic picture of the pressure in the test section and, as such, having two is a redundancy. Thus, they are placed on the "top" of the test section to recorded data for the vertical tests. Finally, the bottom end of the test section must be addressed. The test section extends past the air inlet into the lower plenum. This configuration ensures that all of the air entering the test section will, at least initially, progress upwards into the test section after leaving the air inlet pipe. Previous designs of the test section/lower plenum/air inlet resulted in a noticeable amount of air leaving the air inlet and being redirected into the lower plenum and out the liquid drain. By locating the air inlet within the test section, this effect is minimized.

\section{h) Lower Plenum}

The lower plenum is dimensionally identical to the upper plenum, but it does not have water injection ports. This component of the facility is a 6-inch long, 5inch inner diameter cylinder with a 1/4-inch wall thickness. The primary purpose of the lower plenum is as a transfer tank for the water leaving the bottom of the test section. As such, it has no penetrations. This provides a good viewing chamber for both the water leaving the test section and the exhaust portion of the air inlet. Many important observations can be made by viewing these conditions while the test is running.

\section{i) Air Inlet}

The air inlet is the only part of the experimental facility that is not constructed from acrylic and the component has undergone the most changes as far as design is concerned. The air inlet is a 3foot length of standard schedule 40 PVC pipe attached to a fiberglass and plywood flange. This 
flange is identical to the acrylic flanges used throughout the facility with exception of 4 drains added to facilitate the removal of water from the lower plenum. Also, in order to stabilize the air inlet tube and to provide rigidity, a second "flange" was added that connects to the cage.

The air inlet pipe was designed so that the incoming air flow would be fully developed when it entered the test section. According to Fox [38], this requires an L/D ratio of at least 30 . When the flow is fully developed, it will enter the test section at a known, fairly uniform air stream. Four 1/2-inch diameter holes were cut into the flange to expedite the water drainage from the lower plenum. To these holes are attached four hose connectors which run to the holding tank located below the test facility. The rigidity adding flange connects to the cage while allowing for the drain hoses to run through it. This both protects the drain hoses from disconnecting from the flange and adds rigidity to the pipe. Since the inlet pipe is 3 feet long, any force could feasibly knock it off center and redirect the flow of air into the test section.

\section{j) Additional Equipment}

To facilitate the purging of the absolute and differential pressure transducer lines, a pressure vessel was added to deliver water to the upper ports safely. The vessel consists of a 6-inch diameter stainless steel cylinder which is 24 inches tall. Shown in figure 4.6, the vessel has the following connections. The pressure vessel connects to the air compressor when the appropriate valve is opened. The vessel can then vent when the appropriate lines need to be purged. Water is added via the ball valve located at the top of the pressure vessel when the system is at atmospheric pressure. The pressure vessel is connected to the subsystem that is to be purged by way of a compression fitting which may at will be switched from the absolute pressure transducer system to the differential pressure system when the purge system is not pressurized. Once the appropriate subsystem is chosen, the purging process may be started by pressurizing the vessel and the appropriate subsystem.

\subsubsection{Instrumentation}

There are two major groups of instrumentation; the actual physical instrumentation and the data acquisition system. The setup of these two systems greatly affects the quality of the data taken and impacts the data taking process.

\subsubsection{Instruments and Equipment}

The instruments used in this experiment were decided upon after taking inventory of the measurements that need to be recorded. Table 3.5 illustrates the quantities to measure and the type of measurement device to use. 


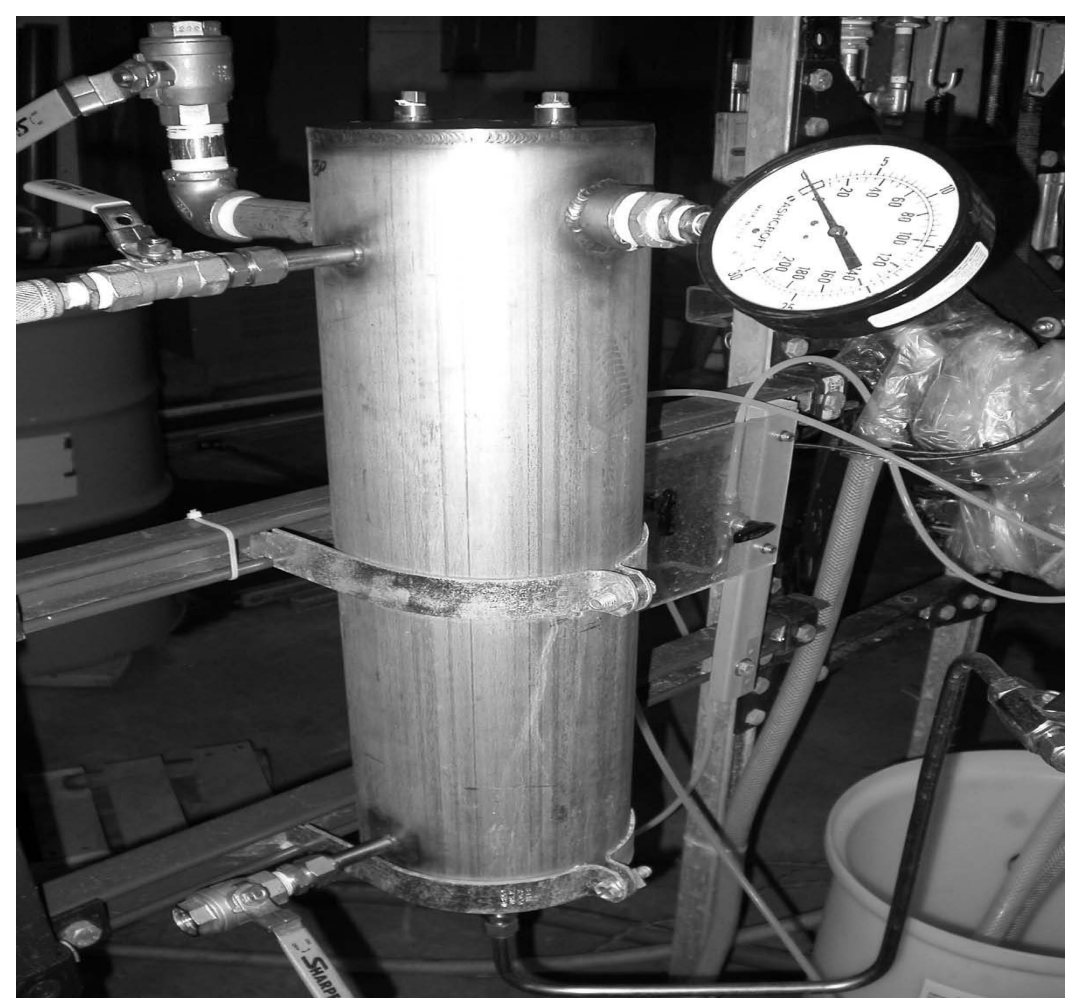

Figure 3.10 Pressure vessel for water delivery to the upper pressure transducers and aiding in the purging process

Table 3.5 Experimental measurements and devices

\begin{tabular}{|c|c|}
\hline Quantity & Measurement Device \\
\hline Air Velocity & Pitot Tube \\
\hline Water Velocity & Rotameters and Magnetic flowmeter \\
\hline Pressure Gradient & Differential Pressure Transducer \\
\hline Upper Location Absolute Pressure & Absolute Pressure Transducer \\
\hline Lower Location Absolute Pressure & Absolute Pressure Transducer \\
\hline Air and Water Temperature & T-type Thermocouples \\
\hline
\end{tabular}

The liquid flow rate is the only measurement of the system that uses two devices in series. This is due to the fact that one of these instruments, the rotometers, serves a dual purpose as both a flow meter and as a control device. Figure 3.11 shows these rotometers as they are attached to the facility.

The error associated with the rotometers is additive across the two of them, and the error incurred by the two rotometers would be unacceptable. Thus, it was necessary to use another instrument to determine the liquid flow rate. A 1/2" Yamatake MGG-18D magnetic flow meter was placed before the rotometers in order to more accurately measure the liquid flow rate. The advantages of using the magnetic flow meter are two-fold. The accuracy of the flow meter is \pm 0.01 GPM. This can be contrasted to the rotometer accuracy of \pm 0.1 GPM. The magnetic flow meter also can be 
connected to the data acquisition system as it outputs a voltage signal proportional to the flow rate. The magnetic flow meter is factory calibrated and connected to a communications protocol to send the data signals to the data acquisition system.

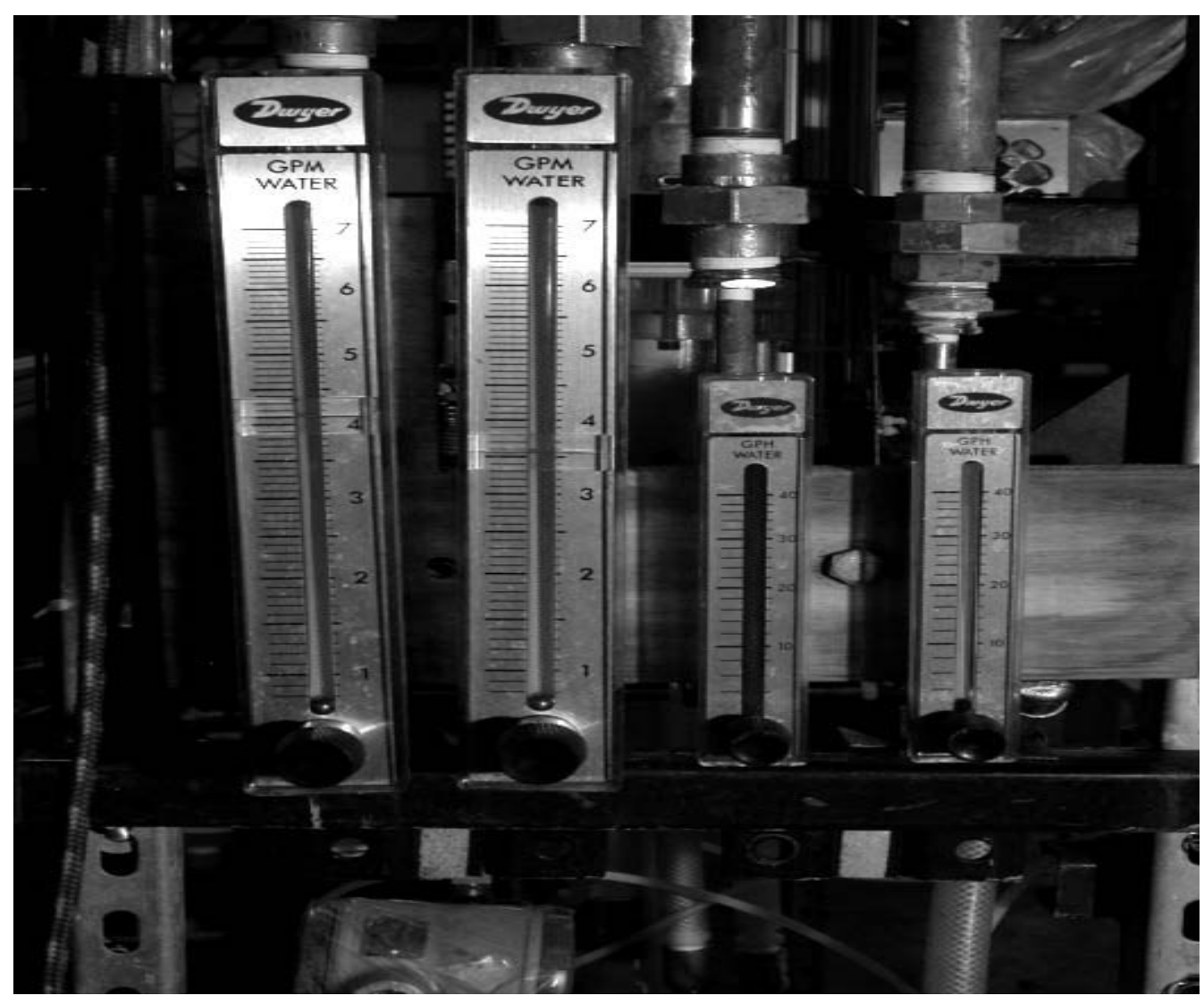

Figure 3.11 Rotometers used to control the liquid flow into the system

The air velocity measurement is made with the use of a pitot static tube system. The basic theory behind a pitot static tube air speed measurement states that if the stagnation pressure and the static pressure are known, from the Bernoulli equation, the dynamic pressure of the flow can be calculated.

$$
\frac{\rho v^{2}}{2}+\rho g h+p=C
$$

Where the fraction on the left hand side of the equation represents the dynamic pressure of the system. Also, the flow is assumed to be moving in streamlines so the change across them is zero, allowing for the $\rho g h$ term to be assumed zero. This allows for equation (3.26) to be simplified into:

$$
\frac{\rho v^{2}}{2}+P=P_{0}
$$

Where $\mathrm{P}_{0}$ is the "total pressure" of the system. With this in mind, a pitot static tube is inserted into an approach pipe leaving the blower at a distance suffcient for the flow to become fully 
developed. This probe contains both a pitot tube and a static pressure port which are then connected to a differential pressure transducer. The difference between their pressures is the dynamic pressure. The dynamic pressure is related to the velocity by the following relationship:

$$
\Delta P_{\text {dynamic }}=\rho \frac{V^{2}}{2}
$$

Thus a value is arrived at for the centerline velocity which can be related to the average velocity by a simple relationship. According to [38] the average velocity across the section of pipe is equal to two thirds of the maximum centerline velocity. Furthermore, the pressure transducer can also be directly connected to the data acquisition system and the measurements automatically displayed and recorded. Both the upper and lower pressure ports on the test section are measured using absolute pressure transducers. These are Honeywell model STA940 pressure transducers. This means that they require a wetted connection to the port at which the pressure is to be measured. To accommodate this requirement, small lengths of 1/4" tubing are connected to the transducers at the test section. The tubing must also be purged of air bubbles in order to guarantee the proper and accurate operation of the pressure transducers. A detailed procedure for purging the lines can be found below in the Operating Procedures section. The pressure transducers measure only the pressure seen at the transducer. That is, an associated gravity head is reported by the transducers according to the physical height of the water column described by the tube attaching it to the pressure port. For the upper absolute pressure transducer, this height is approximately 9 inches where, as for the lower port, the height is approximately 3 inches. This added pressure must be subtracted from the pressure reading in order to define the actual pressure in the test section at those two locations. The differential pressure measurement in the system is also made by way of a pressure transducer, a Honeywell STD924. The pressure transducer is a differential type and as such will measure the difference in pressure between the two pressure ports on the test section. However, the ports on the pressure transducer must also be wetted, as was the case with the absolute pressure transducers. Since the test section pressure ports are 52 inches apart, there will consequently be a 52 inches of water pressure reading on the transducer as a zero point. This is important in the results section, when looking at the data plots. When the differential pressure is being used for comparisons, the 52 inch zero point is removed. That is, when the actual differential pressure, or change in differential pressure is considered it becomes reduced. However, when a general trend or observation is examined, the raw reading from the differential pressure transducer is used and includes the 52 inch factor. This convention is used to properly compare raw signals from the DAQ instead of converting all of the signals when only a trend is being discussed. All three of the pressure transducers (the two absolute pressure transducers and the differential pressure transducer) are calibrated by means of the SMART protocol designed into them. A SMART communicator is used to check and reestablish the calibration periodically.

The final measurement needing to be made is the temperature of the working fluids in the system. These temperatures are necessary in order to properly define the state of the fluids. Properties such as density and viscosity, which are both used in the data reduction and in the construction of the final correlation. To take these measurements, two T-type thermocouples have been inserted into the incoming flows of both the air and the water. Both measurements take place along a length of pipe near the respective flow meters and in a section of the flow which is considered fully developed. Both thermocouples are connected directly to the data acquisition system so that continuous temperature data can be taken from the system and are calibrated by LabVIEW using its built in cold junction. The high speed camera used for visualization is an X-Stream XS-4 CMOS camera with a resolution of $512 \times 512$. It has a maximum capture rate of $5000 \mathrm{~Hz}$. 


\subsubsection{Data Acquisition System}

The data acquisition system, or DAQ, utilized in this experiment consists of a Dell Precision Desktop connected to a National Instruments SCXI-1000 chassis. Within the SCXI-1000 chassis is a SCXI-1102b analog module connected to SCXI-1300 terminal block. Connected to the block are the data connections to the above described instruments. The physical specifications of the system as it is currently described allow for a data collection rate of well over $50 \mathrm{kHz}$. While this is well beyond the needs of the current experiment, such data acquisition power would greatly aid in any visual acquisition setups. The final data collection rate was set to be $10 \mathrm{~Hz}$.

The data acquisition system accepted analog voltage signals between 0 and $5 \mathrm{~V}$. A terminal box is responsible for converting the few instruments that produce current signals into voltages that the DAQ can read. The thermocouples create a 0 to $10 \mathrm{mV}$ signal which is conditioned and amplified in the SCXI-1300 block. A LabVIEW program gathers the voltage signals and displays them on the monitors. The program also applies the calibration curves described above. A screen shot of the LabVIEW front panel is given in Figure 3.12.

\subsubsection{Data Reduction}

After the data has been taken, it needs to be reduced into a usable form that can be analyzed and understood. The raw signals that are gathered by the DAQ are internally converted to physical properties by the LabVIEW script. However, data in this form is not in an optimal state and need to be reduced to usable numbers. Once these data are in the proper form, they still need to be correlated and adjusted to better suit the problem at hand. Several MatLAB scripts were written that can read the data as it is reported by LabVIEW, perform all of the necessary mathematics, and output values that are both meaningful and useful. The data is output from the DAQ in spreadsheet form and the data for each run takes up one data file. However, the most important data with respect to flooding are the steady flow rates and the differential pressure readings that occur at the flooding velocities. That is, the last steady and constant segment of data that is taken before flooding contains all of the information needed to perform the analysis. The LabVIEW program contains a trigger button on the front panel that allows for the experimenter to indicate when the system is being adjusted, i.e. when the air flow rate is being increased. This trigger fills the last column of the data spread sheet with either a one or a zero; a one for a transient system, a zero for a steady state system. The first task of the MatLAB script is to recognize when in the data file the system is being adjusted and when it is steady. By reading this column, the script parses the data into separate matrices and writes them to appropriate Excel spreadsheets. When the last reading in the spreadsheet is reached, the script then determines the point of flooding from the last stretch of steady data. This is accomplished by reading the first 30 points in the spreadsheet and averages them. This average is then compared point by point in the spreadsheet until the characteristic pressure drop is encountered. The script marks this location and performs its averaging and error analysis on the entire final steady data set up to this point. 


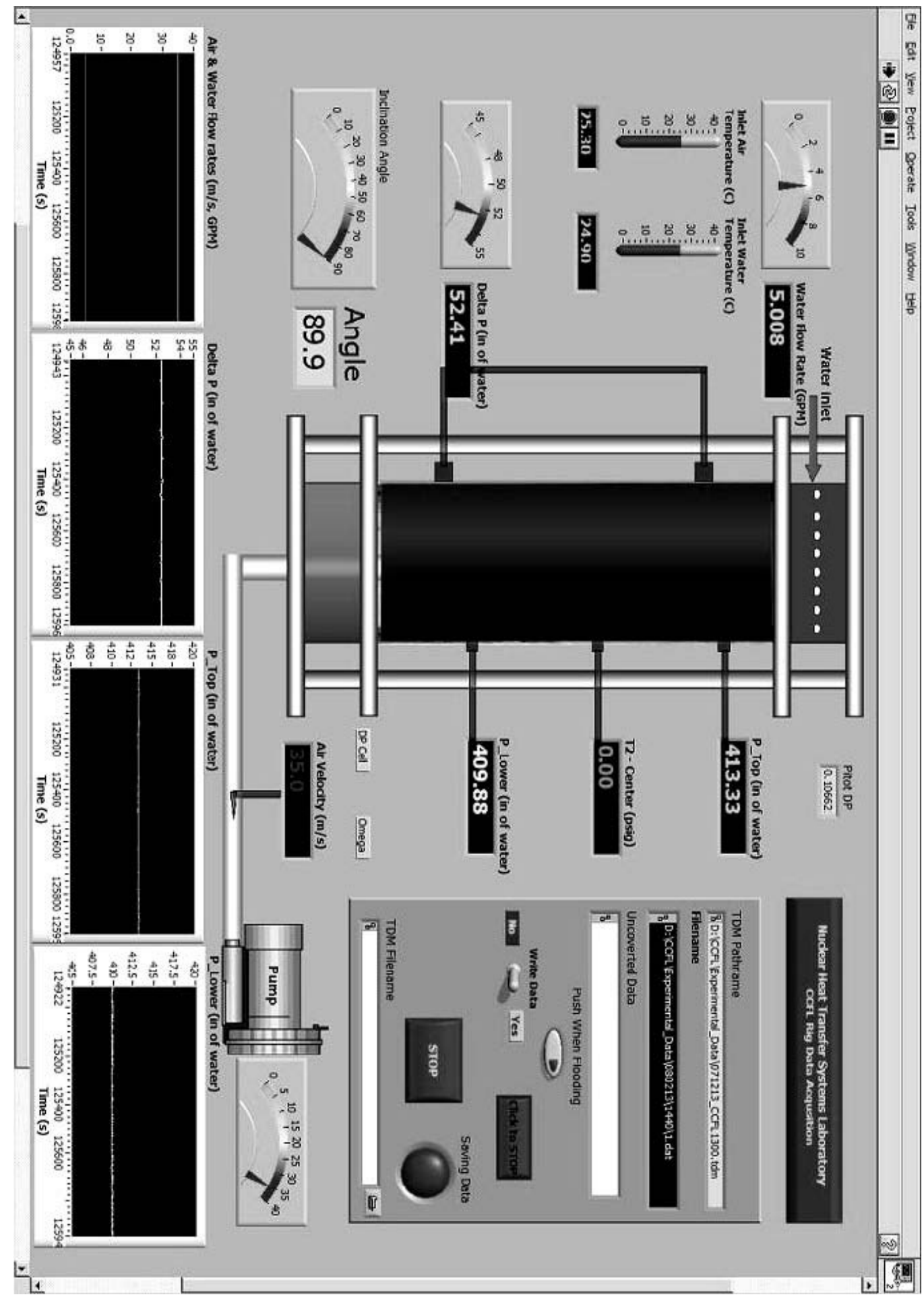

Figure 3.12 Front panel of the LabVIEW program used to collect data 


\subsubsection{Standard Operating Procedures}

The standard operating procedures are presented here both as a guide to operating the experiment and as an in-depth explanation of how the experiment is designed. As with all experiments, care should be taken to fully understand the procedure and to follow all steps to their fullest and in the order presented. The SOP are broken up into three parts: Start Up, Experimental Run, and Shut Down. All component names are referenced to in the following figures.

\subsubsection{Startup}

The startup procedures should be conducted before all test runs unless it is deemed unnecessary by an initial check of the pressure reading instruments. The start up procedures are primarily used for two reasons. First, they allows for the experiment to be run safely by including a double check of all valve initial positions. These starting positions ensure that if any of the first experimental run steps are omitted no serious harm will come to the experimenters or to the equipment. Secondly, the startup procedures initialize the pressure instruments, i.e. the differential pressure transducer and the two absolute pressure transmitters. Since all three of these probes require wet connections to the test section, it is important that all pressure lines are purged of air. Also, since some of the pressure lines occasionally void during operation or rest, it is necessary to bring these readings to at least the same relative reading before each run. Doing so increases the accuracy of data taken.

\subsubsection{Initial Steps}

To ensure the safe use of this equipment (both to the experimenter and the facility) there are certain primary steps which must first be taken. A schematic of the test section valve positions is given in Figure 3.13. It is necessary to close all valves related to the test facility. These valves respectively isolate the lower plenum from the drain; isolate the test facility from the main water supply; and ensure full air velocity from the blower. The reasons for each valve's position upon starting the procedure are given below.

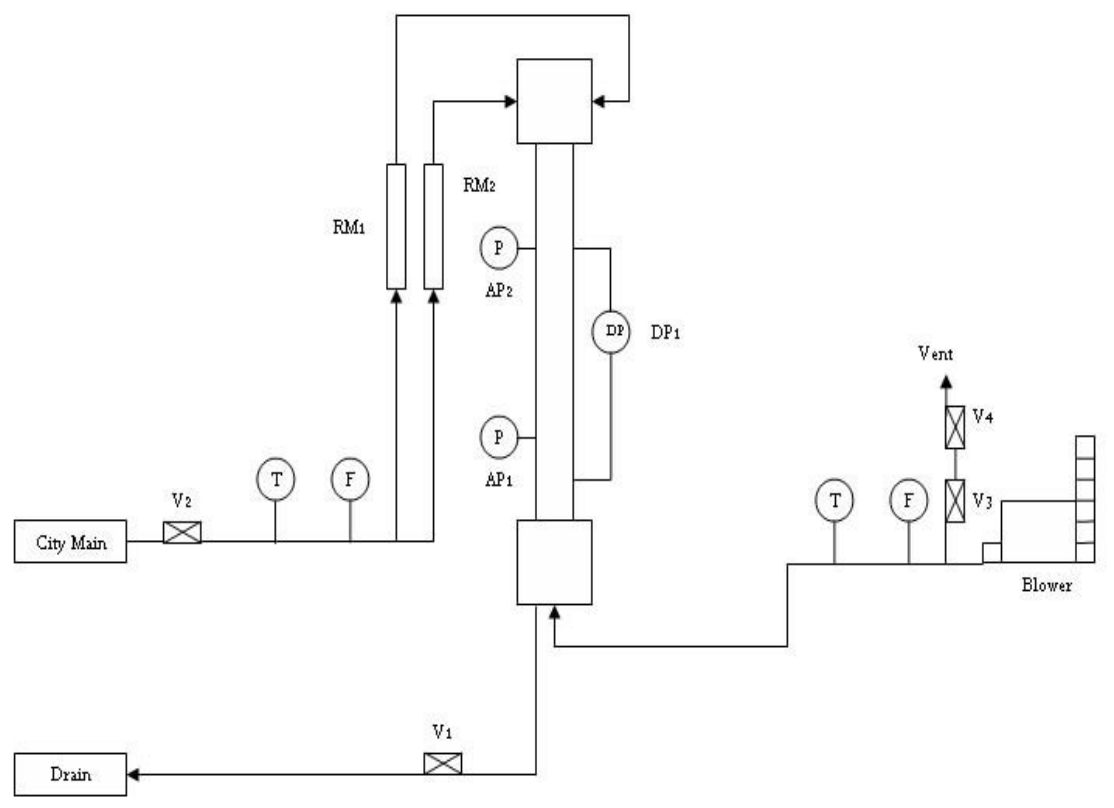

Figure 3.13 Schematic of the flooding facility

The valve on the liquid collection tank (V1) is set to the closed position during start up to isolate the facility from the drain. While this is not of extreme importance to the safety of the 
experiment, it does allow for a more thorough state of rest for the experiment. That is, when a pre-run walkaround is performed (see below) the closed drain line puts the system in a totally isolated state, in addition to the valve positions listed below. The valve connecting the water main to the experiment (V2) in a closed state isolates the facility from the main water supply. Closing this valve during the start up procedure ensures that if the rotometers are left open, no water will enter the system accidentally. This is fairly important with respect to purging the pressure instrument lines as unwanted water flow in the test section could alter the initial measurements gathered thereby. The bypass valves located on the blower (V3 and V4) are redundant control mechanisms situated in series. Both act as a bypass control mechanism for the air supply subsystem. When open, these valves bypass a majority of the air flow to the atmosphere. When either one of them is closed, all air supplied by the blower is directed into the test section. See the Experimental Run section for more details on the function of these valves.

\subsubsection{Purging the Pressure Lines}

There are two subsystems for the collection of pressure data from the test section. The first consists of two absolute pressure transducers, isolated from each other and located at two separate axial locations on the test section. The first pressure port, used for the lower absolute pressure transducer, is located 9 inches above the bottom of the test section. The second pressure port, for the upper absolute pressure transducer, is located at the same radial location but is placed 59 inches from the bottom of the test section. While both transducers are connected via the purging subsystem, they are isolated from each other after the purge has been completed. The differential pressure transducer and its associated ports are located on the radially opposite side of the test section. The ports for this instrument are located at 6 inches from the bottom of the test section and again 59 inches from the bottom of the test section. Again, while the appropriate ports are connected by a purging subsystem, each is isolated from the other during operation and data taking. Schematics of each subsystem, absolute pressure transmitter side and differential pressure transducer side, are shown in figures 5.2 and 5.3 respectively. It should also be noted that while the absolute pressure transducer subsystem procedure is given first here, the differential pressure transducer system may be purged first.

\subsubsection{Purging the Absolute Pressure Transducers}

Refer to figure 3.15 regarding the names of the appropriate valves discussed below. The process is started by opening all valves in this subsystem. This will allow for the pressurized water to enter all lines of the subsystem and initially clear all air from the tubes. Once a su $\square$ cient amount of water is seen to be leaving the ports into the test section the valve nearest the lower absolute pressure transducer, PV2, is closed to isolate it from the purging system. As water continues to leave the pressure port for the upper absolute pressure transducer with increasing velocity, the isolation valve nearest it, PV4, is cycled several times to ensure all air has been removed and that the tubes are completely filled with water. Once it has been su $\square$ ciently determined that the upper absolute pressure transducer lines are free of air, the isolation valve is closed. The subsystem has now been purged. In order to judge the success of the purging, the data acquisition system is started to see what pressure each pressure transducer is measuring.

Since these modules are absolute pressure transducers, each will have a background reading of atmospheric pressure. Also, the preferred measurement for the transducers is in units of inches of water. If they were to be left open to the atmosphere, the base reading would be 406.7 inches of water. However, due to the nature of the test section cage and the tubes connecting the pressure transducers to the test section, an associated hydrostatic pressure is induced in the transducers. For the lower absolute pressure transducer, the transducer itself lies approximately 3 inches below the pressure tap. Thus, a reading of about 409 inches of water would indicate that the lines have been adequately purged. Similarly, the upper absolute pressure transducer lies approximately 9 
inches below the upper pressure port resulting in an appropriate initial reading of 415 inches of water. Once the readings have been confirmed as those given above, the absolute pressure transducer system can be considered purged and functional.

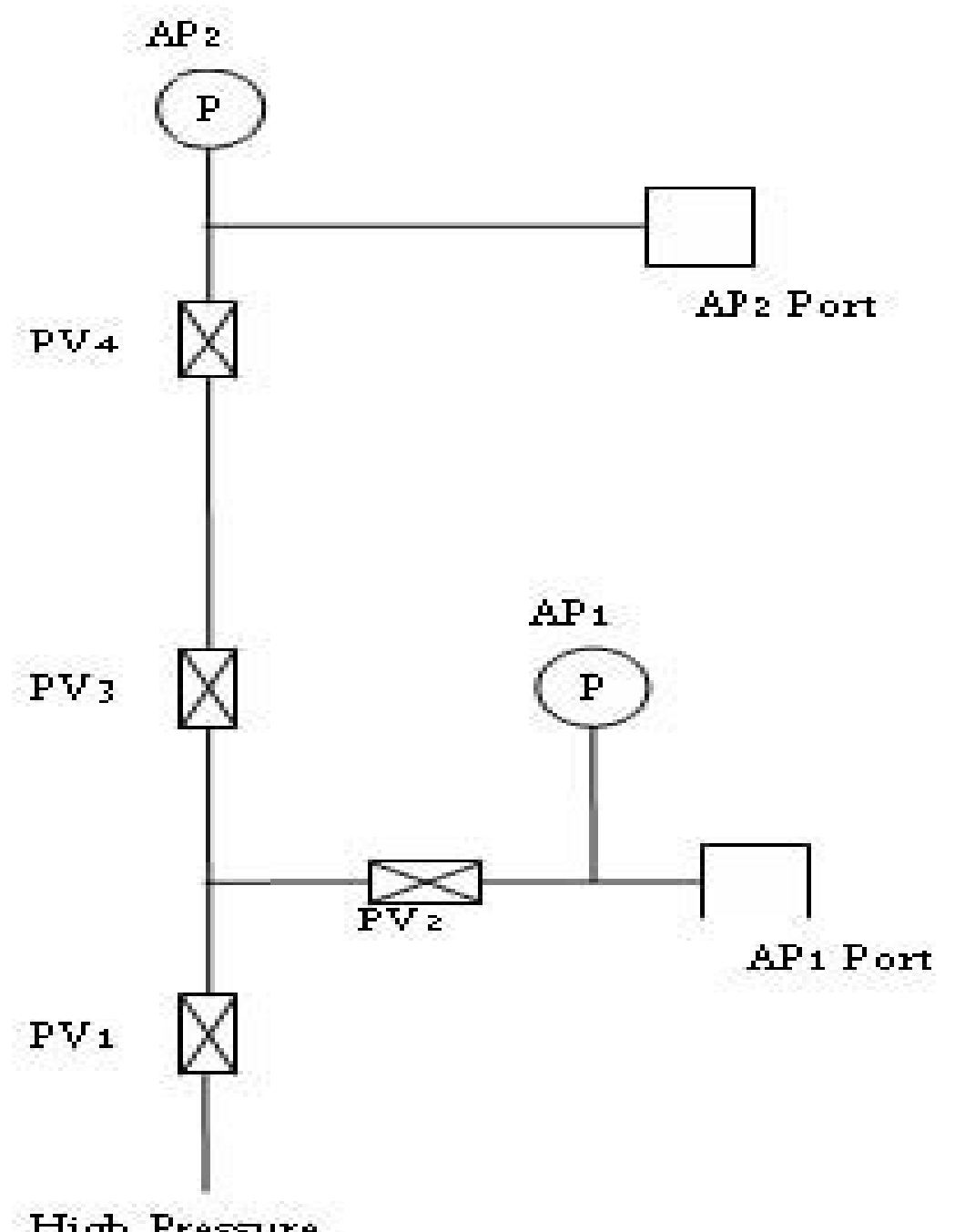

Figure 3.14 Valves and lines mentioned for the purging of absolute pressure transducers

\subsubsection{Purging the Differential Pressure Transducer}

Refer to figure 3.16 regarding the names of the appropriate valves discussed below. This process is similar but notably different from the one described above for the absolute pressure transducer subsystem. The first step in purging the differential pressure transducer system is to make sure that the feed from the pressurized water source is properly connected. Once connected, all valves within the differential pressure transducer subsystem are opened. Water should be seen to exit both the upper, high pressure port and the lower, low pressure port. Once a significant amount of water has passed through the two ports, the valve closest to the upper pressure port is closed to isolate it from the rest of the system. The bypass valve, DPV4, should then be cycled several times to eliminate any air bubbles trapped in the tubing network leading to the lower pressure 
port. Once it has been established that the DPL lines are free of air, the bypass valve is closed. The upper port isolation wave is opened and again water is allowed to flow through the upper port. Cycle the three way valve to ensure all air bubbles are purged.

Again, it is necessary to check whether or not the purge of the lines was successful. Similarly to the absolute pressure transducer side, a reference value needs to be reached in order to ensure that the data taken is sound and repeatable. This is again achieved by noting the pressure reading from the DPT on the DAQ screen. Since this transducer is of a differential type, the static pressure difference between the ports is of importance. The ports are located 52 inches apart from one another so it follows that the static reading without any flow should read approximately 52 inches of water. This is in relation to the fact that if both tubes from the DPT to the respective ports are full of water, the resulting pressure differential should be equal to the head of that water. If, however, the DPT outputs something other than 52 inches of water, the lines to the differential pressure transducer may also need to be purged. This is accomplished by the use of bleed valve located on the back of the differential pressure transducer system. The bleed valve is a three way valve connected to tubes leading from the bleed ports on the differential pressure transducer. In the nominal, aka closed, position, the valve knob should point away from both tubes. To bleed a port, simply turn the valve knob so that it point to the port that needs to be purged. To purge the DPT itself, merely point the knob to one port and then the other, making sure not to let too much water drain from the system. Once the DPT has been purged, repeat the previous procedure to repurge the differential pressure transducer port system.

\subsubsection{Final Start Up Procedures}

After the pressure instrumentation lines have been successfully purged, the final steps can be taken before running an experiment. These steps are needed to bring the facility to the proper running state with respect to the position of valves and the overall conditions. It should also be noted that the following steps are given in no particular order. The importance of these operations is not their sequence but their completion. At this point, the drain valve (V1) from figure 3.14 must be opened to allow all fluid entering the system to exit it. If this step is omitted, water could back up in the lower plenum and enter the air inlet lines. This might result in damage to both the pitot tube air flow instrument and/or the blower itself. Opening the water collection tank valve will also drain any water in the catch basin accumulated from the purge, allowing for a more uniform starting state. Next, the blower bypass valves will be open to set the blower to a starting state. If these valves are set to closed, full air flow will be directed to the test section when the blower is turned on. This results in an incomplete test since the approach to flooding will not be recorded. Also, any test has the tendency to alter the water level in the pressure instrument lines resulting in the need to re-purge them. When all of the preceding steps have been successfully completed in their entirety, the actual test may be run. The zero readings for the pressure transducers should be 52.0inH $2 \mathrm{O}$ for the differential pressure transducer and 515.0inH2O and 509.0inH2O for the upper and lower absolute pressure transducers respectively. It should also be noted that all steps in this section should be completed before running the experiment so that nothing untoward befall the experimenters, the equipment, or the final data desired. 


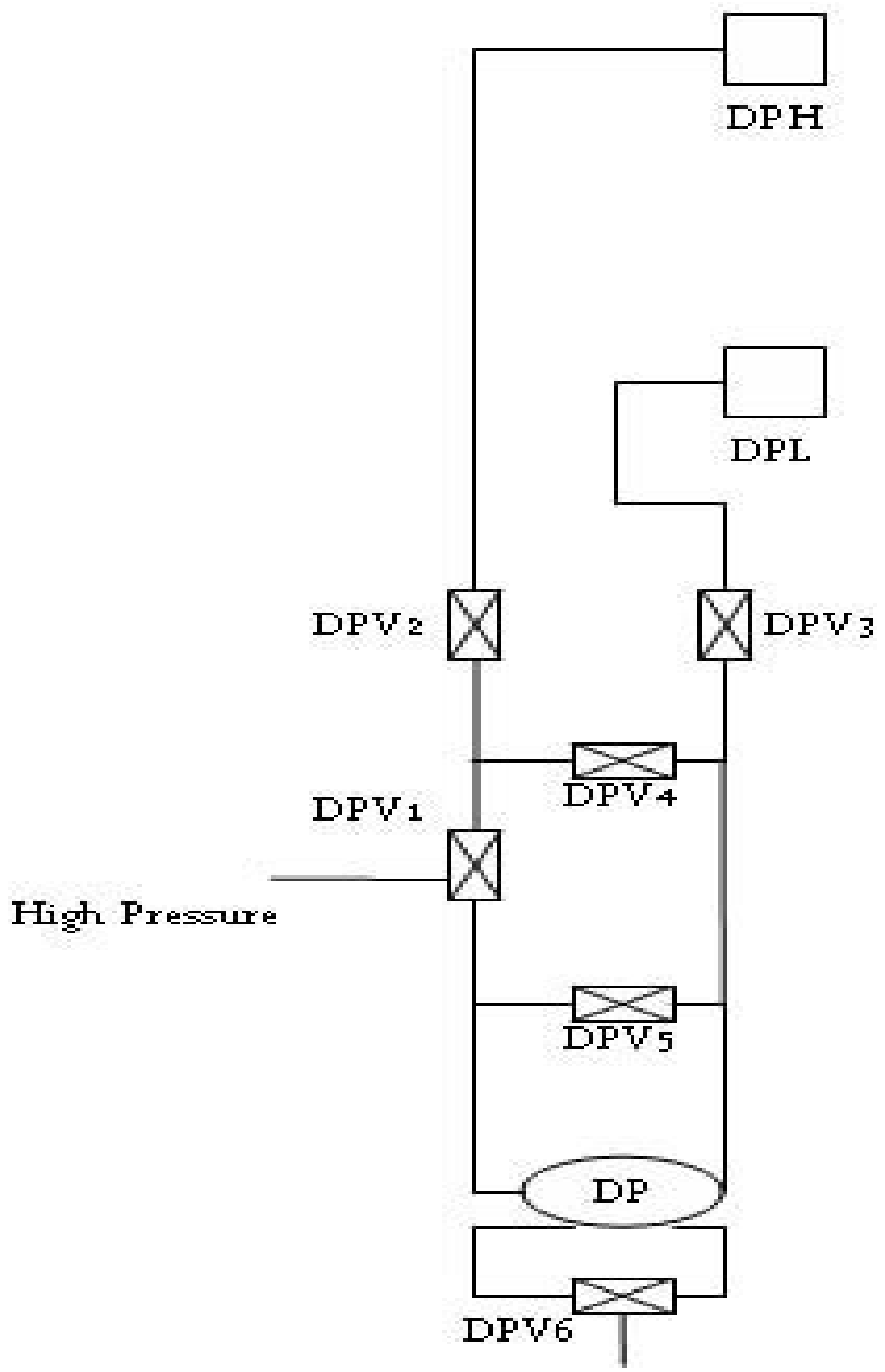

Figure 3.15 Valves and lines mentioned for the purging of differential pressure transducers

\subsubsection{Test Procedures}

The following section outlines the proper and standard methods for conducting an experimental run on the flooding facility. The steps given here should be run in the order given and in their entirety. Any deviation could result in damage to the system, the data acquisition system, or injury to the experimenters. A test matrix for each individual test provides the primary operator with a physical means of recording data and taking notes. Since each test run consists of several approaches to flooding, it is handy to have a rubrik for recording the data for each approach. The necessary data for each test are the date, time, and liquid flow rate.

The first step in the run is to open the main water valve. Since the rotometers should be closed at this point, incoming water should pressurize the lines up to the rotometers. The rotometers should 
slowly be opened and set to the desired flow rate. Both rotometers should read the same value to ensure that equal flow rates at the upper plenum be achieved. To do so, they will have to be adjusted until this state is achieved. It has been witnessed that it takes several seconds for the flow to fully develop in the system. That is, once the rotometers are opened, the flow rate measurement as returned by the magnetic flow meter slowly increases until it reaches a final state. Because of this phenomenon it is necessary to let the system stabilize before the next steps are taken. Once the system has come to steady state, a base line measurement is taken without any air flow in the test section. This is done by first naming the file in the DAQ screen (preferably as *0.dat), clicking "Record Data" button on the DAQ screen and letting the data record for approximately 10 seconds before clicking "Stop Recording". This measurement will act as a control to compare the flow rates with air later in the test.

The blower is now switched on with the bypass valves open to allow for minimum air flow in the system. Even though the bypass is open, there is still a measurable amount of air flow through the test section. The write data file is renamed and once the system comes to steady state, data is again recorded for approximately 10 seconds. It is now required to incrementally increase the air flow rate to properly record the entire approach to flooding. Just before the system is perturbed, the trigger button on the DAQ screen is switched to "on" signifying that the system is in a transient state. To increase the air flow rate incrementally, the bypass valve must be closed slowly and with fine control. To facilitate this, a 10-turn gate valve is used on the bypass with the initial position set to full open. From the fully open position and at steady state, this gate valve is moved a maximum of one half $(1 / 2)$ of a turn closed and the system is allowed to equilibrate making sure to record the air flow rate on the test worksheet, remembering to click the trigger button to set the trigger to off. Data is taken, making sure to change the file name, for approximately 10 seconds. This process is then repeated until sustained flooding is observed, making sure to record the air flow rate at which flooding occurs on the work sheet. After the final data are taken, the air bypass line is opened and the water allowed to flow without air. A final data point is taken. The blower is then shut off at this point.

If further tests are scheduled, the pressure instrument starting conditions are checked per the start up section. If the measurements are within the prescribed limits, the procedure can immediately be repeated for the next liquid flow rate. If, however, the measurements are outside the bounds set, the lines must be purged again before any tests are run. Also, if there are no more liquid flow rate tests scheduled for the current inclination angle, the procedure must start again at the beginning of the start up section, but the shut down procedure need not be performed.

\subsubsection{Shut Down}

This section details the steps taken to bring the facility to a "Final Shut Down State" from which the start procedure may be run for the next set of experiments. Since the only secondary equipment of safety concern is the blower, little work needs to be done to safely return the lab to a non-working state. Since the water main has been isolated during the final steps of the actual procedure and the blower has been switched to off, the system itself need only be safely isolated from these ports. The rotometers are closed completely to ensure that if the main is switched on, no water will enter the system. At this point it is desired to let the system "dry", that is let all of the accumulated moisture in the system settle to its lowest point. While this step is not at present necessary, for future work regarding visualization it will be necessary to dry the test section so that clear pictures can be obtained through the test section.

Now that the system has been fully closed, the levels in the pressure instruments should be checked via the DAQ system. Checking the levels gives a preliminary estimation as to how these ports react to the tests being run. Also, it will give the experimenter an idea as to how involved 
the next purging will be, saving time in the long run. Once a check of the levels has been completed, a final walk around of the facility should be taken. All plumbing junctions should be checked for leaks and care should be taken to distinguish between water accumulated from leaks and water accumulated from the normal operation of the facility. All electronic connections and terminal blocks should be checked for both water and that the necessary connections are still good. The test section and all associated acrylic attachments (e.g. plenums and tubing) should be checked for cracks or other instances of structural stability. Finally, the cage and frame should be checked for any structural problems or loose fittings. Once a complete walk around of the facility has been completed, the experiment may be considered "Shut Down".

\subsubsection{Results and Discussion}

This section presents the data gathered using the flooding facilities described above. It begins with a brief description of flooding as it is defined based on these experiments. Then, a description of the characterization tests performed on the facility is given. These test help to confirm the data taken. Next, a section covers the raw data taken with the experimental facility. A description of the error analysis methods used to judge the data is provided. The steps taken to correlate the data are presented. These involve the initial observations and trials used to create the final analysis. This error is then added to the data points in the form of error bars and presented. A final section provides the visual data taken for the experiments.

Flooding should also be fully defined as it relates to the gathered data. For these experiments, flooding is defined as the occurence of flow reversal in a countercurrent flow system which is accompanied by a characteristic pressure drop across the test section.

\subsubsection{Characterization Tests}

In order to have confidence in the data that the flooding facility produces, it is necessary to characterize several of the attributes of the system. This includes testing for:

- Test Section Orientation

- Working Fluid Flow Rates

- Annular Liquid Film

- Air flow through inlet/air flow approach

- Air supply history

- Instrument shakedown tests

- Absolute Pressure transducers

For the current set of data and for the eventual derivation of a correlation, the test section must be in as close to a vertical position as possible. In order to check this orientation, three methods were used. The first required the use of a standard carpenter's level, also known as a torpedo. The torpedo was placed on the test section at two radial locations, one in the plane of inclined motion to check that the winch and counter torque springs are equal. The second radial location is 90 degrees from this position to ensure that the rotational bearings are properly aligned. This will give a rough estimate of the orientation and allow for the test section to be close to vertical to a first approximation. The next test allowed for a more accurate measure by using a plumb bob. By hanging the bob from the upper plenum and accurately measuring the distance of the test section from the line, a much more accurate confirmation that the test section is vertical can be achieved. This test was also conducted at two radial locations similar to the previous tests. The final test for vertical orientation involved the use of a laser level. This test was used only as a redundancy to the plumb test as there is no real way to improve upon it. Again, testing at two radial locations, the laser level was pointed at the edge of the test section. When the edge was found, it was 
checked against the level line.

Another test used to characterize the test section to double check the flow rates of the working fluids. The easiest way to check the liquid flow rate was to double check the measurement with the rotometer readings. For a range of liquid flow rates, the magnetic flow meter readings were compared to the rotometer readings. The more inaccurate instrument would be the rotometer with the $\pm 0.2 \mathrm{GP} \mathrm{M}$ increments. The test is used to make sure that there is no discrepancy between the flow meters. The pressure gradient across the test section will change as the liquid flow rate changes. As the liquid flow rate increases, the pressure gradient will decrease due to the increased amount liquid in the test section. That is, as the the liquid flow increases, the film thickness of the liquid increases adding to the body forces on the water.

The air test double check was accomplished by testing to different kinds of pressure measurement devices. The first test used two independent absolute pressure transducers, one for the center static pressure and a second for the stagnation pressure, to measure the pressure difference. The difference between the readings was taken as the pressure differential. This differential, however, is inherently more erroneous than using a single differential pressure transducer. The two absolute pressure transducers return an error of approximately $\pm 0.7 \mathrm{~m} / \mathrm{s}$, while the differential pressure transducer returns an error of $\pm 0.16 \mathrm{~m} / \mathrm{s}$ for the maximum centerline velocity. As long as the two readings were comparable, the pitot tube can be considered to be an accurate measuring device.

Some observations about the facility while it is running should also be added. An important check on the state of annular flow that can be observed in the lower plenum while the water is running in the test section. The bottom of the test section is clearly visible through the lower plenum as is the water running from the test section into the lower plenum. At all pre-flooding liquid flow rates a clear annular sheet of fluid is seen running into the lower plenum. This indicates that the flow within the test section is annular in nature and assures the experimenter that an annular regime is in fact being observed. Furthermore, one can look down the air outlet pipe on top of the experiment for another form of visual inspection. Since the air outlet is a 2-1/2 inch tube, it is easy to see what is happening in the test section. Shown in figure 3.17 is a photograph of the inside of the test section as viewed in this manner. As can be seen in the picture, the flow regime is obviously annular and there are very little disturbances on the film. Another annular flow characteristic can be seen from visually observing the test facility. At the pressure ports located on the test section, there appears to be waking of the liquid film. A snapshot of this phenomenon is shown in figure 3.18 . 


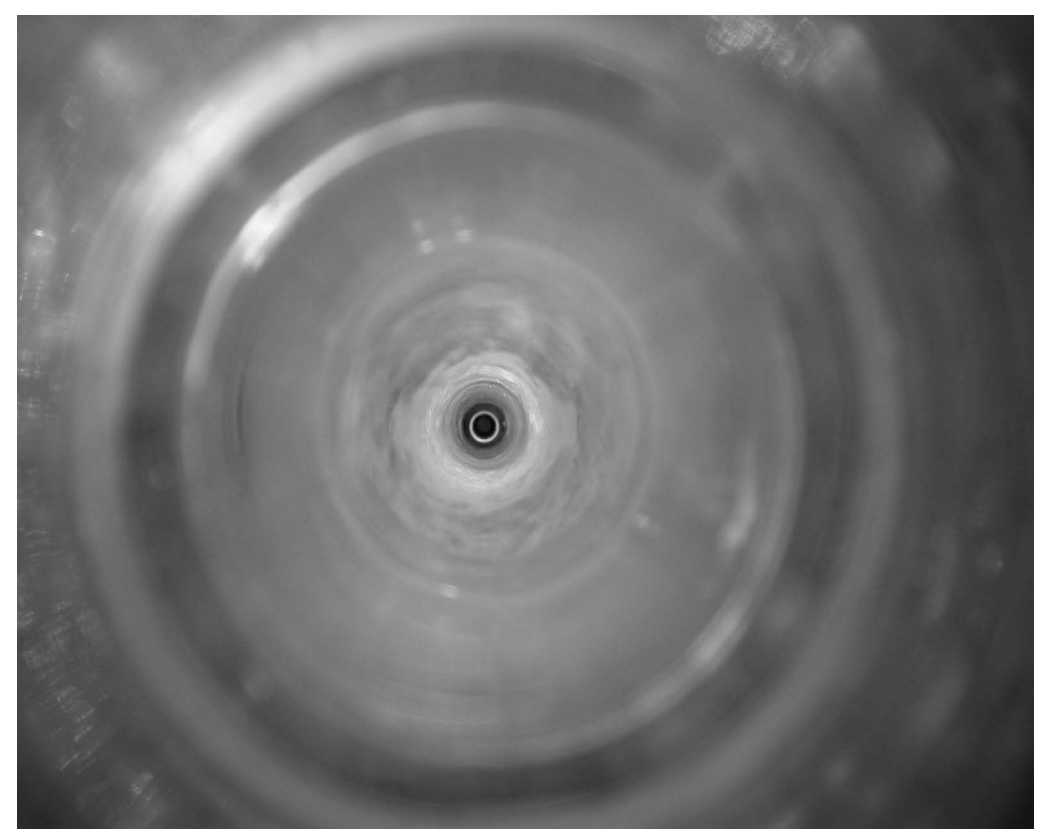

Figure 3.16 Test section flow without air injection, showing the annular nature of the liquid film.

In this figure, the wake is seen as the region between the two lines sprouting from the pressure port and extending down the test section while simultaneously spreading out. This wake is caused by the pressure port penetration into the test section. While no structures actually pass through to the inside of the test section, the hole milled into the test section itself was quite large, 1/4 inch, and does disturb the flow. This represents a design flaw. However, once there is air flow in the system, these wake lines visually disappear and it is believed that an effect they may have on destabilizing the flow is miniscule due to the fact that the flow is fully turbulent for all flow rates tested as determined by the liquid film Reynolds number defined by equation (3.14).

Early designs were plagued by an air supply problem. These included an air inlet section design which proved to cause too great of a pressure drop. This problem was compounded by the pressure drops of the approach lines to the test section. The original hard plumbing was replaced with 1-1/2 in. inner diameter flexible hosing which reduced the length of the approach and the friction seen by the incoming air. The friction being the standard tube wall friction for fluid flows. Originally it was assumed that a large air compressor could supply the needed air flow rates using only pressure as a driving force. However, it soon became apparent that the compressor on hand could not deliver the needed flow rates for a long experiment time. The cause of this was insufficient knowledge of the duration and air requirements. That is, a compressor and tank are meant only to supply pressure and not necessarily air, at least not in great quantity. While the compressor could supply a pressure of upwards of $125 \mathrm{psig}$, it could not do so for more than a brief moment. Thus, it became impossible to generate enough air flow for a long enough time period to induce flooding in the experiment. The solution to this problem came in the form of a regenerative blower. Blowers have historically been used in flooding experiments 


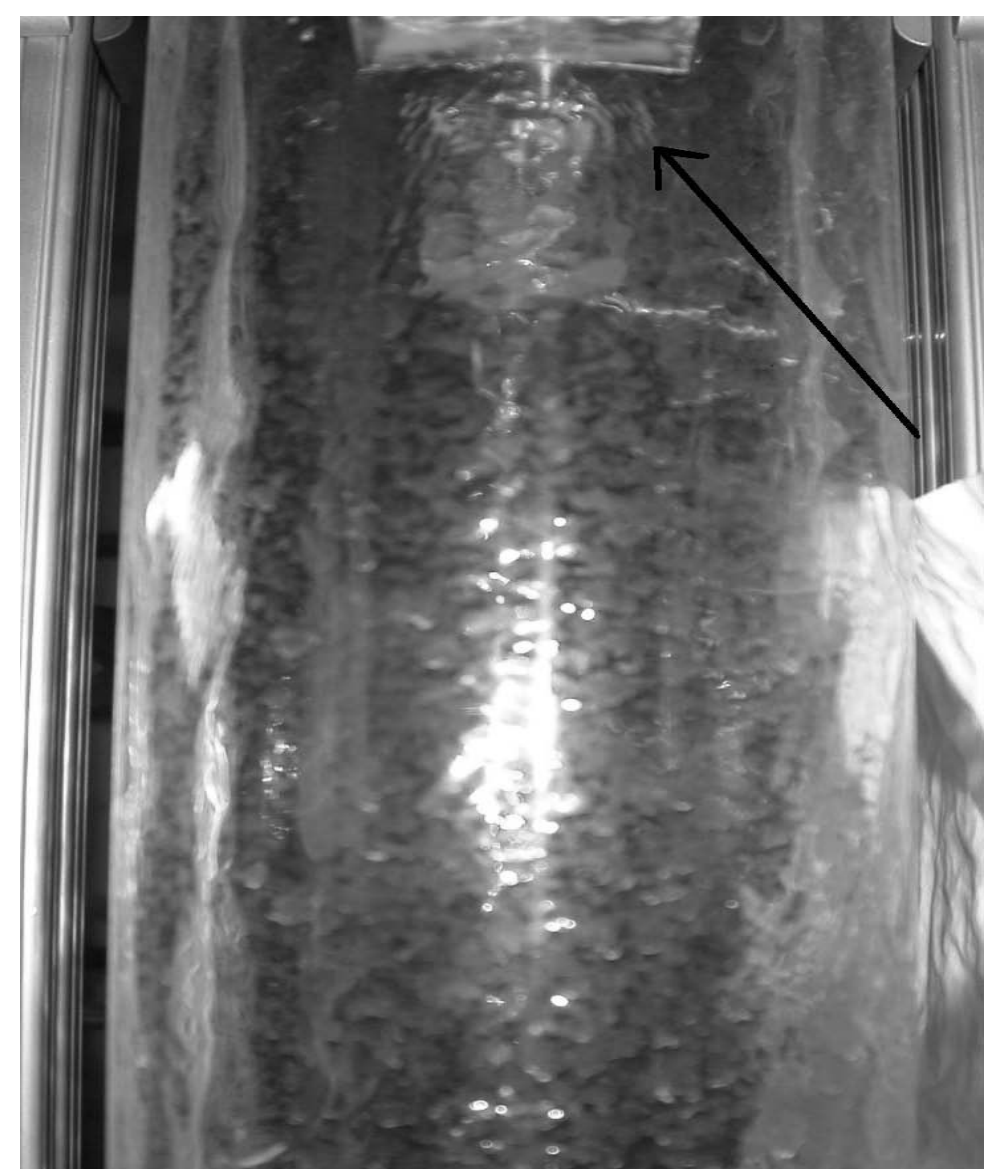

Figure 3.17 Appearance of wakes in the flow during a liquid only run of the facility

The instruments were also tested to ensure their accuracy. All pressure sensing equipment was calibrated, or their calibration checked, before being used on the facility. Also, the thermocouples were exposed to a wide range of temperatures to ensure that they were working correctly. Finally, as stated above, the liquid flow rate measurements were double checked against the control rotometer readings for a variety of flow rates.

It should also be noted that the length of the hose approaching the test section from the air blower was changed in order to expand the range of data taken. The longer hose was to be used if inclination angles were to be tested. However, this induced a large frictional pressure drop across the air inlet and thus reduced the available air velocity. The shorter hose reduced the frictional pressure drop and a higher maximum air velocity could be used. It was found that this had no effect on the trends or on the correlation results.

Finally, the absolute pressure transducers located on the test section are used to gather state data for the experiments. These two instruments provide valuable data that is later used by the data reduction scheme about the properties of the fluids being used. Using the thermocouples to measure the temperature, the physical properties of the fluids can be found.

\subsubsection{Raw Data and Observations}

For early tests using the same liquid flow rate, the increments by which air flow rate is first increased are large so that a general understanding of the flooding point can be obtained. Once flooding is observed to occur, the resulting air flowrate is recorded and the air flow rate 
immediately reduced to a point at which flooding no longer occurs. This would complete one "run". The subsequent runs are conducted by starting the air flow rate, without altering the water flow rate, at a point much lower than the expected air flow rate to induce flooding, and then very slowly increasing the air flow rate. The system is then again allowed to reach an equilibrium and steady state data are recorded. Thus, for each liquid flow rate, the final run will contain the minimum air flow rate at which flooding will occur. For runs which contain many incremental air velocity increases, the data for each steady point can be plotted as a function of air velocity and pressure gradient across the test section. An example of this is shown in figure 3.19.

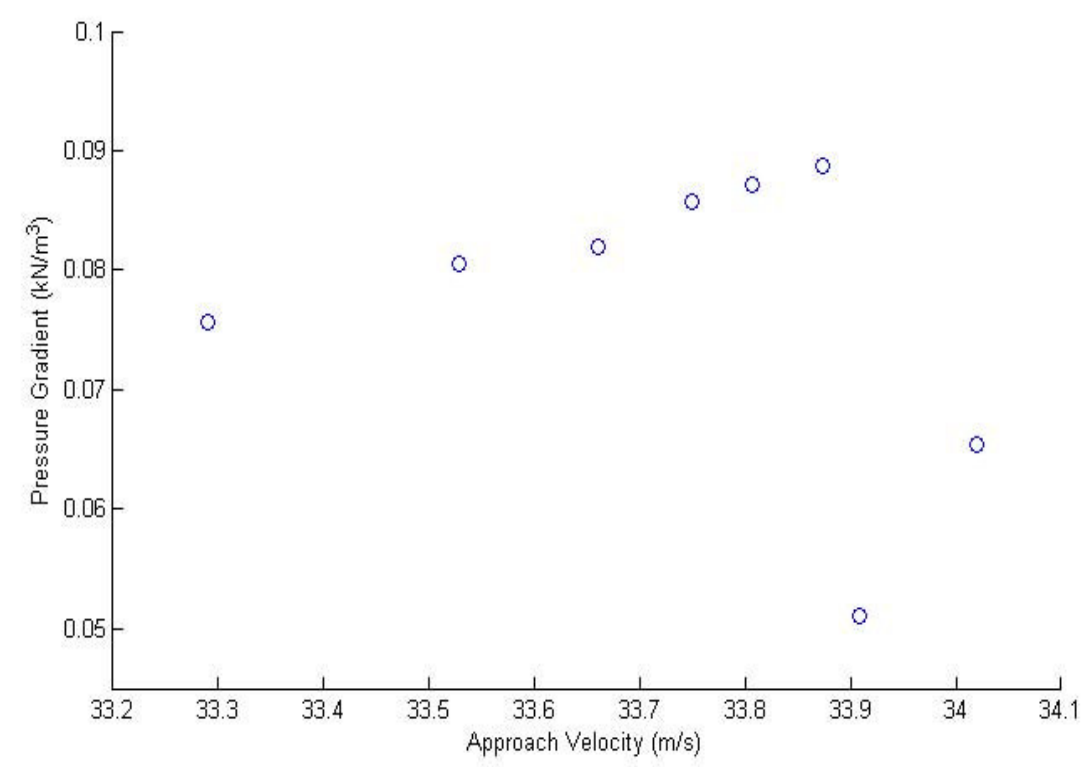

Figure 3.18 Approach to flooding point by incremental steam velocity increases

This figure illustrates the slow run technique. The ordinate is described as the pressure drop seen by the liquid due to the air flow in the test section over the distance between the pressure ports. By taking many data readings at steady air flow rates, a more accurate picture of the run up to flooding can be seen. The final portion of each run contains the flooding point. That is, the average velocity of the final steady interval will be the flooding velocity for a given liquid flow rate. In figure 3.20, a typical final steady interval segment of a run is shown.

When the data from each run are examined, several key factors must be considered. As can be seen from the figure, the air velocity is a constant until the flooding point. At this point, the velocity drops significantly and begins to exhibit an oscillatory nature indicative of flooding for this experimental facility. The important part of this data is the time before this point. That is, all data preceding the drop in air velocity should be averaged over the length of time preceding it. This average velocity, averaged over the time elapsing before the flooding point, is the flooding air velocity. 


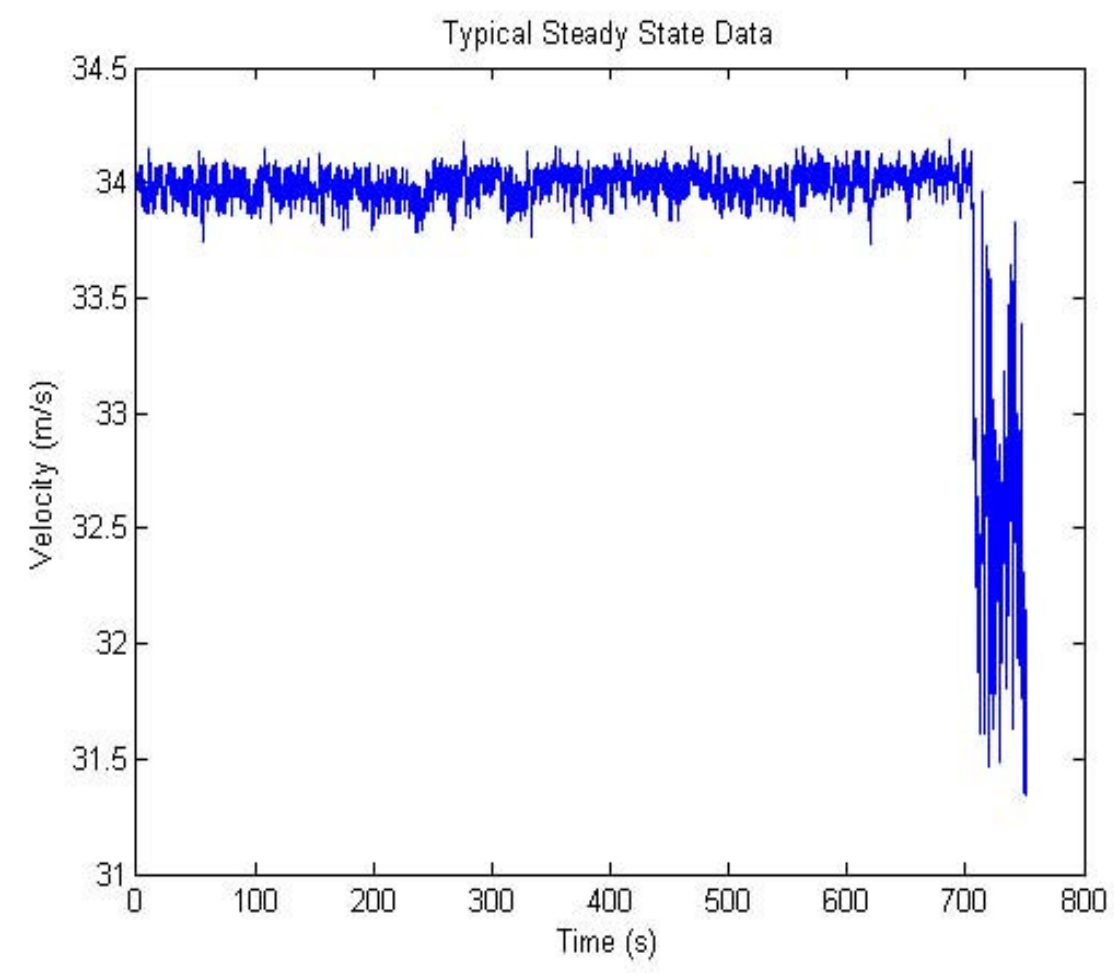

Figure 3.19 Typical centerline air velocity for a steady state data run that achieves flooding

The air flow rate at which flooding occurs is not always the point at which sustained flooding was seen to occur. An unstable flooding band was observed during several very slow approaches. It has been seen that when the flow rates of the system are very near to the flooding velocities, flooding may begin and progress for several flooding undulations, but then suddenly stop and return to a non-flooding state. This is shown in figure 3.21. While logic would dictate a priori that there are extremely high velocities which will always result in flooding and low air velocities which will always result in countercurrent flow, there appears to be a band of velocities in which flooding may or may not occur and remain stable. That is, from the experiments run, there are air velocities for any given liquid velocity which will result in periodic or unsustainable flooding in the system. 


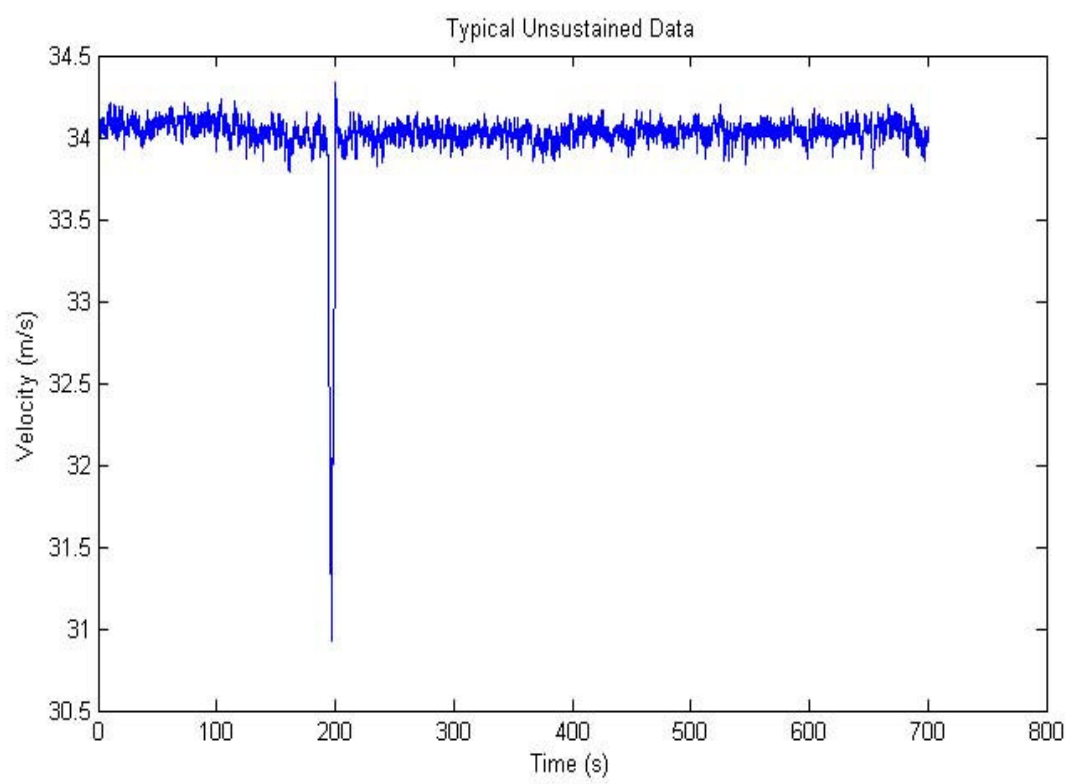

Figure 3.20. Sample data point in which flooding appears to occur but soon reverts back to a counter current flow

This leads to a discussion about the time given for each air velocity increment. It has been observed that even at air velocities over the flooding point, it may take as long as 2 or 3 minutes for flooding to occur. Because of this, it is necessary to allow the system to run at steady state for at least 5 minutes per air velocity value before any conclusions can be drawn. Conversely, flooding may not occur at one velocity for over 15 minutes, but when nudged to a higher air velocity, flooding is almost instantaneous. The result is that each air velocity should be run for 10 minutes to account for the time needed to generate flooding and that the proper air flow rate is found.

While the onset of flooding can easily be recognized by the chaotic and violent actions of the fluids in the test section, it would be preferable to have a concrete, easily identified, and recordable method for deciding when flooding is reached. It has been pointed out in the literature survey that there is an associated differential pressure drop in an experimental test section on the onset of flooding [10]. If this pressure drop is seen to occur in the test section, it would be an acceptable indicator that flooding has been reached.

Shown in Figure 3.21, such measurements have been made in the test section and as a result a reliable method for indicating flooding has been reached. From the figure it is obvious that the pressure across the test section is essentially constant up to the point of flooding. When this point is reached, that is, when the conditions in the test section are right, a large drop in the pressure difference across the test section is seen along with the associated drop in air velocity. From the data it appears that this drop in pressure across the test section happens almost instantaneously, indicating that there is no delay in the change of air velocity. 


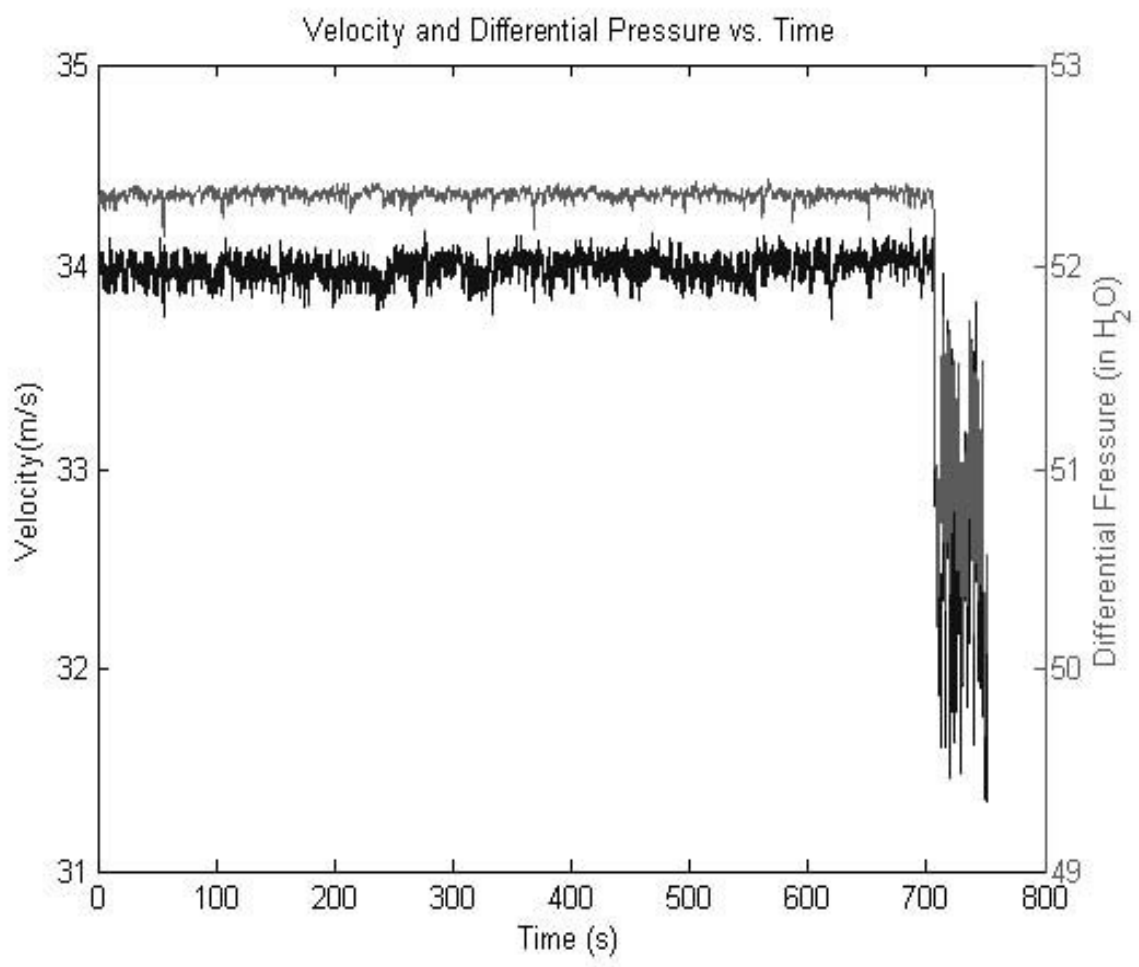

Figure 3.21 Pressure drop across the test section and the gas velocity at the onset of flooding

From visual observations at the point of flooding, several conclusions can be made. The first point is that flooding results in the formation of a visible wave towards the bottom of the test section. This wave then proceeds up the length of the test section carrying a large portion of the liquid in the test section with it. Additional waves may or may not form while the initial wave is travelling upwards. The flooding wave is seen to begin above the lowest pressure port. Since this wave is above the pressure port, any pressure that is necessary to push it upwards would be seen by it. The pressure reading is the low pressure side of the differential pressure transducer, accounting for the weight of the water head for the upper pressure port. Therefore, any increase in pressure at this location will result in a decrease of differential pressure, and thus return the observed drop in differential pressure.

\subsubsection{Data Selection for Correlation}

All of the acquired data are presented in the above section. However, there are necessary reasons for disregarding some of these data when considering the construction of a correlation for predicting the onset of flooding. As noted above, many tests exhibited intermittent flooding and a return to annular flow. For each liquid flow rate, it is necessary to find an approximate span of air flow rates that will induce flooding. This is analogous to using a rough estimate to later zero in on an exact solution. When conducting experiments, it is common practice to find the rough flooding point by using large incremental changes in air flow rate and recording data for shorter time intervals. This results in overshooting the actual flooding point, sometimes to a large degree. It is these points that need to be removed when formulating a correlation because they do not reflect the actual flooding. It is this fact that necessitates the need to run several tests at one liquid flow rate, the first hunting run and several slow approaches to zero in on the actual air flow rate.

Another source of erroneous data points is the "unstable band". This refers to the data points where flooding is not seen to occur sustainably. As mentioned above, at some air flow rates just 
below the actual CCFL, flooding will start and then stop. This has the opposite effect than the one described previously; these values underestimate the air flow rate necessary to induce flooding. Once these points have been identified and removed, the process of discovering the correlation of parameters can begin.

\subsubsection{Visual Images}

Pictures of the flooding phenomenon were obtained by means of the high speed camera. The basic results are shown in Figure 3.22. In this series of pictures, the onset of flooding is captured at a frame rate of $2000 \mathrm{~Hz}$.

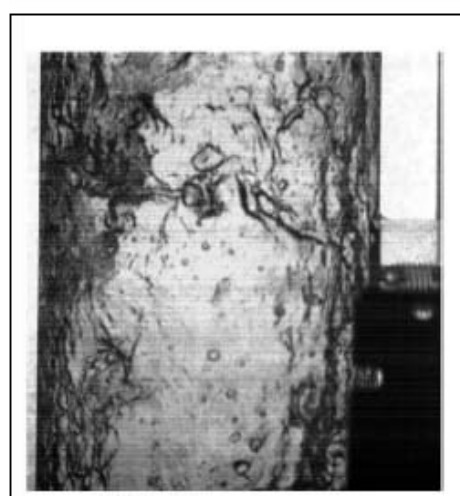

(a) Stable countercurrent flow

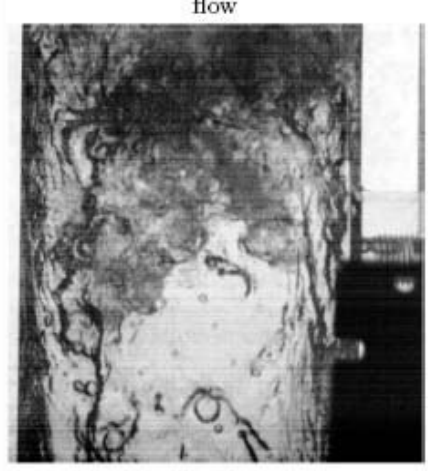

(c) Onset of flooding

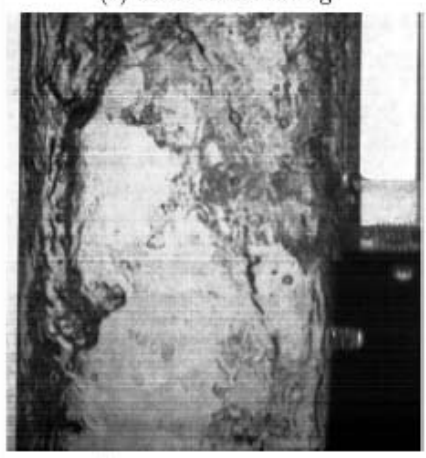

(e) Bidirectional liquid

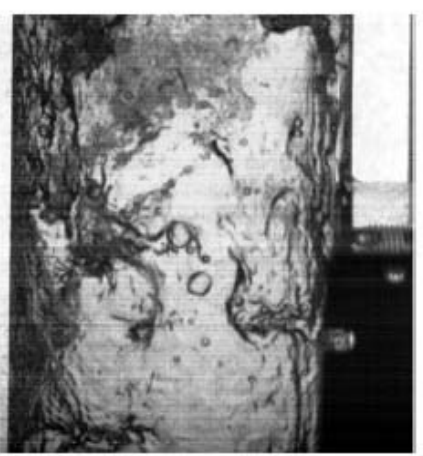

(b)Beginning of flow reversal

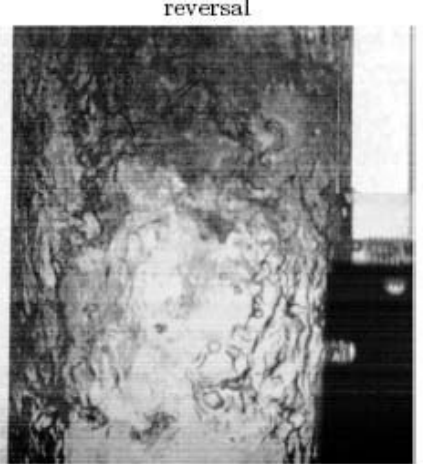

(d) Local Flooding

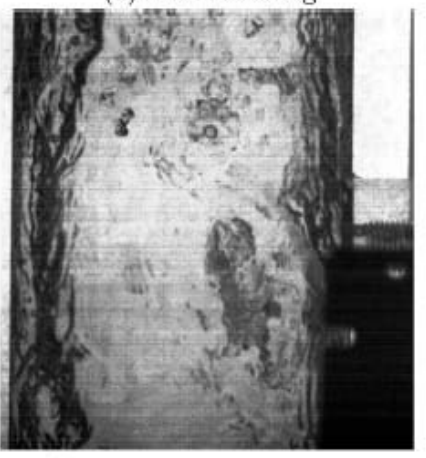

(f) Post CCFL environment

Figure 3.22 Series of pictures capturing the onset of flooding.

In these images the state of the fluids in the test section changes dramatically. In (a), the system is at steady countercurrent flow at the air velocity which will eventually induce flooding. In (b), the beginning of flow reversal is taking place. The chaotic nature of flooding is starting to become 
visible near the top of the picture. Flooding has begun in (c) as evident by the violent mixing of the phases shown as the dark cloud. In (d) the local layer of liquid has started to move upwards. In (e) the liquid film is moving in two directions. Finally, (f) the liquid flow near the wall is still in the downwards direction while at the interface the liquid is progressing up. It should be noted that another wave similar to the one shown in (c) will form near this location and the process will repeat.

\subsubsection{The Full Data Set}

The data points, in their entirety, are presented in graphical form below in figure 3.34 as a plot of the roots of $\mathrm{j}_{\mathrm{f}}$ versus $\mathrm{j}_{\mathrm{g}}$ in order to compare it with the published reports. The terms $\mathrm{j}_{\mathrm{f}}{ }^{*}$ and $\mathrm{j}_{\mathrm{g}}{ }^{*}$ are defined by [7] as:

$$
\begin{gathered}
j_{f}{ }^{*}=j_{f} \sqrt{\frac{\rho_{f}}{g D\left(\rho_{f}-\rho_{g}\right)}} \\
j_{g}{ }^{*}=j_{g} \sqrt{\frac{\rho_{g}}{g D\left(\rho_{f}-\rho_{g}\right)}}
\end{gathered}
$$

From this figure there is an obvious downward trend. The downward trend confirms that as the liquid flow rate increases, the necessary air flow rate for flooding decreases as is seen other experiments $[6,19]$. Also, the relative scale of the $\mathrm{j}^{*}$ values is comparable to other sources.

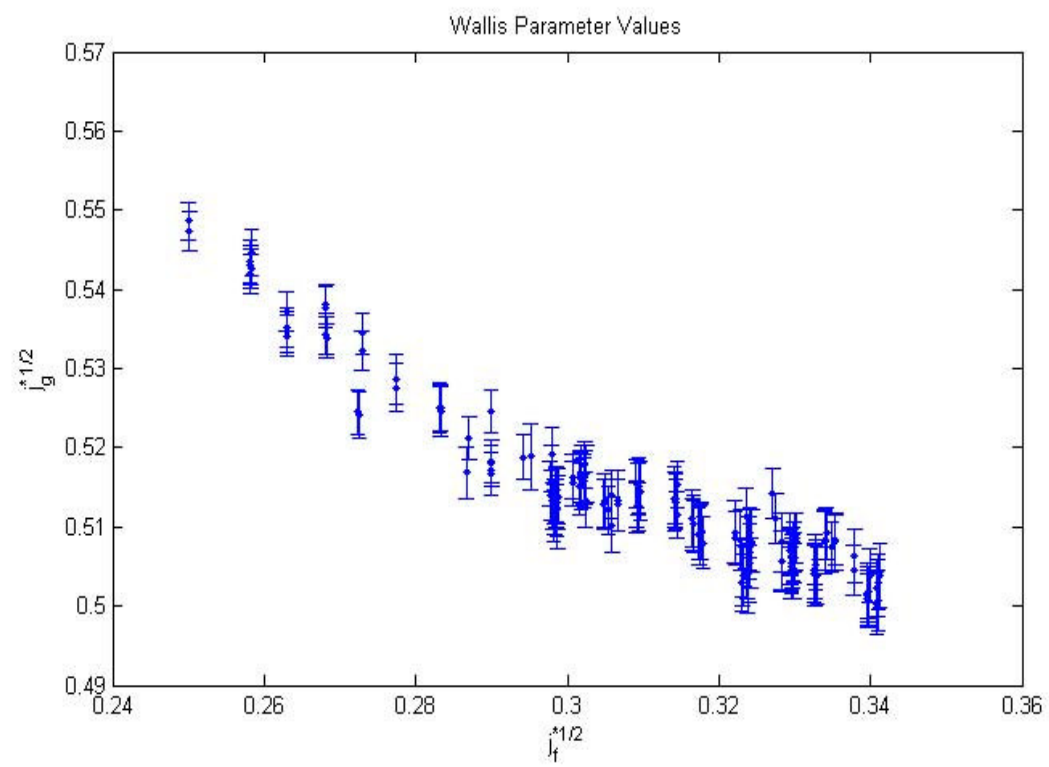

Figure 3.23 All of the collected data presented at flooding as a function of the Wallis parameters

\subsubsection{Conclusions}

The phenomenon of countercurrent flow limitation was investigated experimentally in order to arrive at a useful correlation for the onset of flooding in large-diameter vertical tubes.

Intended to clarify the basic mechanisms behind the phenomenon of flooding, this investigation has also provided valuable knowledge for follow-up steam-air experiments that will model the 
PWR surge line. Furthermore, it can be used for further work on the phenomenon of flooding and other two-phase fluid dynamics problems. The data collected can also be used for the determination of a mechanistic model of flooding.

The experiments conducted produced a large set of data consisting of fluid velocities and pressure measurements. The experimental facility was designed and constructed to investigate a large range of fluid velocities. These data showed similar trends with those reported by other investigators with respect to the relationship between the fluid velocities. Also, the characteristic pressure drop change across the test section was observed to take place during the onset of flooding. These trends are described throughout the published literature and lend credibility to the collected data. The correlations of Wallis and Kutateladze were compared to the collected data and found to be deficient. The data also exhibits a low amount of error. Such a data set can be used by the scientific community to gain a better understanding of the flooding phenomenon.

A correlation suitable for use in reactor safety codes was derived from the resulting data. The correlation is used by calculating the film thickness in the tube and thus the void fraction. Once the void fraction is determined, the fluid velocities can be measured and their relative velocity calculated. This relative velocity is used to calculate a modified Froude number which is compared with a constant to determine if flooding has been reached. This correlation was found to correctly predict the onset of flooding for large diameter tube for liquid flow rates as low as 3.9 GPM and as high as 7.2 GPM. The corresponding air flow rates for these liquid flow rates are given as superficial velocities ranging from $7.47 \mathrm{~m} / \mathrm{s}$ to $6.45 \mathrm{~m} / \mathrm{s}$ respectively.

While these experimental programs are providing valuable data for well-defined geometries, they do not completely represent the situation in the surge line of a PWR. Prediction of flooding in the pressurizer surge line is difficult due to the complex geometry of the surge line and the various possible configurations for water entrance into the surge line. Another difficulty in application of flooding models for reactor safety codes arises from the high temperature and pressure condition during severe accidents, where the fluid properties and two-phase interactions are different from those at experimental conditions. These factors will be considered in the model development and uncertainties will be noted. Rothe and Crowley [61] addressed pressure scaling issues and concluded that for saturated water behavior in small-scale facilities, the dimensionless Wallis $j^{*}$ parameters properly scale the effect of system pressure.

\section{Recommended Future Work}

While this investigation provided new and important information to the field of two-phase fluid dynamics, there are some suggestions as to what should be attempted next.

- A more thorough and detailed measurement of the film layer would provide validation to its use as a characteristic length scale for flooding determination. This would involve taking actual film thickness measurements and comparing them with the correlations used here.

- An investigation into the e $\square$ ect of inclination angles on the flooding phenomenon. Since the prototype surge line contains many di $\square$ erent inclination angles on its approach to the pressurizer, it is important to take these angles into account. The experimental facility designed here is capable of examining di $\square$ erent angles.

- To more closely model a real pressurizer, steam and water tests should be conducted in order to take into account the effect of mass transfer. This condensation effect is expected to greatly affect the flooding in closed geometries and should be examined. 
- A more stable and powerful source of air should be found in order to examine the post flooding environment inside the test section. This would provide valuable data as to the nature of the post-flooding regime.

- Looking at various test section diameters would improve the justification for the large diameter threshold. This would also add valuable observation of the diameter e $\square$ ect for large diameter tubes.

- A mechanistic model of the flooding phenomenon should be developed using this data as a basis. Such a model would be valuable to the field of two-phase fluid dynamics. 


\subsection{Steam-water Experiments}

\subsubsection{Significance of Steam-water Tests}

While the air-water tests provide a visualization of the flooding phenomenon, steam-water tests are needed to provide experimental conditions more similar to those in a PWR pressurizer surge line. More specifically, the effect of condensation is present in steam-water tests that was not present in air-water tests. In addition, due to the higher temperatures, the properties of the fluids are different than in air-water tests and affect the behavior of the water and steam. The empirical model resulting from steam-water experiments will provide a more satisfactory method to evaluate the onset of flooding in current safety analysis codes.

\subsubsection{Scaling Analysis}

\subsubsection{Geometry}

Tube diameter is a primary factor that must be properly scaled in the experiment. Tube diameters are commonly divided into two broad groups, large diameter and small diameter. Since a reference PWR pressurizer surge line diameter is 10 inches, the experimental facility must have a large-diameter test section.

The surge line geometry is particular to each reactor and may consist of several pipe sections at various inclinations. For the current project, focus is placed on the pipe section connected to the pressurizer. Descriptions of the diffuser at the bottom of the pressurizer tank, which determines the water flow configuration into the surge line, are generally not available.

Two types of diffuser configurations are described herein [73]. In one configuration, the cylindrical wall of the surge line is extended about 2 feet into the bottom of the pressurizer tank is capped on top with a solid circular plate. Flow passes through rectangular axial slots located around the periphery of the cylindrical pipe. In the second configuration, the surge line is terminated with a smooth penetration on the bottom of the tank and the diffuser is a hemispherical screen covering the surge line opening on the bottom of the tank. The screen is constructed of a perforated plate with circular holes. The current investigations make the simplifying assumption that the diffuser configuration will produce a liquid film around the inner periphery of the surge line, for annular flow.

\subsubsection{Initial and Boundary Conditions}

As predicted by the SCDAP/RELAP5 code, for a typical 4-loop Westinghouse PWR in natural circulation during a hypothetical station blackout [48], the flow regime in the junction where the surge line connects to the hot leg is bubbly flow, while the flow regime in the junction where the surge line connects to the pressurizer is either slug or annular flow. The gas upflow velocity is in the range of $1 \mathrm{~m} / \mathrm{s}$ to $7 \mathrm{~m} / \mathrm{s}$. Liquid downflow occurs at the lowest gas flow rate when the PORV is closed. The pressurizer pressure is about $160 \mathrm{bar}$, the liquid draining down in the surge line is at its saturation temperature, and the gas flowing up in the surge line is superheated, with an average of $25 \mathrm{~K}$ above its saturated temperature.

\subsubsection{Results of Scaling Analysis}

In designing the test facility and determining test conditions, the important parameters for flooding phenomena in Table 3.1 were identified.

Based on experimental data for several tube sizes, Vijayan [10] proposes that tube diameters exceeding $67 \mathrm{~mm}$ be considered large. An inner diameter of 3 inches $(76.2 \mathrm{~mm})$ was selected for the current experiments. A tube length of 72 inches was chosen to allow sufficient length for 
flooding and for possible variation in the flooding location between air-water and steam-water tests.

The fluid density ratio under PWR cannot be reproduced in the air-water tests. The steam-water tests will have a lower steam-to-water density ratio than in the actual system because the tests will be run at a lower pressure. Rothe and Crowley [61] addressed pressure scaling issues and concluded that for saturated water behavior in small-scale facilities, the dimensionless Wallis $j^{*}$ parameters properly scale the effect of system pressure. This argument will be addressed in future steam-water testing.

Liao [5] evaluated the expected conditions and estimated a liquid Re of about 218,000, based on a $j_{f}$ of $0.1 \mathrm{~m} / \mathrm{s}$, a system pressure of $160 \mathrm{bar}$ and temperature of $630 \mathrm{~K}$. This Re cannot be preserved in the laboratory experiment; however, the liquid Froude number can be. The liquid-phase Froude number is estimated at $4 \times 10^{-4}$ for the actual system. The same liquid Froude number requires a $j_{f}$ of $0.055 \mathrm{~m} / \mathrm{s}$ in the current air-water test facility. The corresponding water volumetric flow rate of 4.2 GPM is within the capabilities of the present facility.

Chung [26] reasoned that an increase in liquid viscosity will result in flooding at a lower air flow rate because waves on the film surface are formed with smaller radii of curvature. Counteracting this destabilizing effect, viscosity also has a damping effect on interface oscillation, thereby delaying the onset of an instability. The destabilizing effect of increased liquid viscosity was confirmed by experiment; however, the effect is only important when the viscosity is changed by an order of magnitude or more. Zapke and Kroger [39] refute the conclusion that liquid viscosity has a small effect, by plotting Chung's data in terms of dimensionless parameter that demonstrates the non-negligible effect of liquid viscosity.

The results of the scaling analysis are provided in Table 3.6. From scaling calculations, the test facility pressure is maintained between 1 and 4 bar. While the tests would ideally be performed at closer to the actual pressure, the lower pressures were chosen because key flooding parameters such as the superficial velocities can be matched. Further, there are safety and equipment limitations for higher pressure tests. It is noted that most steam-water tests have been performed at atmospheric pressure.

\subsubsection{Steam-water Facility Description}

\subsubsection{Test Facility}

The major components of the steam-water test facility are the test section, water supply system, steam supply system, steam-water outlet at the upper end of the test section, and water collection and recirculation system. The facility, including the test section, was constructed out of stainless steel (SS304) to withstand high temperatures and pressures. The length of the test section between the inlet plenum and outlet plenum was wrapped on the outside with heater tape. In addition, part of the steam inlet piping just before entering the test section was also wrapped with heater tape. The entire facility was insulated with 2-inch thick fiberglass insulation to prevent steam condensation and cooling of the hot water. A schematic of the entire system can be seen in Figure 3.24. 
Table 3.6 Scaling of surge line specifications and reactor conditions.

\begin{tabular}{|c|c|c|c|}
\hline Parameter & Actual Surge Line & Experiment & Comment \\
\hline \begin{tabular}{|lll}
$\begin{array}{l}\text { Tube } \\
\text { (inches) }\end{array}$ & diameter, & D \\
\end{tabular} & 10 & 3.0 & $\begin{array}{l}\text { Classified as "large } \\
\text { diameter" }\end{array}$ \\
\hline Tube length & Reactor-specific & 72 inches & \\
\hline 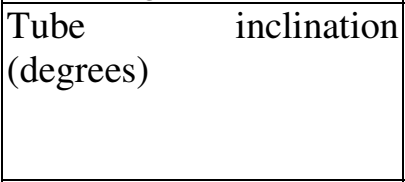 & $0-90$ & $0-90$ & $\begin{array}{lr}\text { Actual surge } & \text { line is } \\
\text { comprised } & \text { of } \\
\text { multiple } & \text { pipe } \\
\text { sections. } & \\
\end{array}$ \\
\hline Pressure (bar) & 160 & $1-4$ & $\begin{array}{lr}\text { Determines } & \text { fluid } \\
\text { density ratio. } & \text { To be } \\
\text { addressed in } & \text { steam- } \\
\text { water tests, } & \\
\end{array}$ \\
\hline Steam temperature & $\begin{array}{l}\text { Saturated steam to } 25 \\
\text { K superheat }\end{array}$ & $\begin{array}{l}\text { Saturated steam to } 10 \\
\mathrm{~K} \text { superheat }\left(100{ }^{\circ} \mathrm{C}\right. \\
\left.-153^{\circ} \mathrm{C}\right)\end{array}$ & $\begin{array}{l}\text { to be addressed in } \\
\text { steam/water tests }\end{array}$ \\
\hline Water temperature & \begin{tabular}{|l|}
$\begin{array}{l}\text { Subcooled to } \\
\text { saturated }\end{array}$ \\
\end{tabular} & $\begin{array}{l}\text { Subcooled to } \\
\text { saturated }\end{array}$ & $\begin{array}{l}\text { to be addressed in } \\
\text { steam/water tests }\end{array}$ \\
\hline Liquid Froude number & $4 \times 10^{-4}$ & $4 \times 10^{-4}$ & $\begin{array}{l}j_{f} \text { of } 0.055 \mathrm{~m} / \mathrm{s} \text { in } \\
\text { experiment, water } \\
\text { flow rate of } 4.2 \mathrm{GPM} \\
\text { is within capabilities }\end{array}$ \\
\hline
\end{tabular}




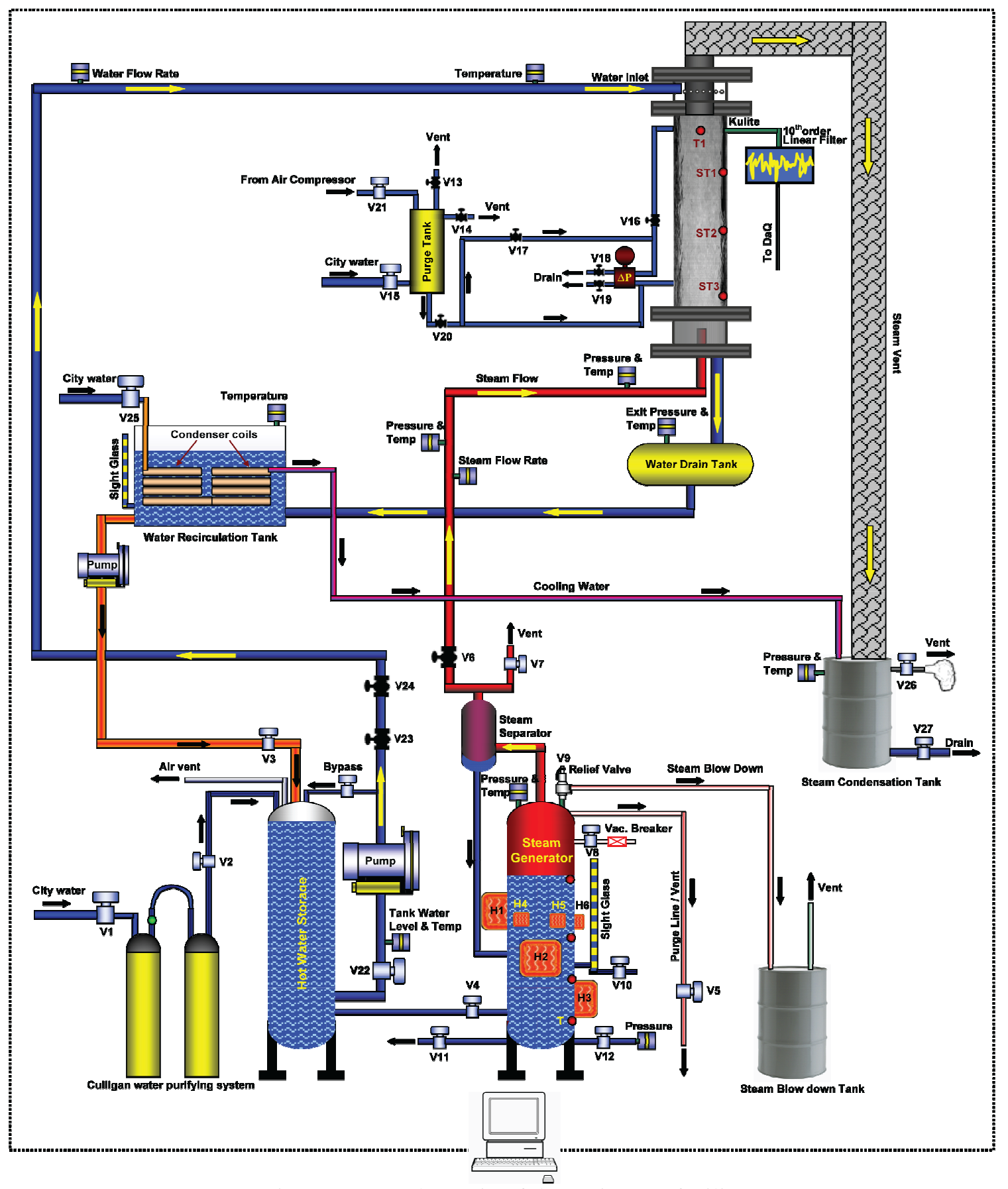

Figure 3.24 Schematic of the entire test facility

\subsubsection{Test Section}

The test section was designed similar to the air-water test section. It is a 6-foot long, 3-inch ID tube with $1 / 4$-inch thickness. There are five $1 / 8$-inch NPT threaded half couplings welded to the test section for pressure and thermocouple ports. Three ports are located at the top and two are located at the bottom. Two of the top ports and both of the bottom ports are pressure ports while the remaining top port is a thermocouple port. A mounting bracket is welded to the middle of the test section to support the weight of the structure. The mounting bracket is attached to a pillow block bearing via two 3/8-inch bolts that rest on a 1-inch stainless steel rotational rod. The size of 
the bearings and rod were chosen so that it could hold the largest possible mass of the test section filled with water with a factor of safety. In addition, a second mounting bracket is welded to the bottom and is attached to a hook to incline the structure. For vertical tests, a pipe clamp was attached to the test section to hold it in a vertical position. The test section can be seen prior to insulation in Figure 3.25.

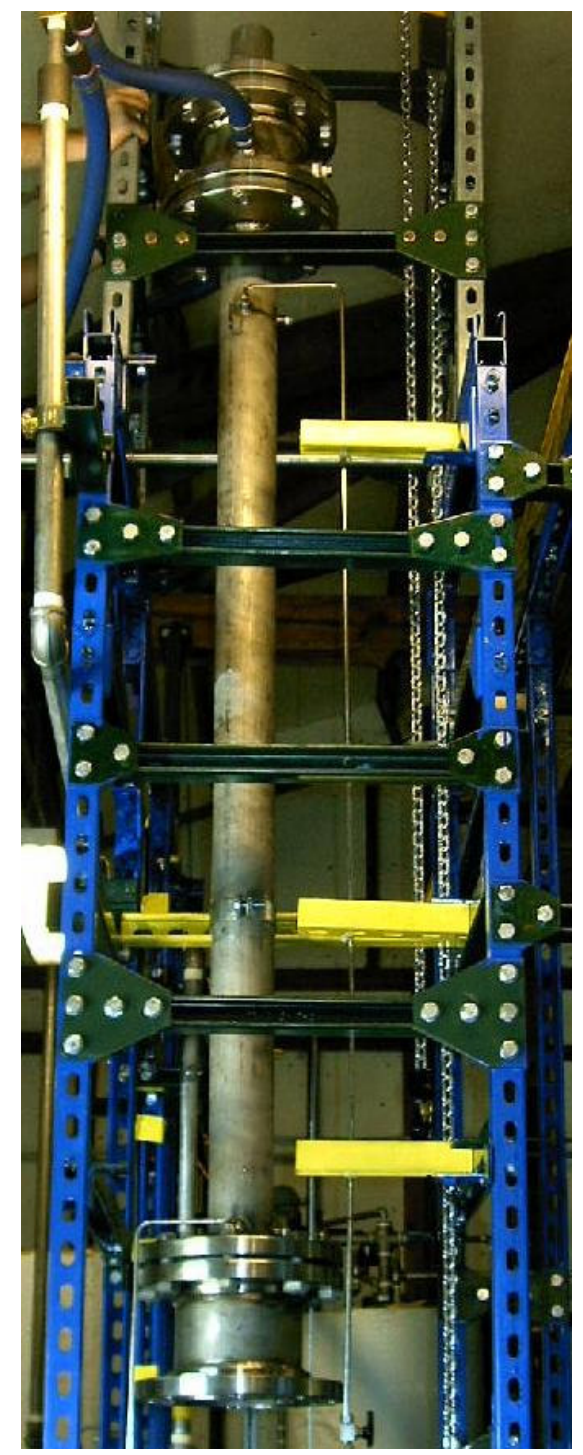

Figure 3.25 Test section prior to insulation.

\subsubsection{Water Supply System}

The water supply system consists of the Culligan Water Services tanks, a water storage tank, a hot water pump, and a water injection device.

Deionized water is used for both the steam and water in the facility. The water is treated by Culligan Water Services filters. City water passes through the Culligan tanks and is stored in a large water storage tank. The water storage tank is a 24-inch diameter, 7.5 -foot tall vessel. It is open to the atmosphere to prevent it from being pressurized. It also has a $5 \mathrm{~kW}$ heater to maintain an appropriate water temperature. 
The hot water pump is a Deanline Vertical Incline pump and pumps water up to 13 GPM into the test section. The pump uses $1 / 2$-horsepower and the maximum operating temperature is $250{ }^{\circ} \mathrm{F}$. Two gate valves are located after the pump on the water line to control the flow rate of water into the test section.

The water injection device was designed similar to the air-water water injection device. It allows the creation of an annular falling film in the test section and allows for unimpeded flow of steam out of the test section. The design consists of a $73 / 8$-inch long, 6-inch pipe acting as a plenum surrounding the top of the 3 -inch ID, 3.5-inch OD test section tube. There are four $3 / 4$-inch NPT threaded half couplings welded to the plenum to facilitate water injection spaced at 90 degrees from each other. Only two of them are used for experimental tests in this project. Similar to the air-water design, twelve $1 / 4$-inch holes were drilled into the top portion of the test section equally spaced along the circumference. A 2-3/4 inch OD, 2-1/4 inch ID tube is inserted inside the test section to create an annular film approximately $1 / 8$-inch thick. Water enters the plenum, flows through the twelve 1/4-inch holes where it comes into contact with the inner tube and is forced downward into the test section. Both the bottom and top of the tube have a bevel of 15 degrees to the vertical. As in the air-water design, the purpose of the bevel is to prevent the formation of vortices and disrupting the water inlet. The water inlet can be seen in Figure 3.26.

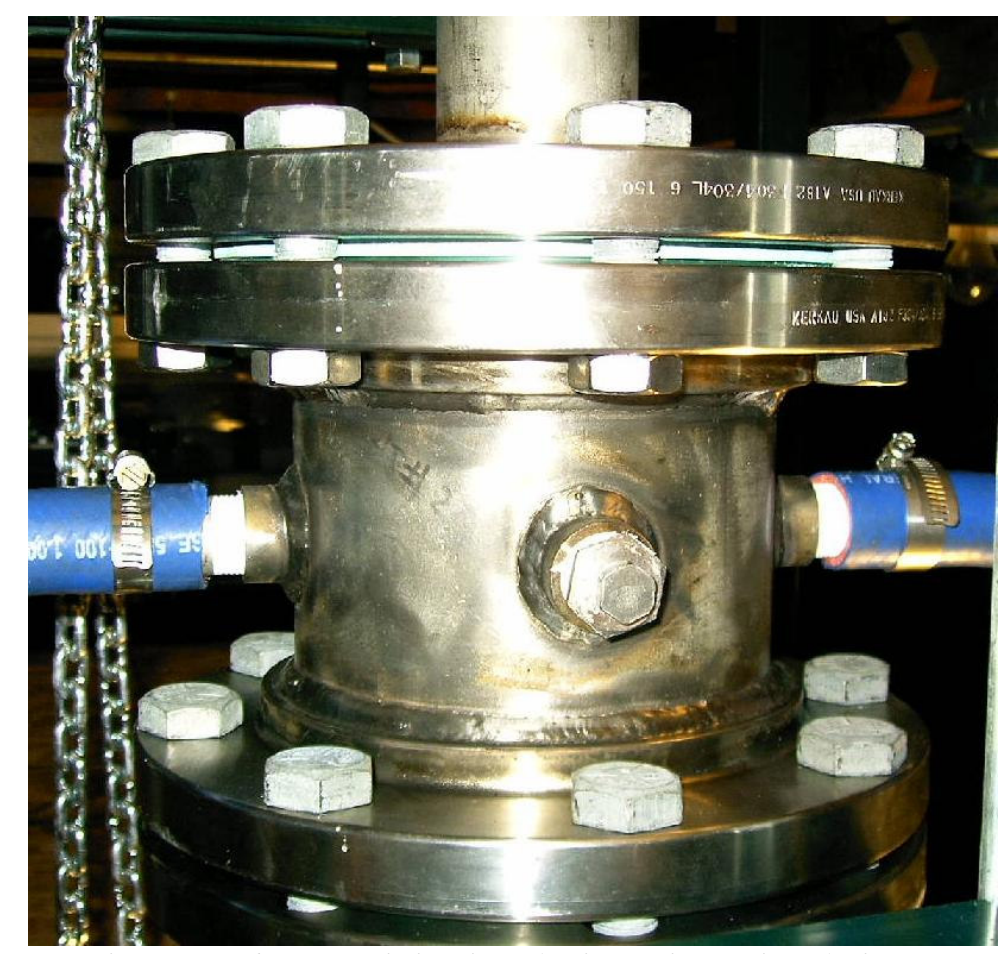

Figure 3.26 Water injection device prior to insulation

\subsubsection{Steam Supply System}

The steam supply system consists of the Culligan Water Services tanks, the steam generator, and the steam injection device.

The Culligan Water Services tanks are connected to the water storage tank. The water storage tank is connected to the steam generator. The deionized water is able to flow between the water storage tank and the steam generator when the steam generator is depressurized and a valve is 
opened. In this way, the water storage tank and the steam generator can be refilled at the same time.

The steam generator consists of a pressure vessel, immersion heaters, and a control panel. The pressure vessel was designed by the contractor and manufactured by Kennedy Tank and Manufacturing Co., Inc. The steam generator is shown uninsulated in Figure 3.27 and insulated in Figure 3.28. The pressure vessel shell is Schedule 10 stainless steel 304 pipe, 60 inches in height and 24 inches in diameter, along with two 24 -inch, Schedule 10 stainless steel end caps that were welded to the top and bottom of the body. A drain line from the bottom center, two blowdown lines from the top, weld necks for the heaters and several other penetrations were added. The vessel was built for 150 psi and hydrotested at 180 psi for 12 hours.

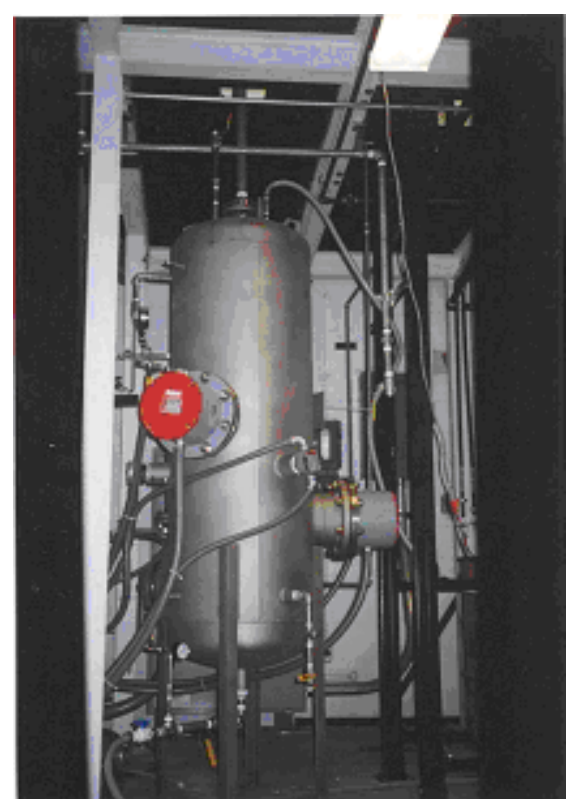

Figure 3.27 Steam generator before insulating

The two pressure relief valves are $1 / 2$-inch bronze valves manufactured by Kunkle and are factory set to open at $130 \mathrm{psig}$. A vacuum breaker line with a check valve inboard of the vacuum breaker is also attached. During cool down, the pressure falls below atmospheric pressure, causing the vacuum breaker valve to open. This allows air to flow into the steam supply and avoids placing the vessel under a vacuum.

Three 8-inch, flanged immersion heaters manufactured by Watlow Process Systems were purchased for the current project. The heaters have inconel sheaths. Each heater has a total output of $50 \mathrm{~kW}$. Two of the heaters have two $25 \mathrm{~kW}$ circuits and one heater has eight $6.25 \mathrm{~kW}$ circuits. The possible power levels are up to $150 \mathrm{~kW}$ in increments of $6.25 \mathrm{~kW}$. Type $\mathrm{K}$ thermocouples are used to measure the heater sheath temperature. Watlow Series 146 Temperature Regulators receive the thermocouple signal and break the circuit if an overtemperature condition is detected. The temperature regulators are set to activate when the sheath temperature exceeds $600{ }^{\circ} \mathrm{F}$.

Power is supplied to the steam generator from a $200 \mathrm{amp}, 180 \mathrm{~kW}$ source via the control panel. The control panel was custom designed and manufactured by Watlow. Via the control panel, up to $50 \mathrm{~kW}$ may be supplied to each of the heaters. Systems engineering support for the steam generator, heaters, and control panel is supplied by Thermtech Systems, Inc. 


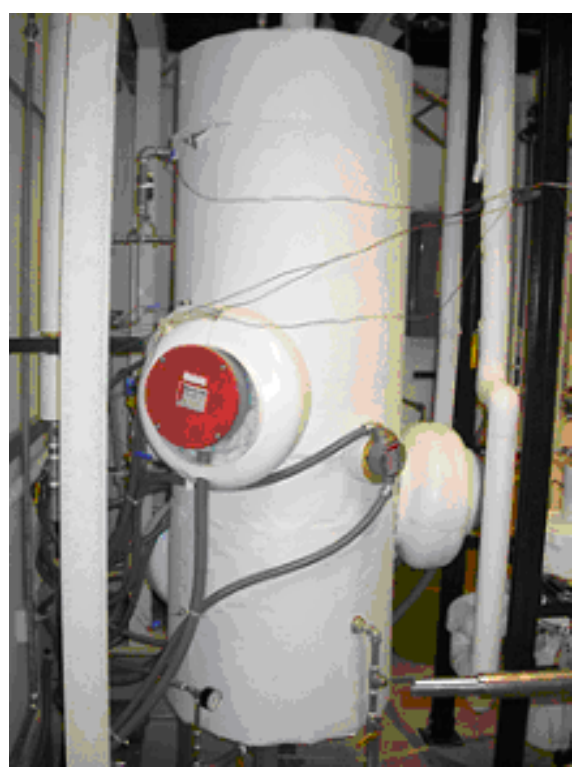

Figure 3.28 Steam generator after insulating.

Orion instruments supplied the magnetic liquid level indicator. This device shows the water level inside the steam generator without exposing glass to high pressure, as is the usual design of sight glasses. The Atlas model indicator comes with a Reed switch device which the PI hooked up to shut off all heater power when the liquid level falls below a prescribed level.

A separator removes water droplets from steam exiting the steam supply. Because the separator is also a pressure vessel, an ASME-certified unit was purchased from Clark Reliance Corporation. A one-inch stainless steel steam line is used to transport steam from the separator to the test section steam inlet. A vortex flow meter for measuring the steam flow rate and the air supply line are on this steam line.

Heat loss tests were conducted on the steam generator after it had been insulated. The closed system that was tested included the pressure vessel, the water level indicator, the separator and associated piping up to the isolation valve on the steam line. The pressure vessel is expected to be the largest source of the integral system heat loss because, although the heater penetrations become warm $\left(60^{\circ} \mathrm{C}\right)$, they must be uninsulated to avoid electrical terminal connection damage.

For the heat loss tests, the system was heated to saturation temperature at $100 \mathrm{kPa}$ and let to sit with a $2 \mathrm{~kW}$ heater on. Because the system temperatures and pressure slowly increased, the heat loss was known to be less than $2 \mathrm{~kW}$. A second test was performed at $400 \mathrm{kPa}$. The saturation temperature is $143{ }^{\circ} \mathrm{C}$, and thus the temperature difference driving heat losses is 1.5 times that at $100 \mathrm{kPa}$. Again, with a $2 \mathrm{~kW}$ heater on, the system temperatures and pressure gradually rose, indicating a heat loss of just less than $2 \mathrm{~kW}$.

The steam injection device was designed similar to the air-water air injection device. It consists of

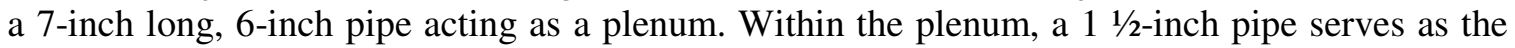
steam inlet. It is insulated by a 2 -inch pipe and reducing coupling welded at the top and bottom to create an air pocket. This air pocket minimizes steam condensation before entering the test section.

\subsubsection{Steam Outlet}


Unlike air-water testing, the steam outlet must be leak tight to prevent any exiting steam and hot

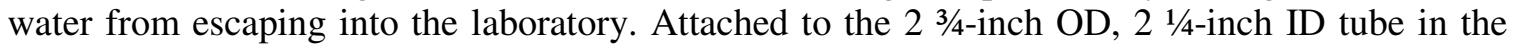
water injection device is a $23 / 4$-inch neoprene tube. This tube is able to withstand up to $27 \mathrm{psi}$ and $250{ }^{\circ} \mathrm{F}$ which is greater than the temperatures and pressures achieved during a test. In addition, the neoprene tubing has the added benefit of being flexible. The tube connects the top of the test section to a 55 gallon drum that acts as a blowdown tank. The drum has a hose of city water constantly running into the top of it to condense the exiting steam. At the bottom of the drum a hose is connected to drain the heated water and condensed steam. Another hose open to the atmosphere is attached at the top of the drum to ensure that the drum does not become pressurized. The blowdown tank can be seen in Figure 3.29.

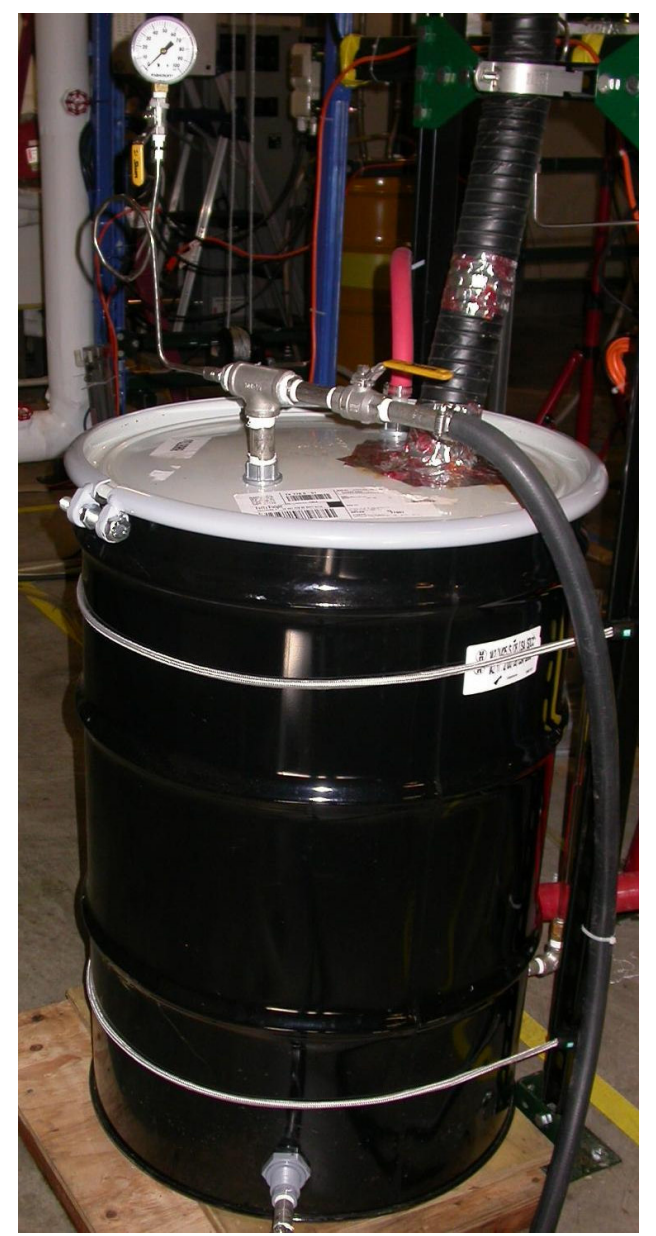

Figure 3.29 Steam-water outlet tube connected to the blow down tank

\subsubsection{Water Collection and Recirculation}

To prevent the need for constantly deionizing new water, a water recirculation system was installed. The hot water exits at the bottom of the test section via four hoses and collects in a stainless steel tank. The stainless steel tank drains into a larger tank made of aluminum. The aluminum tank contains two coiled copper tubes. City water runs through the copper tubes to cool the hot water exiting the test section. The water in the aluminum tank then runs through a small recirculation pump back into the water storage tank. The recirculation pump can not operate with water temperatures close to saturation so it is necessary to cool the water to prevent cavitations in the pump. The coiled copper tubes cool the water by about $30^{\circ} \mathrm{C}$. 


\subsubsection{Instrumentation}

A total of 14 temperatures, 6 absolute pressures, 2 differential pressures, and 2 flow rates are recorded. The data is recorded by a data acquisition system assembled from National Instruments components. The LabVIEW software is used to display and save data. The locations of the instrumentation is shown in Figure 3.30.

Temperature measurements are made at the water inlet, steam inlet, water exit, along the test section, and steam generator. There are three temperature measurements taken on the outside surface of the test section. In addition, a temperature measurement is taken inside the top of the test section in the vapor space. All of the thermocouples are T-type (copper-constantan). All but the surface thermocouples on the test section are mounted through CONAX fittings sealed with Teflon disks. The surface thermocouples on the test section are attached with a high temperature epoxy.

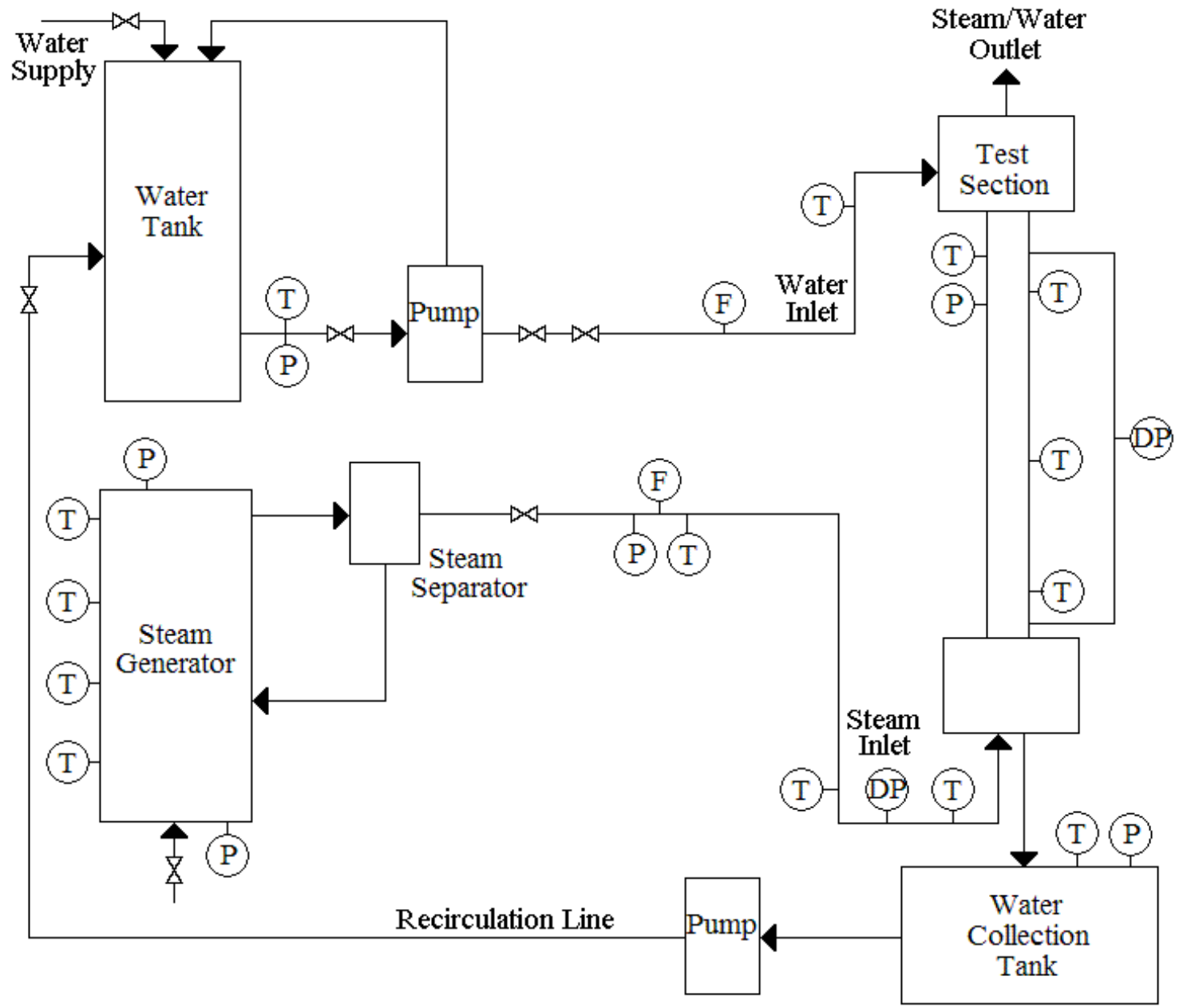

Figure 3.30 Steam-water test facility with instrumentation locations

Honeywell absolute pressure transducers are used for measurements on the steam line, the water line, and the water collection tank. An Omega absolute pressure transducer is used for a pressure measurement at the top of the steam generator. A Dwyer pressure transducer is located at the bottom of the steam generator and is used to measure the water level inside. For a pressure differential across the test section, a Honeywell differential pressure transmitter is used. A fast response pressure transducer measures the pressure transients during flooding in the test section. 
Flow rates are recorded for the water inlet and the steam inlet. A Yamatake magnetic flow meter measures the water flow rate into the test section. A Foxboro vortex flow meter measures the steam flow rate into the test section.

\subsubsection{Experimental Procedures}

\subsubsection{Startup Procedures}

To prepare the facility to operate, the water storage tank and steam generator are filled with deionized water. The water level in the steam generator must be high enough to cover all of the heaters throughout a test. The water level in the water storage tank must be high enough to provide a constant supply of water to the hot water pump. In addition, all valves on the steam generator are checked to ensure that they are closed. The pressure transducer lines are primed with water.

The data acquisition computer is turned on along with the power supplies. All measurements from the instrumentation are checked for proper operation. A set of baseline data is recorded for current laboratory conditions.

Heaters in the steam generator are turned on to a predetermined power level to heat the water. When the pressure in the steam generator is $10 \mathrm{psi}$ above atmospheric, the valve to the outside vent is opened long enough to purge the air from the steam generator. This ensures that only steam flows through the steam line to the test section. The steam generator pressure is increased until the desired operating pressure is reached.

The cooling system is turned on by opening a valve on the city water line to start the flow of water through the copper tubes to cool recirculating water and to start the flow of water into the blowdown tank to condense exiting steam. Another valve is opened at the bottom of the blowdown tank to drain a mix of cooling water and condensed steam.

The valves on the water line are opened to prevent cavitation in the pumps. The recirculation tank is partially filled with deionized water to ensure an initial water supply for the recirculation pump.

\subsubsection{Test Procedures}

Once the steam generator pressure has reached a predetermined level, the valve on the steam line to the test section is opened so that a low steam flow rate flows through the facility. Steam is allowed to flow through the piping and the test section into the blowdown tank until the piping and test section have been heated. A valve on the steam line is briefly opened to drain any condensed steam caught in the line.

The hot water pump is turned on and the water flow rate is adjusted to a predetermined level. The recirculation pump is turned on and the water flow rate is adjusted to maintain a constant water level in the water storage tank. The flow rate in the recirculation line is approximately equal to the flow rate in the water line leading to the test section. Once a steady steam and water flow rate is established, data collection begins and continues until the end of a test.

The water flowing through the test section and recirculating back into the water storage tank is allowed to heat up using the energy from the steam as it condenses inside the test section. In addition a $5 \mathrm{~kW}$ heater inside the water storage tank is turned on to help heat up the water. This continues until the water reaches a temperature of $70^{\circ} \mathrm{C}$. 
While maintaining a constant pressure in the steam generator, the valve on the steam line is incrementally opened to increase the steam flow rate. The valve is opened a very small amount each time so that the system is able to come to an equilibrium and the onset of flooding is not skipped.

\subsubsection{Shut Down Procedures}

After the system has reached the onset of flooding, it is allowed to remain in a state of flooding for one minute. After this point, the valve on the steam line is slowly closed to decrease the steam flow rate and bring the system back to steady state. Once steady state has been reached, data collection is terminated. The valve on the steam line is closed completely and the steam generator power is turned off. The hot water pump and recirculation pump are turned off. The steam generator is allowed to depressurize and the facility is allowed to cool.

\subsubsection{Experimental Test Conditions}

All tests were operated under the same procedures and with many of the same conditions. In every test the steam generator pressure was high enough so that the steam was under a choked flow condition. This allowed for a more steady flow rate that could only be altered by opening the valve on the steam line further. The steam exiting the steam generator and entering the test section is superheated by up to $20^{\circ} \mathrm{C}$.

All tests had a water inlet temperature of $70{ }^{\circ} \mathrm{C}$. This temperature was chosen to give a $10{ }^{\circ} \mathrm{C}$ safety margin from the maximum operating temperature of the recirculation pump. The minimum water flow rate is based on the minimum water flow rate to produce an annular film. The maximum water flow rate is based on the water flow rate with the valves fully open on the water line. The ranges of conditions for these experiments are shown in Table 3.7.

Table 3.7 Range of test conditions for steam-water tests

\begin{tabular}{|l|l|}
\hline Parameter & Range \\
\hline Test Section Pressure $(\mathrm{atm})$ & $1-4$ \\
\hline Steam Generator Pressure $(\mathrm{psig})$ & $30-40$ \\
\hline Steam Flow Rate $(\mathrm{g} / \mathrm{s})$ & $0-20$ \\
\hline Steam Pressure $(\mathrm{psia})$ & $15-20$ \\
\hline Steam Temperature $\left({ }^{\circ} \mathrm{C}\right)$ & $115-130$ \\
\hline Water Flow Rate $(\mathrm{GPM})$ & $2.5-13.5$ \\
\hline Water Temperature $\left({ }^{\circ} \mathrm{C}\right)$ & 70 \\
\hline
\end{tabular}

\subsubsection{Results and Discussion}

\subsubsection{Comparison to Air-Water Tests}

Prior to steam-water testing, air-water testing was done in the steam-water facility. This data was compared to the data from the air-water facility and served as benchmark data for steam-water tests. The basic geometry of the two facilities is the same, but the materials used differ. Discrepancies between the two sets of air-water data is contributed to these material differences. The most significant is the acrylic used in the air-water facility and the stainless steel used in the steam-water facility. The surface roughness of the two materials is different and affects the flow of the water down the test section. Other minor differences include the water outlet and air/steam outlet. In the air-water facility, the water exits into an open container. In the steam-water facility, the water exits into a closed container. In the air-water facility, the air exit is open to the atmosphere. In the steam-water facility, the steam exit is connected to a neoprene tube that leads to a blowdown tank. 
The data from the air-water tests in both facilities is shown in Figure 3.31. The data is plotted as the Kutateladze numbers. "Air 1" refers to the data taken in the air-water facility and "Air 2" refers to the data taken in the steam-water facility. In both sets of data, the same downward trend can be seen. The difference in values is contributed to the differences in the facilities.

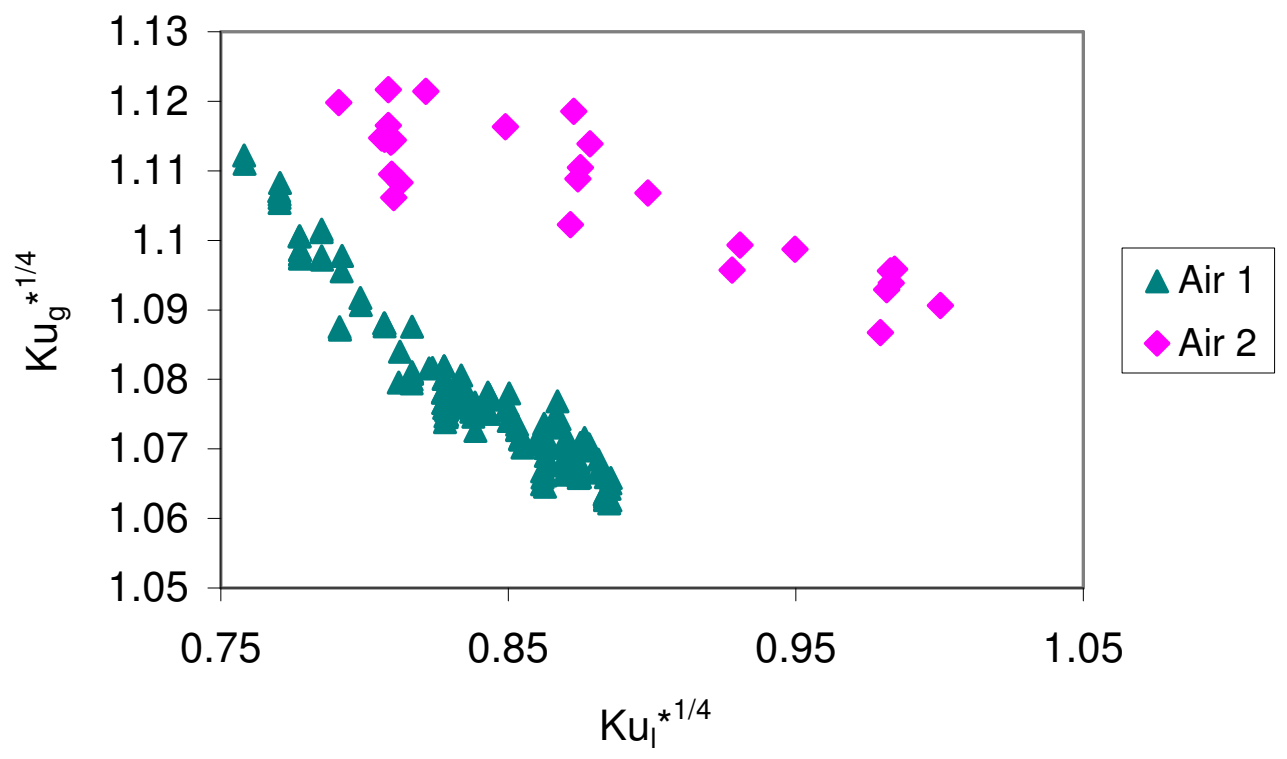

Figure 3.31 Data from all air-water tests

"Air 1" corresponds to the air-water facility and "Air 2" corresponds to the steam-water facility.

In the steam-water facility, the range of water flow rates was increased to accommodate a larger data set. The expanded range includes the range of tests in the air-water facility. Since the two facilities were designed as similarly as possible, much of the data may be compared. This includes the air and water velocities at flooding points as well as the overall trends of the data.

\subsubsection{Data and Observations}

During a test, the test section is at steady state for some time before flooding occurs. During flooding, however, a tumultuous process is occurring inside the test section. Since the test section is made of stainless steel and is covered in fiberglass insulation, flooding can not be seen. However, flooding can be observed based on the data acquired from the instrumentation.

The primary indication of flooding is seen in the differential pressure (dP) across the test section. When there is no water or steam flow in the test section, the dP is 55.75 inches of water, which corresponds to the distance between the differential pressure ports. When water at a steady flow rate is flowing in the test section, the $\mathrm{dP}$ is slightly higher, between 56 and 57 inches of water. At the onset of flooding the $\mathrm{dP}$ drops 2 inches of water or more, depending on the water flow rate. During flooding, the $\mathrm{dP}$ oscillates. In Figure 3.32, the $\mathrm{dP}$ as a function of time is shown. This test was run at 6.95 GPM. The onset of flooding occurred at 4,015 seconds. 


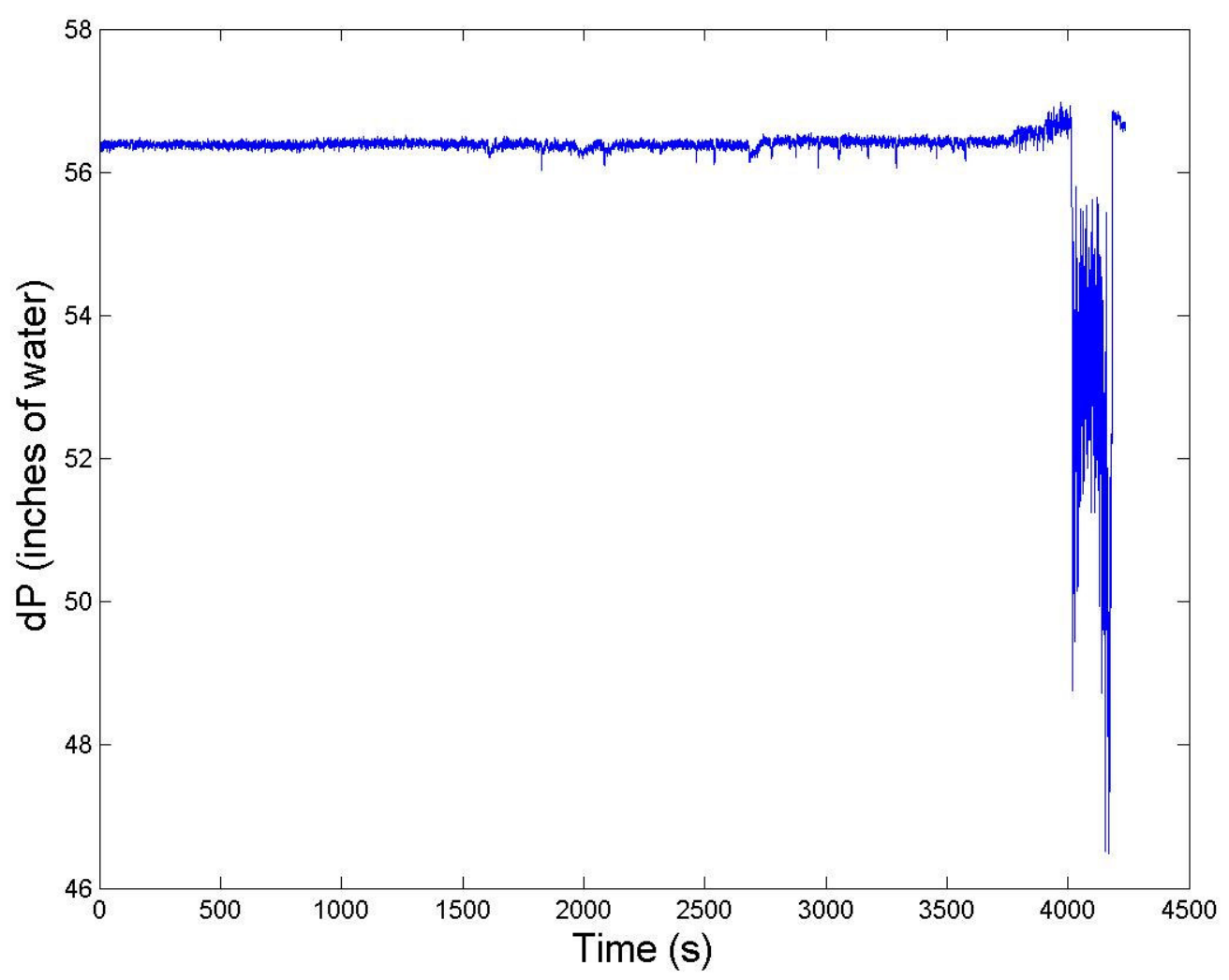

Figure 3.32 Differential pressure across the steam-water test section as a function of time

A secondary indication of flooding is seen in the absolute pressure of the water exit tank. During steady state operating conditions the absolute pressure in the water exit tank is atmospheric, 14.7 psia. The test section and water exit tank are not pressurized and are indirectly open to the atmosphere. At the onset of flooding the absolute pressure in the water exit tank rises about 0.4 psia. During flooding, the absolute pressure in the water exit tank oscillates similar to the dP in the test section. Figure 3.33 shows the pressure in the water exit tank as a function of time. This test was run at 6.95 GPM. The onset of flooding occurred at 4,015 seconds. 


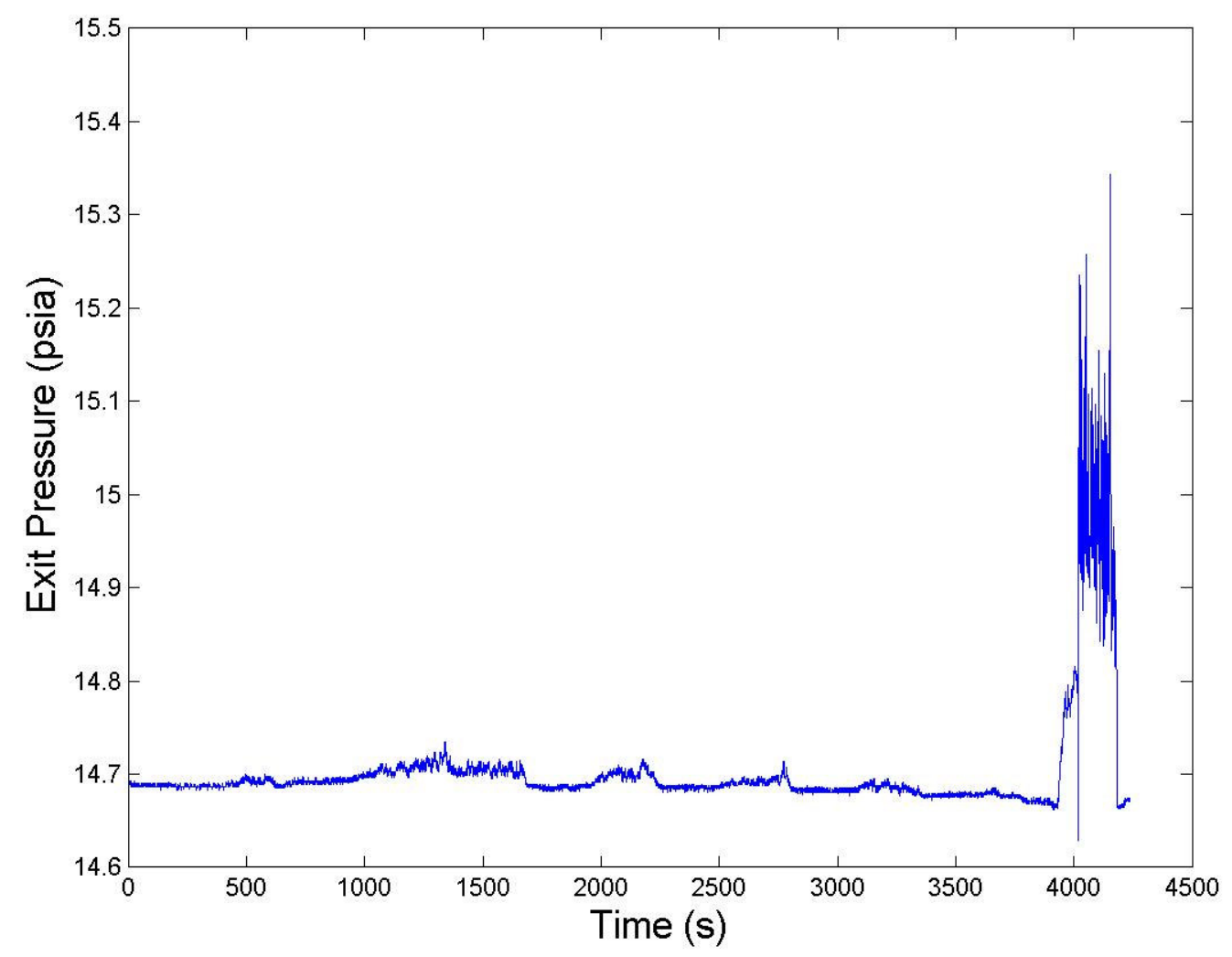

Figure 3.33 Absolute pressure in the water exit tank as a function of time

A third indication of flooding deals with the temperature measurements taken inside and on the outside surface of the test section. One thermocouple is located inside the top of the test section in the vapor space. During steady state conditions this provides the temperature of the steam exiting the test section. Three thermocouples are located on the outside surface of the test section. One is at the top, another is in the middle, and the last is at the bottom. During steady state conditions this provides the temperature of the wall of the test section. This temperature is influenced by the temperature of the water at that particular axial location. The temperature of the water at the bottom of the test section is higher than the temperature at the top. This is because the inflowing steam condenses on the falling water film.

During steady state conditions, the temperature of the steam at the top of the test section is between 70 and $90{ }^{\circ} \mathrm{C}$. During the approach to flooding, as the steam flow rate is increased, the temperature of the steam at the top of the test section increases to between 95 and $105{ }^{\circ} \mathrm{C}$. During flooding, the thermocouple inside the test section reads a temperature of about $100{ }^{\circ} \mathrm{C}$.

During steady state conditions, the temperature on the surface of the test section is between 50 and $75{ }^{\circ} \mathrm{C}$, depending on the temperature of the water at the inlet. During the approach to flooding, as the steam flow rate is increased, the temperature at the bottom surface of the test section increases to between 70 and $95{ }^{\circ} \mathrm{C}$. The middle and top surface temperatures remain close to the water inlet temperature until the onset of flooding. During flooding, the temperature on the surface of the test section at all axial locations is about $100{ }^{\circ} \mathrm{C}$. Figure 3.34 shows the temperature measurements taken inside and on the outside surface of the test section as a function of time. The black line shows the temperature inside the test section while the red, green, and blue lines show 
the temperatures on the outside surface of the test section at the top, middle, and bottom, respectively. Additionally, the water inlet temperature is plotted in pink to compare with the temperatures across the test section. This test was run at 6.95 GPM and the onset of flooding occurred at 4,015 seconds.

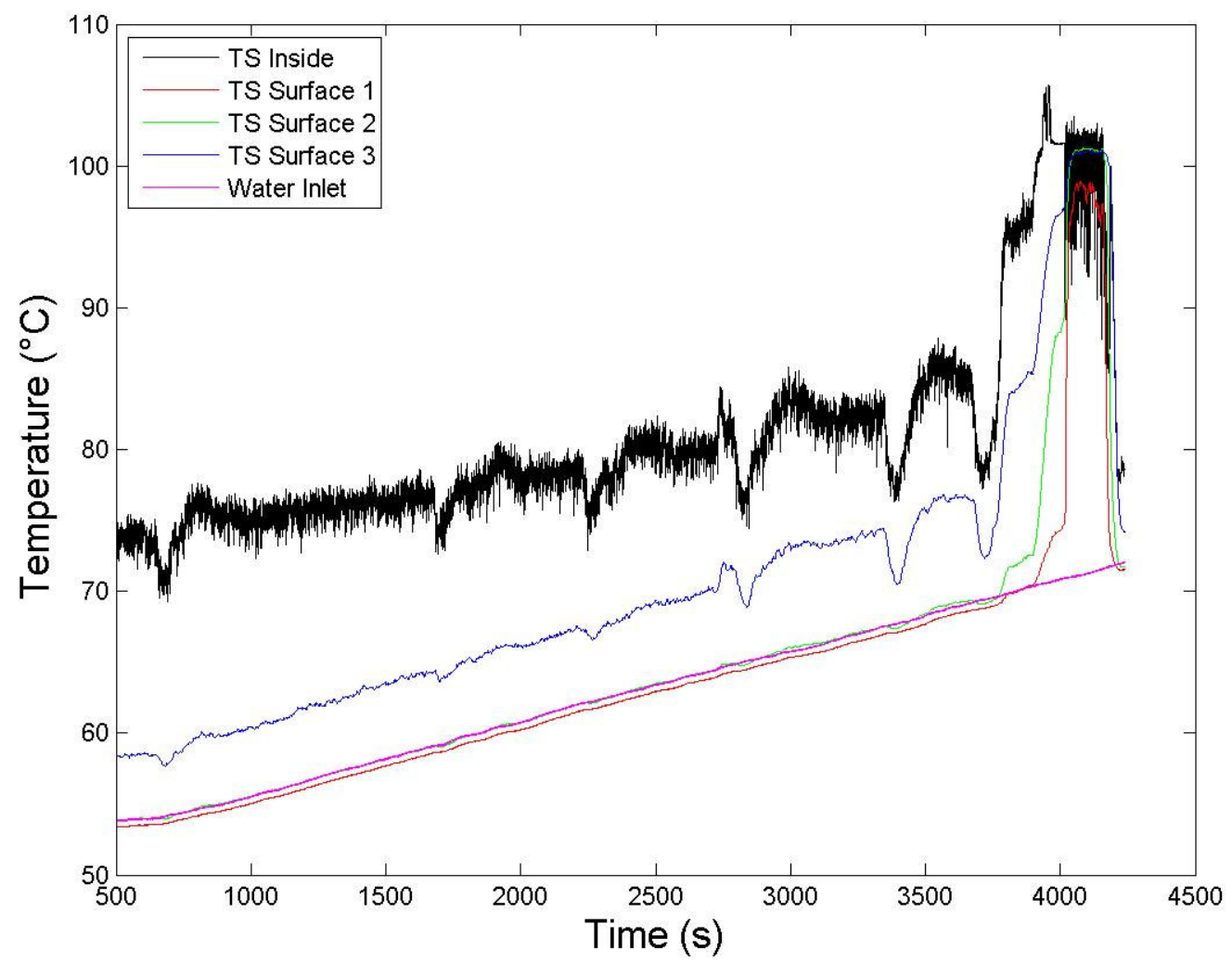

Figure 3.34 Temperatures across the test section as a function of time

The water film in the test section remains subcooled throughout until the approach to flooding. The water close to the steam inlet is the first location to reach saturation temperature. The remainder of the water in the test section remains subcooled until the onset of flooding. During flooding the steam and subcooled water mix inside the test section and give an oscillating temperature reading inside the top of the test section. The temperature oscillates between about 90 and $105^{\circ} \mathrm{C}$.

\subsubsection{Reduced Data}

At the conclusion of every test, the recorded data was analyzed and the point at the onset of flooding was extracted. In this way, the data was reduced and graphed. The point at the onset of flooding was determined based on the differential pressure drop in the test section. It was calculated to occur when the differential pressure dropped by more than one inch of water than the previous recorded point.

The velocity of the steam entering the test section was graphed as a function of the water flow rate and is shown in Figure 3.35. The velocity of the steam was measured with a vortex flow meter on the steam line and corrected for the expansion when entering the test section. The water flow rate was measured with a magnetic flow meter on the water line before entering the test 
section. There is a downward trend in the data suggesting that the higher the water flow rate into the test section, the lower the steam flow rate is needed for flooding to occur.

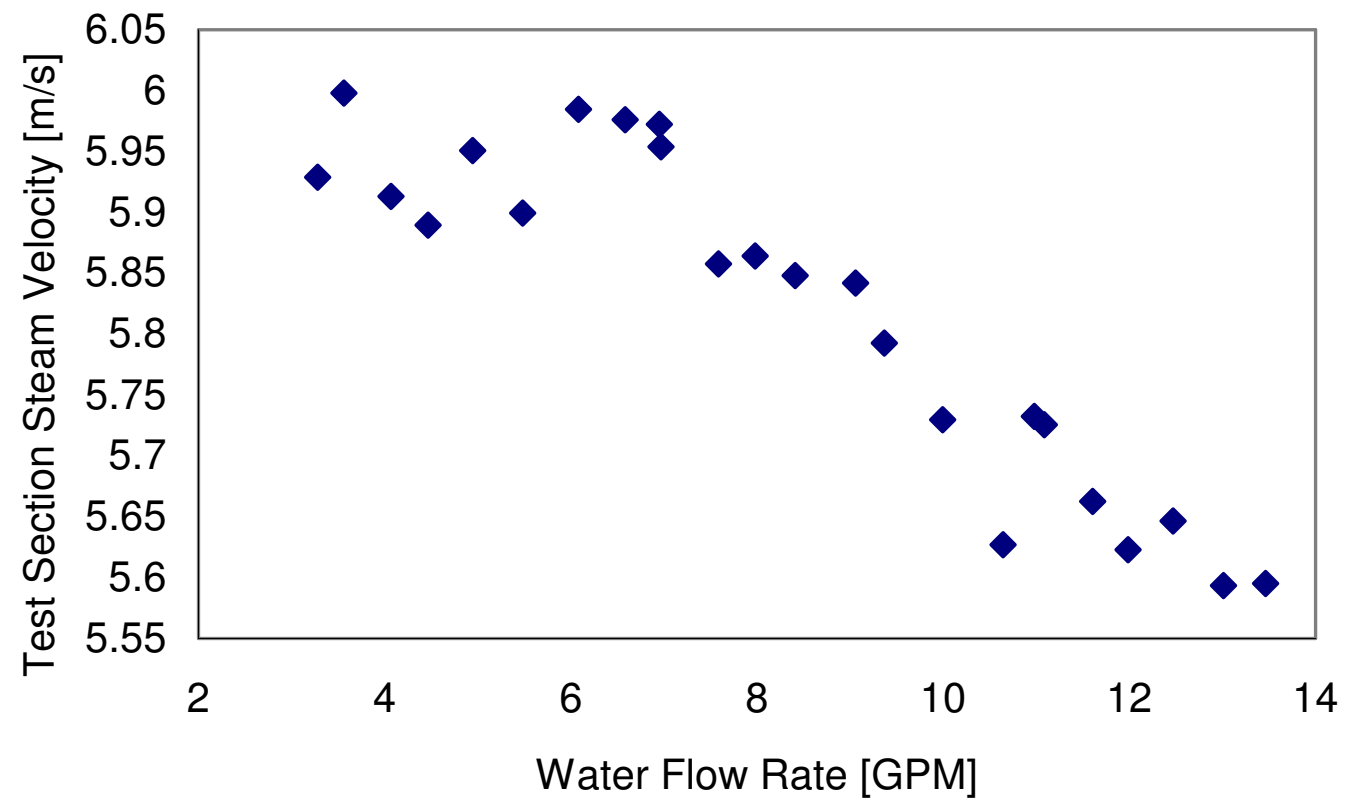

Figure 3.35 Flooding data presented as steam velocity as a function of water flow rate

The data at the onset of flooding was graphed as the Wallis parameters and is shown in Figure 3.36. Similar to Figure 3.35, the data shows a downward trend.

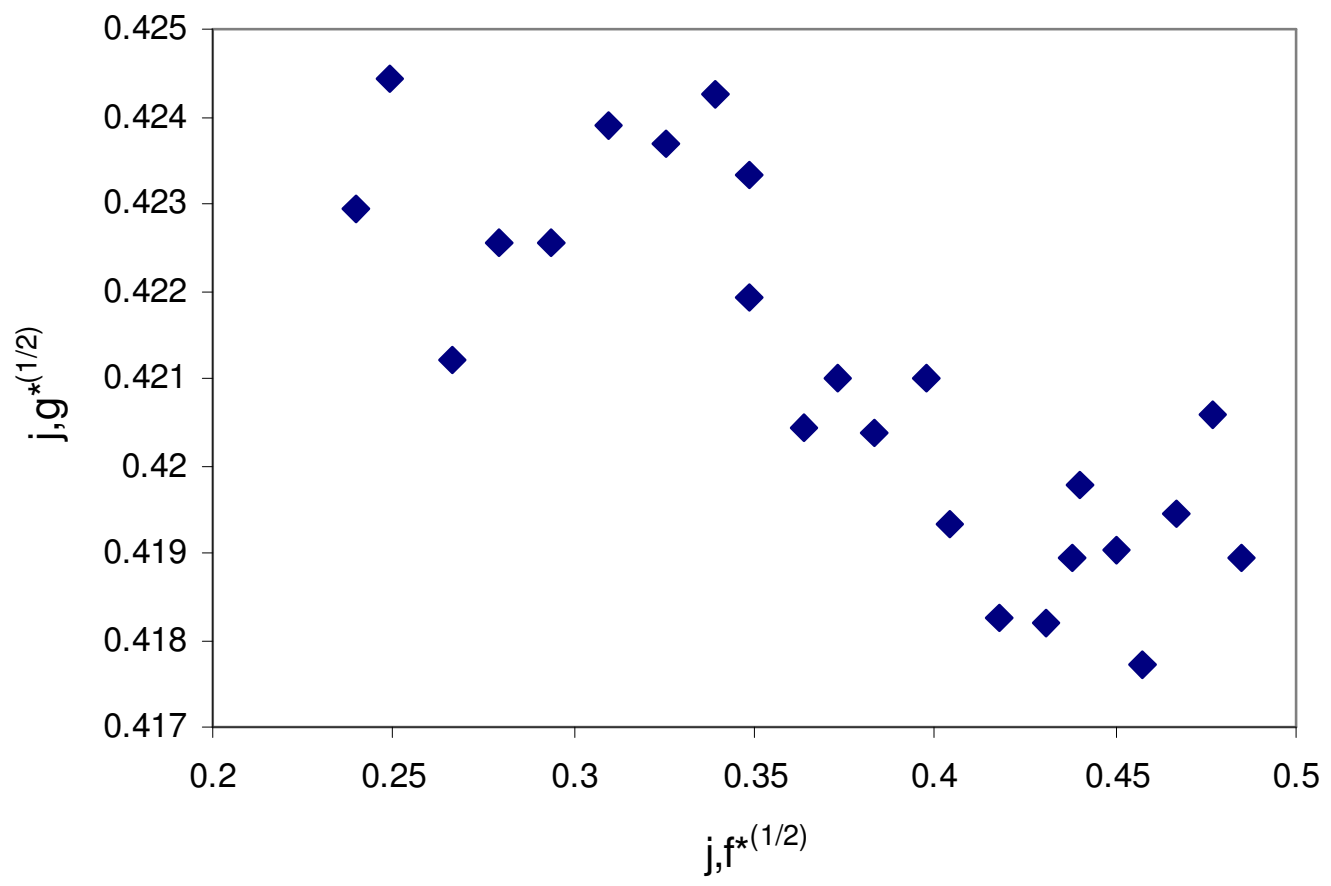

Figure 3.36 Flooding data presented as the Wallis parameters 
The differential pressure drop for each test was graphed as a function of water flow rate and is shown in Figure 3.37. The differential pressure drop was calculated by subtracting the lowest differential pressure within 20 seconds after the onset of flooding from the differential pressure right before the onset of flooding. There is an upward trend which means the higher the water flow rate, the greater the differential pressure drop will be during flooding.

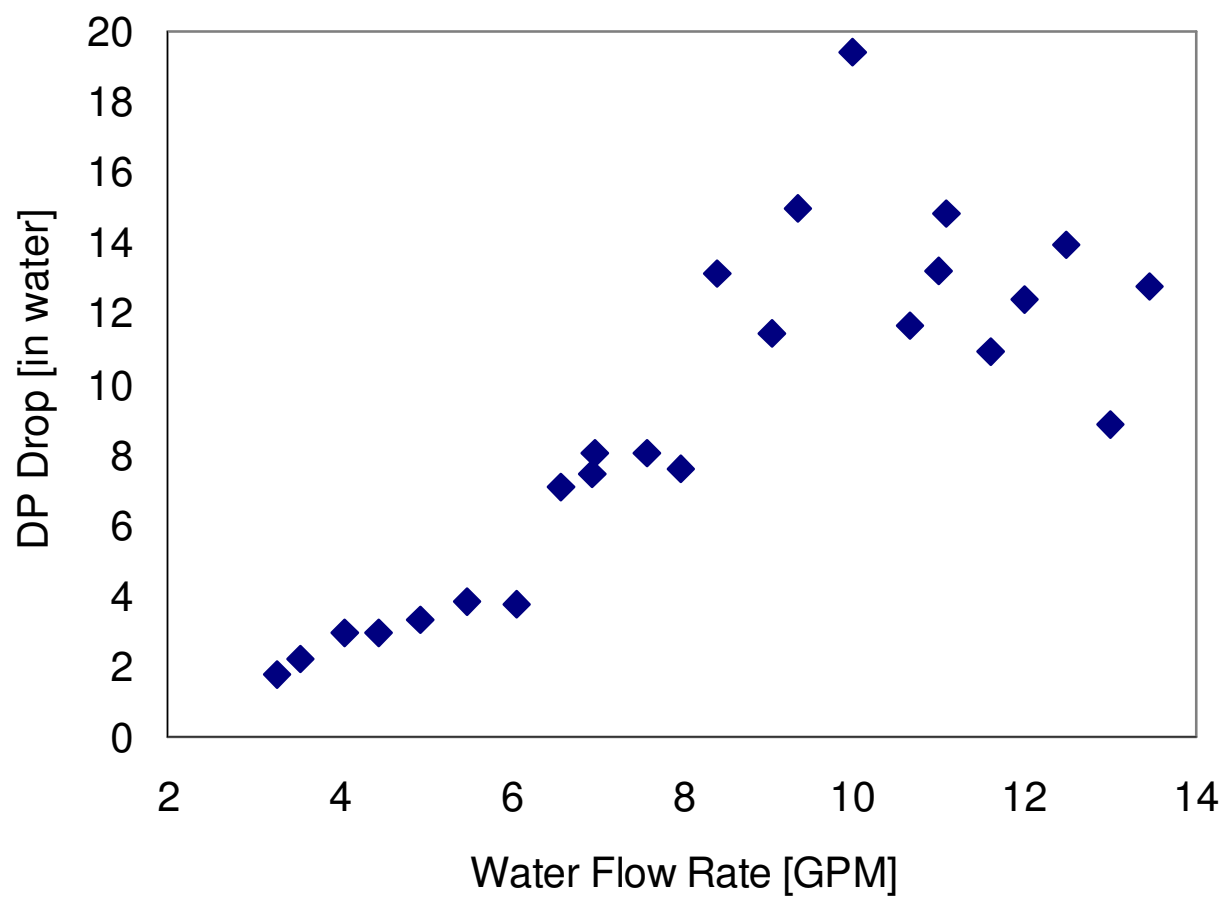

Figure 3.37 The differential pressure drop as a function of water flow rate

\subsubsection{Empirical Model Development for Steam-water}

The steam-water data was plotted alongside the air-water data from both facilities as the Wallis numbers. Figure 3.38 shows the three sets of data. "Air 1" refers to the data taken in the air-water facility, "Air 2" refers to the air-water data taken in the steam-water facility, and "Steam" refers to the steam data. Although the steam data appears to form a horizontal line, it corresponds to the steam-water data in [84]. The range of $\mathrm{j}_{\mathrm{f}}{ }^{* 1 / 2}$ values in the steam data corresponds to the area of intersection of boundary 3 and boundary 4 . The $\mathrm{j}_{\mathrm{g}}{ }^{1 / 2}$ values shown in Figure 3.38 match the data presented in [84] closely for similar test conditions. 


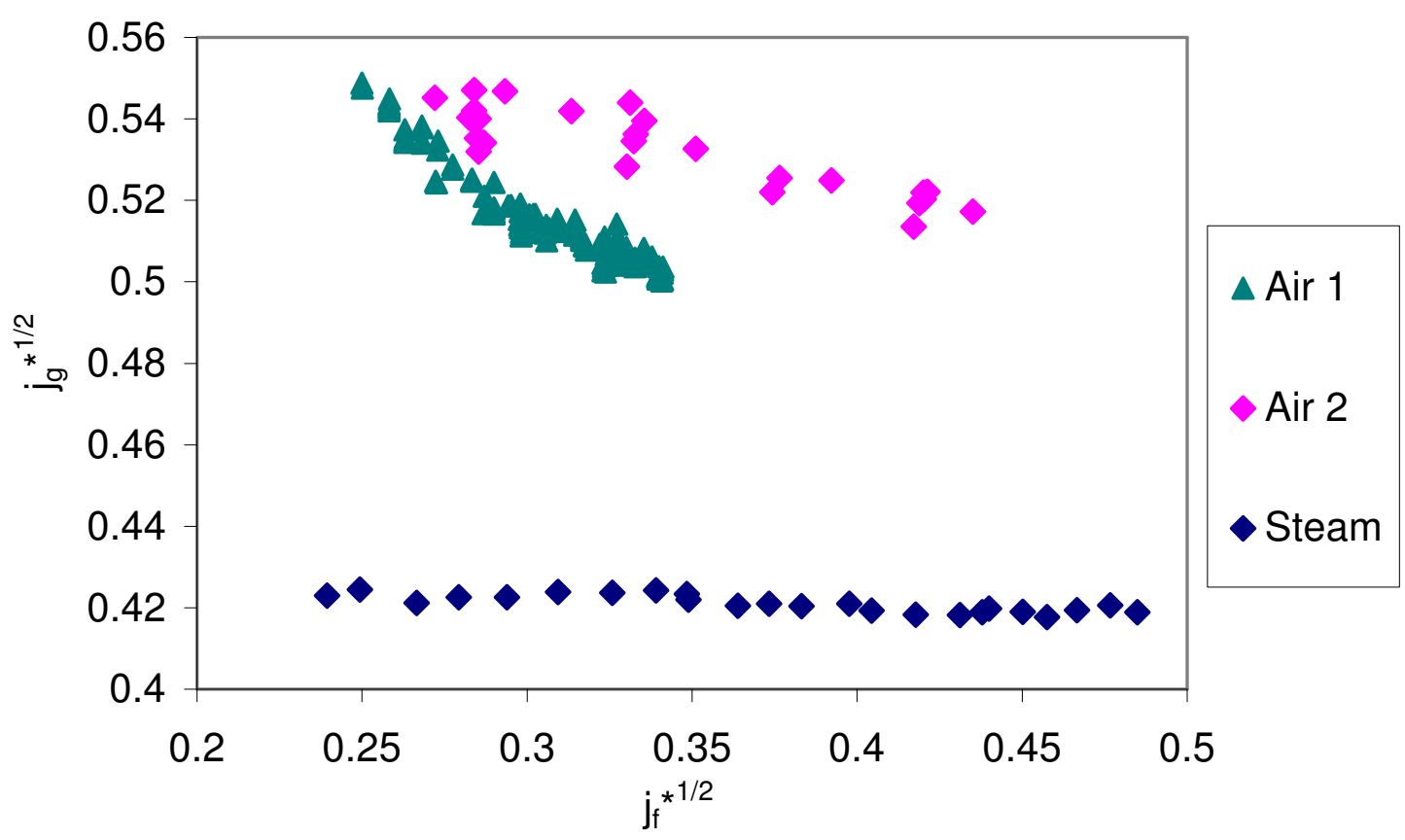

Figure 3.38 Air-water and steam-water data plotted as the Wallis numbers

Since the Wallis numbers are used for small diameter tubes, the Kutateladze numbers are more appropriate to use for both the air-water and steam-water facilities since both test sections have a large diameter. To incorporate the effect of steam condensation due to subcooled water in the experiment, the vapor Kutateladze number was recalculated using the Jakob number to produce an effective vapor flow $\mathrm{Ku}_{\mathrm{ge}}$ [85].

$$
K u_{g e}=K u_{g}-f K u_{f}\left(\frac{c_{p} \Delta T_{s u b}}{h_{f g}}\right)\left(\frac{\rho_{f}}{\rho_{g}}\right)^{1 / 2}
$$

In Figure 3.39 the data from air-water tests is plotted as well as the data from steam-water tests corrected to account for condensation. The data is plotted as the Kutateladze numbers. "Air 1" refers to the data taken in the air-water facility, "Air 2" refers to the air-water data taken in the steam-water facility, and "Steam" refers to the steam data corrected for condensation. All data sets show the same downward trend. 


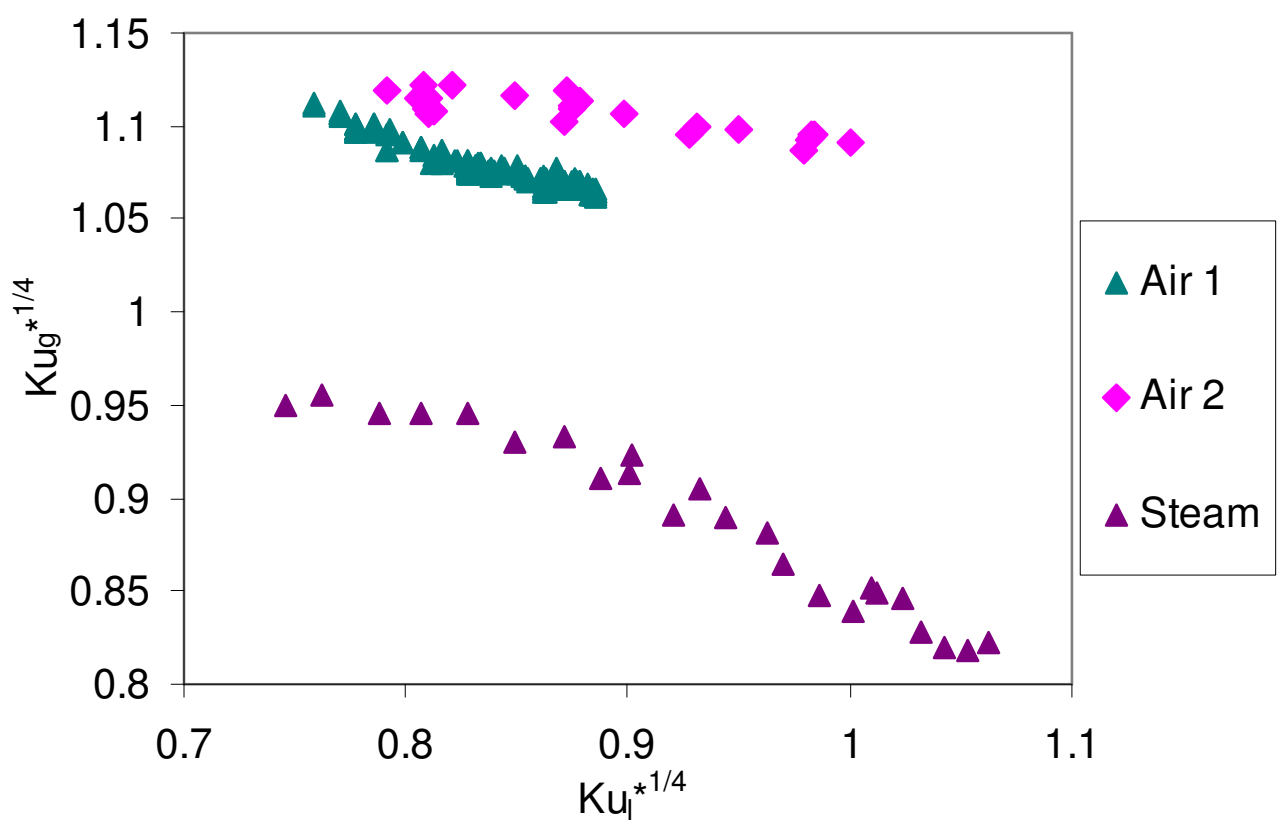

Figure 3.39 Air-water and corrected steam-water data plotted as the Kutateladze numbers

A modification of the Kutateladze correlation can be drawn from both the air-water data and steam-water data in these two facilities. The general form of the Kutateladze-type correlation is shown in equation (3.32).

$$
K u_{g}^{1 / 4}+m K u_{l}^{1 / 4}=C
$$

For the steam-water data, the gas Kutateladze number was replaced with the effective vapor flow. Modifying both $\mathrm{m}$ and $\mathrm{C}$ to fit the steam-water data gives the correlation shown in equation (3.33). This equation properly correlates the steam data taken in these experiments.

$$
K u_{g e}{ }^{1 / 4}+0.478 K u_{l}{ }^{1 / 4}=1.332
$$

The air-water data can also be applied to the general Kutateladze correlation. Modifying the correlation to fit the air-water data from the air-water facility gives $\mathrm{m}$ and $\mathrm{C}$ values of 0.325 and 1.35 , respectively. The steam-water data corrected for condensation is plotted in Figure 3.40 with $5 \%$ error lines of the steam-water correlation. These two lines are $95 \%$ and $105 \%$ of the value of the correlation line. All of the steam-water data fits between these error lines. 


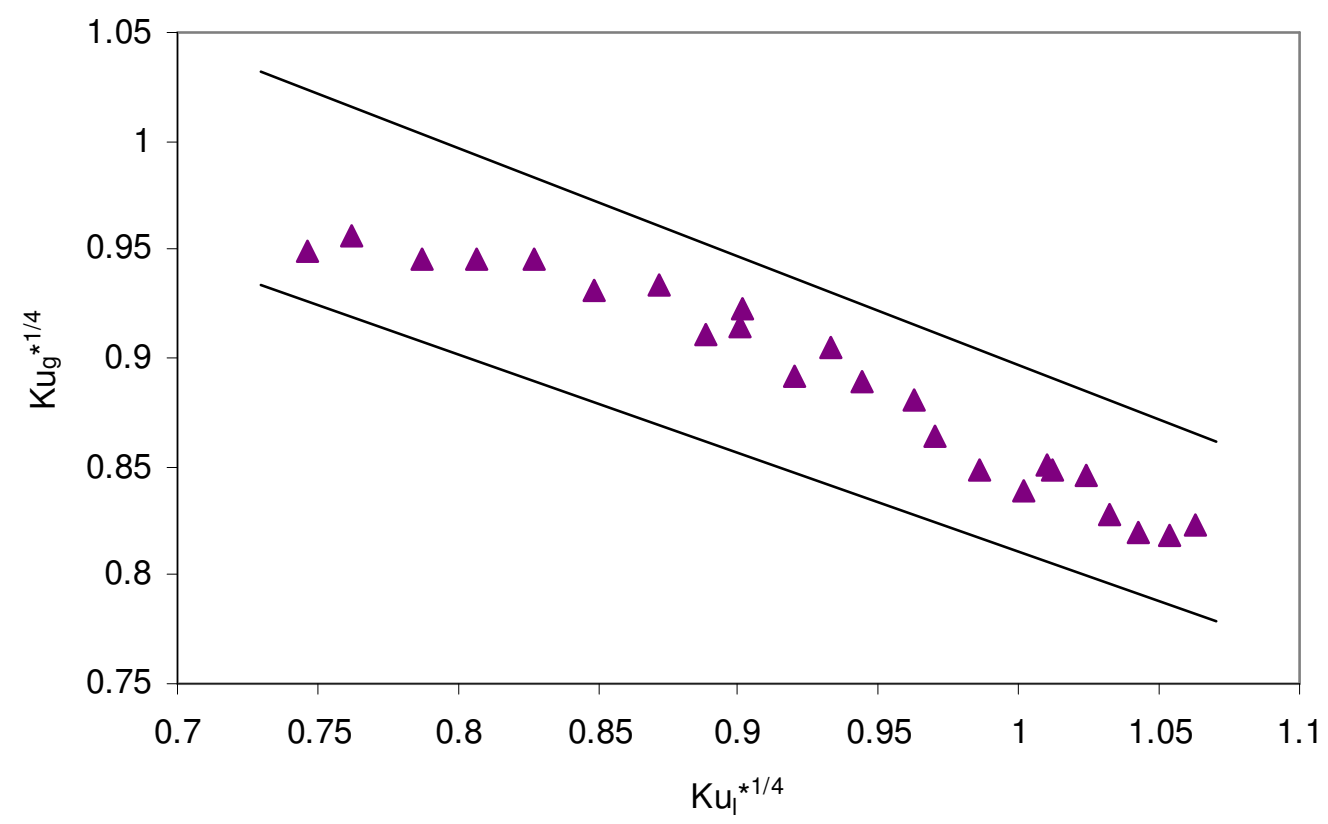

Figure 3.40 Steam-water data corrected for condensation plotted with 5\% error lines

\subsubsection{Conclusions and Future Work}

The phenomenon of countercurrent flow limitation with steam and water was investigated experimentally to acquire a useful correlation. The steam-water data obtained showed similar trends to those from air-water testing in the same facility as well as steam-water data from other facilities. These conclusions are unique in that they have not been seen for steam-water systems in large-diameter tubes. A Kutateladze type correlation was obtained to fit the steam-water data by altering the coefficients. This correlation correctly predicts the onset of flooding for a large diameter tube with water flow rates between 2.5 and 13.5 GPM.

Future work will include varying the water inlet temperature. The tests reported here were performed with the expected subcooling in the surge line. An empirical model will be developed that will take into account the temperature difference between the water and steam. Other future work could include altering the steam and water outlets. Attaching valves to both ends of the test section will allow it to be pressurized to provide data on steam-water flooding at various pressures. 


\subsection{Experiments with Inclined Tubes}

A number of experimental runs have been conducted with the test section inclined at different inclination angles with respect to the vertical. Figure 3.41 shows the schematic of the experimental setup used for providing different test section inclinations. The test section is inclined using a pulley-winch system. The entire test section rests on pillow block bearings which are rigidly mounted on the supporting structure as shown in the figure. The bearings allow for free rotation of the test section about a horizontal axis passing through the center of the pillow block bearings. A steel rope connects the winch and the test section via a pulley. By engaging/turning the handle of the winch, the test section can be smoothly brought to any desired angle of inclination. Similar to the air-water tests in a vertical test configuration, air is injected from the bottom and water is injected from the top of the test section to obtain countercurrent flow.

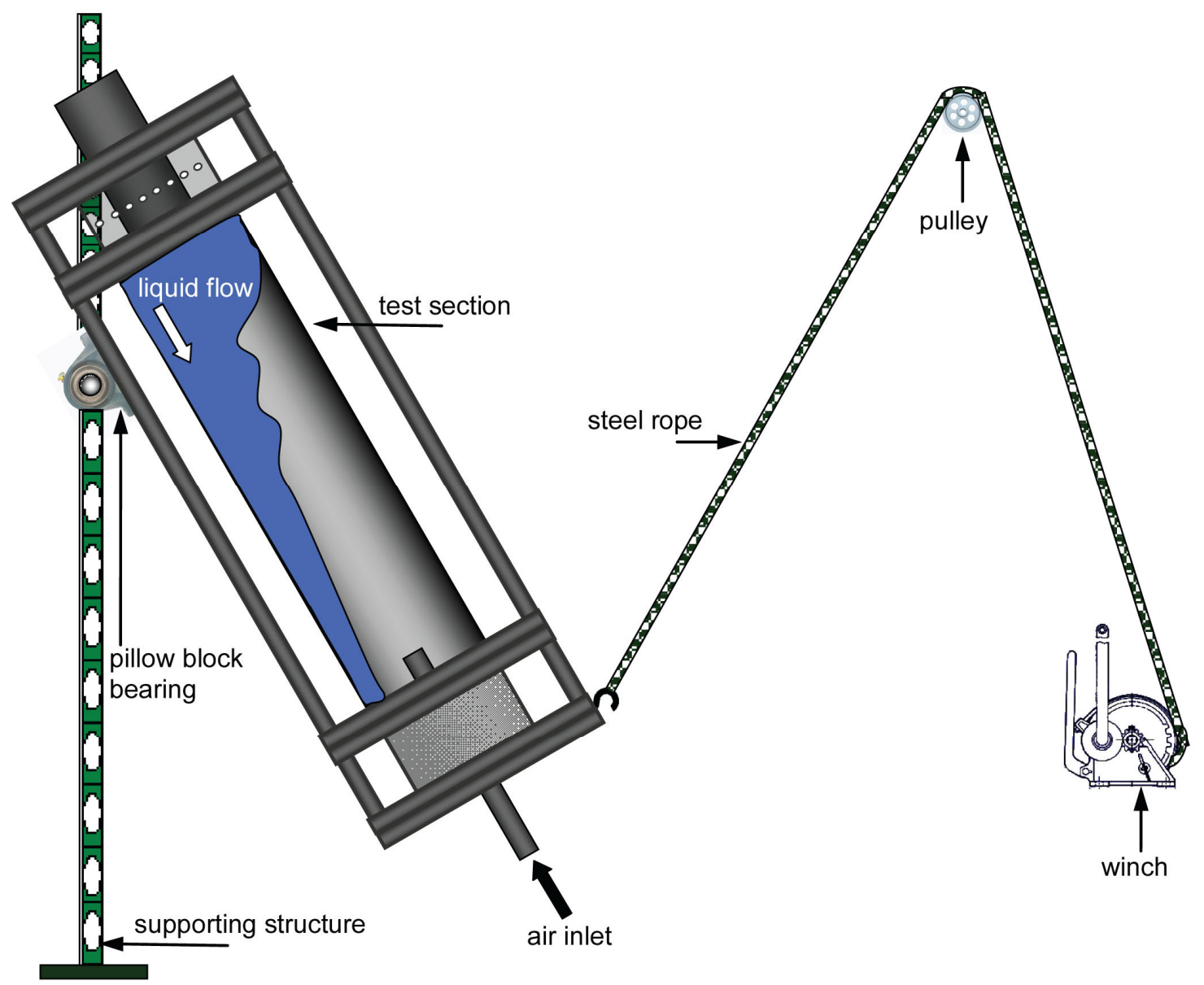

Figure 3.41 Schematic of the setup for an inclined test section

Experiments were conducted over a wide range of inclination angles. It was found during the initial shakedown tests as well as the tests conducted more recently that the falling liquid film no longer retained its annular nature when the inclination angle was increased beyond $5^{\circ}$. However, the efforts to observe flooding in the test section at different inclination angles and over a wide range of test conditions proved to be unsuccessful with the current experimental facility and setup. An investigation was conducted as to why this was occurring and is explained in the following paragraphs. 


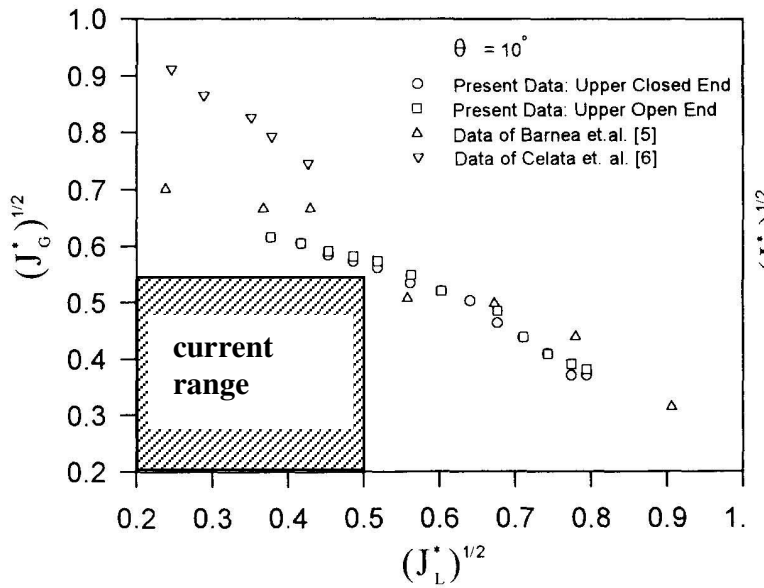

(a)

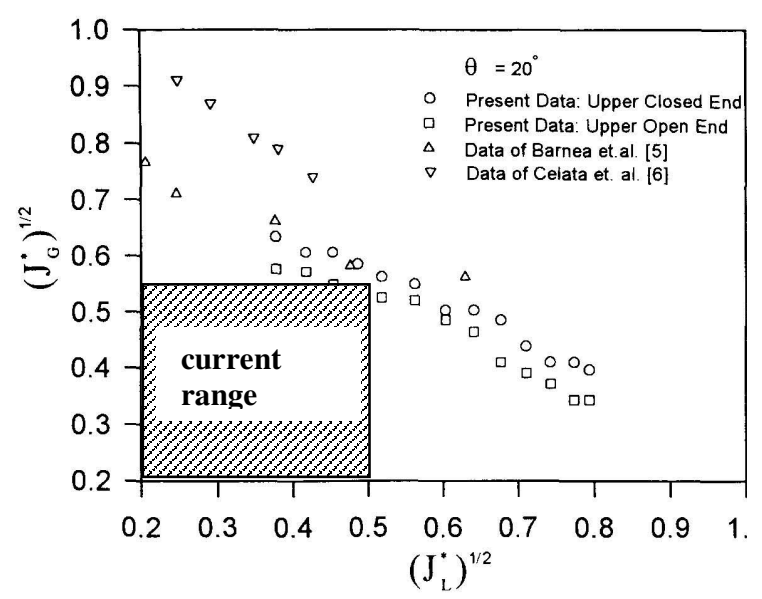

(c)

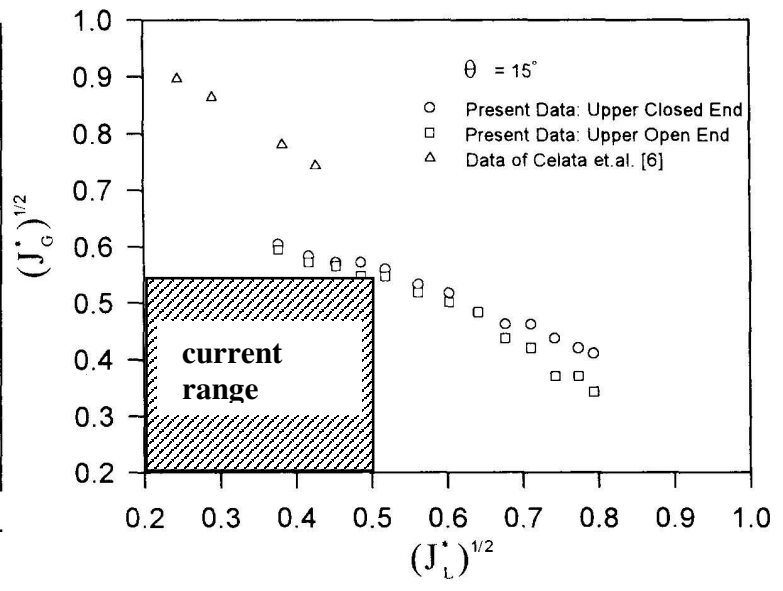

(b)

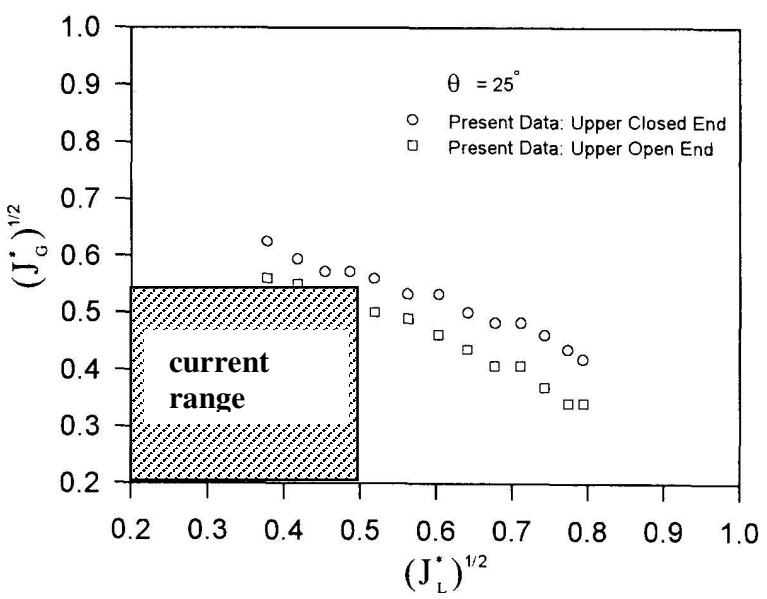

(d)

Figure 3.42 Wongwises data [53] compared with flow range of the current experimental facility

A review of the available literature $[25,30,39,53,72]$ on flooding experiments in inclined test sections revealed that the range of non-dimensional flow conditions over which flooding occurred is vastly different and higher than the range supported by the current experimental setup. Figure 3.42 $(\mathrm{a}-\mathrm{d})$ shows the data from Wongwises [53] for different inclination angles under a wide range of gas and liquid flow conditions expressed in terms of Wallis parameters $J_{G}{ }^{*}$ and $J_{L}{ }^{*}$. The data is also compared with that of Barnea et al [30] and Celata et al [72]. Also superimposed in the figure is a hatched region depicting the flow range supported by the current experimental facility. As seen from the figure, the non-observance of flooding in the present experimental setup at different inclination angles is due to the limited flow range supported by the facility. A value of $\left(J_{L}{ }^{*}\right)^{1 / 2}=0.5$ corresponds to a liquid flow rate of 15 GPM which is the maximum water flow rate that could be derived out of the city water supply available to the facility. Furthermore, the experiments of Wongwises [53] and most of those available in the literature were carried out in tubes of diameter less than $30 \mathrm{~mm}$. The test section considered in this study has a larger diameter of $76.2 \mathrm{~mm}$ (ID). This intuitively indicates that a much higher absolute gas and liquid flow rates 
are needed in larger diameter tubes to achieve flooding when compared to smaller diameter tubes in inclined configurations.

In an effort to observe flooding, the experiments were conducted at the maximum liquid and gas flow rates that the facility could support and at different inclination angles. However, no flooding was observed. Some amount of droplet entrainment was seen visually. However this was due to the water droplets that were carried out from the location where the annular water film transitioned into a stratified flow. Since the liquid film cannot retain its annular nature in an inclined configuration, the annular film breaks down and the liquid flowing on the top surface of the test section flows across the cross section of the tube and combines with the liquid flowing at the bottom surface resulting in a stratified flow. It is at this location the countercurrent flow of air intersects the path of the liquid flowing across the cross section of the tube and hence entrains droplets out of the test section. Therefore this was not considered as flooding in the experiments.

Based on the results described above for the air-water tests, it is supposed that flooding would also not be observed for the steam-water tests in an inclined configuration since the steam-water test section design is nearly a replica of the air-water test section. 


\subsection{Model Development}

\subsubsection{Application of Current Flooding Models in Reactor Safety Codes}

Current major US design basis accident safety analysis codes, RELAP5 and TRAC utilize Wallis or Kutateladze-type correlation, or a hybrid between these two flooding correlations to predict limiting flow rates in the countercurrent flow $([45,46])$. In order to utilize these correlations for safety analysis, empirical correlation coefficients are estimated from correlated data by experiments on prototypical or scaled down test facilities. Similarly, US severe accident codes such as SCDAP/RELAP5 have adopted flooding models based on Wallis-type correlations. In MELCOR, the flooding curve is used to generate co-current interfacial friction parameters ([59]), as opposed to a direct estimation of flooding occurrence.

\subsubsection{Empirical Model Development for Air-Water System}

As discussed with regard to correlation development, the physics and the fluid properties may be represented by the Froude number and the Ohnesorge number.

The Froude number is the ratio of inertial to buoyancy forces. To correlate flooding data, the Froude number has been calculated based on the relative velocity of the fluids. Since the tube is considered a large-diameter tube, radial effects are expected to be minimal and a more appropriate characteristic length is the film thickness. A modified Froude number is defined as below.

$$
F r_{m}=F r\left(\frac{\delta}{D}\right)^{-2}
$$

The film thickness is obtained from a formulation by Belkin et al. [60] for annular flow along vertical walls:

$$
\delta=0.135 \frac{v_{f}{ }^{2 / 3}}{\left[g\left(1-\frac{\rho_{g}}{\rho_{f}}\right)\right]^{1 / 3}} \operatorname{Re}_{f}{ }^{7 / 12}
$$

where the liquid Reynolds number is defined as:

$$
\operatorname{Re}_{f}=\frac{j_{f} D}{v_{f}}
$$

and the superficial liquid velocity is the ratio of liquid volumetric flow rate over flow area.

The Ohnesorge number is a ratio of liquid viscous to surface tension properties. Here too, the liquid film thickness is a more appropriate characteristic length than the tube diameter. The Ohnesorge number has been calculated as:

$$
O h_{f}=\sqrt{\frac{\mu_{f}^{2}}{\rho_{f} \delta \sigma}}
$$

The data obtained in this investigation has been correlated in the following form: 


$$
F r_{m}^{0.1}-0.1 m O h_{f}=C_{\text {exp }}
$$

where the constants $m$ and $C_{\text {exp }}$ are $1.17 \times 10^{3}$ and 1.93 respectively.

$$
\mathrm{Fr}_{m}{ }^{0.1}-1.17 \times 10^{3} \mathrm{Oh}_{f}=1.93
$$

Figure 3.43 shows the linearity of the data due to the exponent on the modified Froude number. The error bars show the error of about $3 \%$. The error bands represent $+/-5 \%$ uncertainty.

The new correlation was validated against the experimental data of Lacy and Dukler [44]. These data were obtained for an aqueous $\mathrm{NaCl}$ solution $(0.12 \mathrm{wt} \%)$ which was released through a porous tube section into a $50.8 \mathrm{~mm}$ inner diameter acrylic tube in annular flow. Air was injected at the bottom of the acrylic tube. This study concluded that wave growth and bridging across larger diameter tubes is not the initiating mechanism for flooding. In the Lacey experiment, a change of direction of the liquid film velocity distribution in the region of the porous-tube water feed zone was studied by film thickness and pressure gradient measurements. The mechanism for this change of direction was suggested as the cause of flooding.

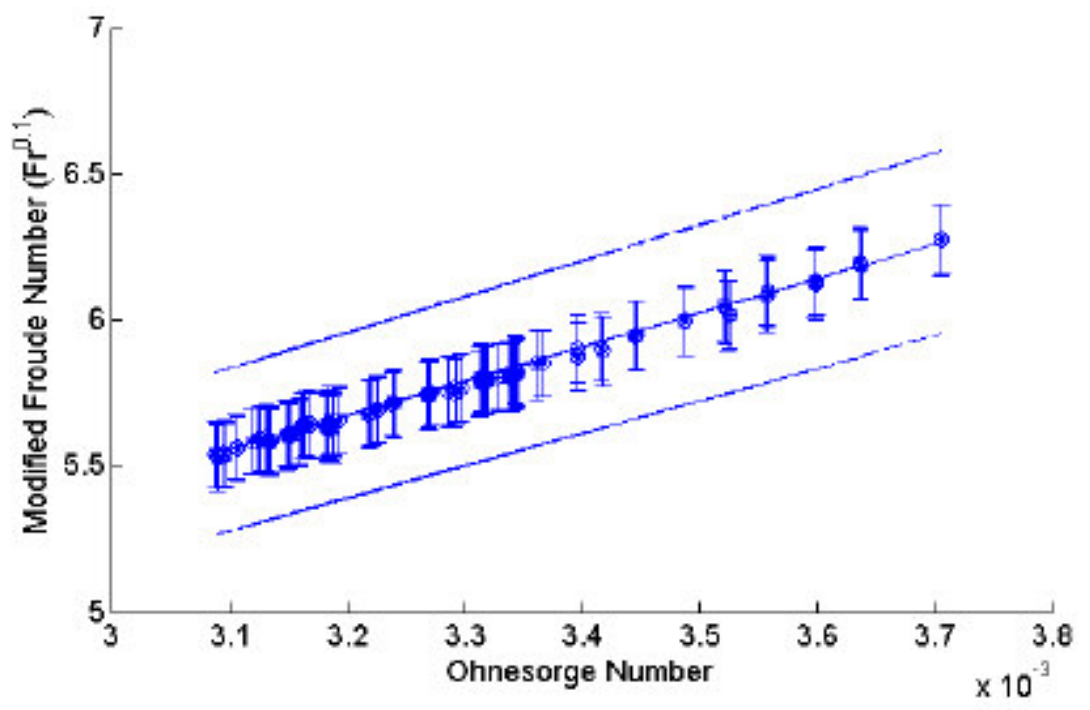

Figure 3.43 Modified Froude Number vs. Onhesorge Number for Current Experimental Data 


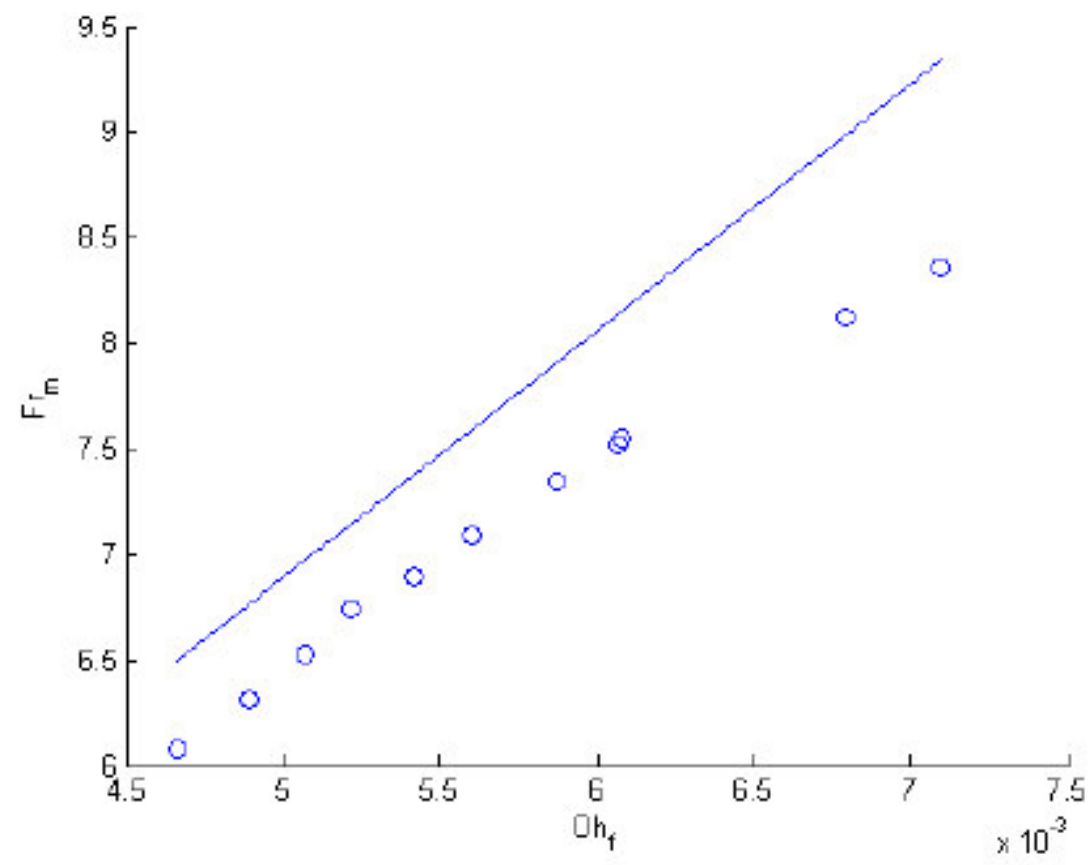

Figure 3.44 Comparison of New Correlation against Lacy [44] Data

Since this data had similar conditions as the present experiment, calculations by the proposed correlation were compared against the Lacy data. Figure 3.44 reveals in a plot of modified Froude number vs. Ohnesorge number that the trend is reproduced well. The average difference between data and analysis is $7.9 \%$ overprediction. At low Ohnesorge numbers, the error is about $6 \%$, increasing to about $11 \%$ at the upper end of the range. Possible sources for the discrepancies are the water injection method and the tube diameter. Lacy's tube diameter of $50.8 \mathrm{~mm}$ is below Vijayan's proposed large-diameter criteria of $67 \mathrm{~mm}$.

While the correlation provides reasonable results, the authors are pursuing data collection over a wider range of liquid and air flow rates to cover a wider range of operating conditions.

The empirical models for flooding are generally of forms that are readily incorporated into reactor safety codes. Considering the incorporation of the air-water correlation into the MELCOR code as an example, the parameters in equations (3.34) through (3.39) are all available during MELCOR calculations or are defined within this set of equations.

\subsubsection{Mechanistic Modeling of Flooding - General Considerations}

Regarding mechanistic models, Bankoff [19] categorized potential flow models of flooding as stability theories of a traveling wave. These potential flow models are used to calculate flooding criteria based on interfacial instability. Models that fit into the category of potential flow models include Imura [23], Tien [61], Yao [62], and Shibata [63]. Each of these models employs assumptions that are not consistent with the physics of flooding [19]. The model developed by Imura [23] relies on an empirical correlation for the mean film thickness and the dimensionless wave number. In his model, Tien [61] neglected the curvature of the tube and flow pattern. Closure relations for this model are a function of the wave number which makes his correlation empirical in this regard. Yao [62] defines flooding as a scenario in which there is no liquid penetration beyond the gas flow. This is not a conservative assumption when analyzing flooding in nuclear reactors. Yao also uses a simplified dynamic interface condition that is not representative of the shape of the interface. The analyses of Imura, Tien, and Yao all rely on 
linearized kinematic conditions at the gas-liquid interface. Shibata [63] compared linear and nonlinear kinematic conditions at the interface and found that the non-linear condition yields a better result when compared to experimental data. The model Shibata derived from non-linear analysis is in rectangular coordinates and does not capture the unique mathematical properties of stability analysis on cylinders. Both the classic stability analysis of a stationary jet by Rayleigh (original reference not available) and the analysis of Imura [23] find that the stability criteria of cylindrical systems are expressed in terms of modified Bessel functions, which do not arise from stability analysis in a rectangular plane. The model based on the non-linear analysis of Shibata consists of many terms and is not efficient to solve.

Previous work indicates that a comprehensive physics-based model for the prediction of flooding based on Kelvin-Helmholtz stability criteria should consider phenomena in a cylindrical coordinate system, account for curvature of the interface, use non-linear kinematic conditions and not require empirical closure relations. The development of this stability-based model would allow for the prediction of flooding based on the premise that flooding is caused by the need for momentum of the liquid and gas flows to be conserved. A change of the void fraction in the system affects the closure relations of this momentum balance by reducing the flow area of the gas, increasing the flow area of the liquid, and reducing the interfacial area between the fluids. This means that a theoretical flooding curve can be generated by calculating the gas superficial velocity for a given liquid superficial velocity using both the conservation of momentum equations for the liquid film and gas core and the Kelvin-Helmholtz stability analysis and finding the minimum of those two values.

\subsubsection{Mechanistic Model for Air-Water Systems - Effect of Tube Inclination}

A physics-based model with simplifying assumptions was developed (Liao and Vierow, [1]) for evaluating the effect of inclination angle on the occurrence of flooding for adiabatic systems. For a given liquid superficial velocity in the countercurrent flow system of the pressurizer surge line, the gas superficial velocity should be as large as possible at the onset of flooding, so that the steam can vent as fast as possible without inhibiting the pressurizer drain rate. Therefore, the system could depressurize in a timely manner to initiate ECCS actuation. As indicated by flooding experiments, for a given liquid superficial velocity, the gas superficial velocity attains a greatest value at a certain channel inclination, which is defined as the optimum channel inclination. The analytical model was proposed to predict the optimum channel inclination under simplified conditions. The model predictions compare favorably with experimental data.

Recently, Zapke and Kroger [15] performed experiments on air-water flooding under ambient conditions, in an inclined and roughly rectangular channel with a height of $100 \mathrm{~mm}$ and width of $10 \mathrm{~mm}$. The inclination angle varied from 0 to 90 degrees. Their experiment results are replicated here in Fig 3.47 to illustrate the phenomenon of the optimum channel inclination for gas venting under flooding conditions. Each data point in figure 3.45 represents the gas and liquid superficial velocities upon occurrence of flooding in the channel with a certain inclination angle. Data points were grouped by the liquid superficial velocity. For each group of data points, the gas superficial velocity increases with increasing inclination angle until it attains a maximum value at the optimum channel inclination, and then decreases with increasing inclination. 


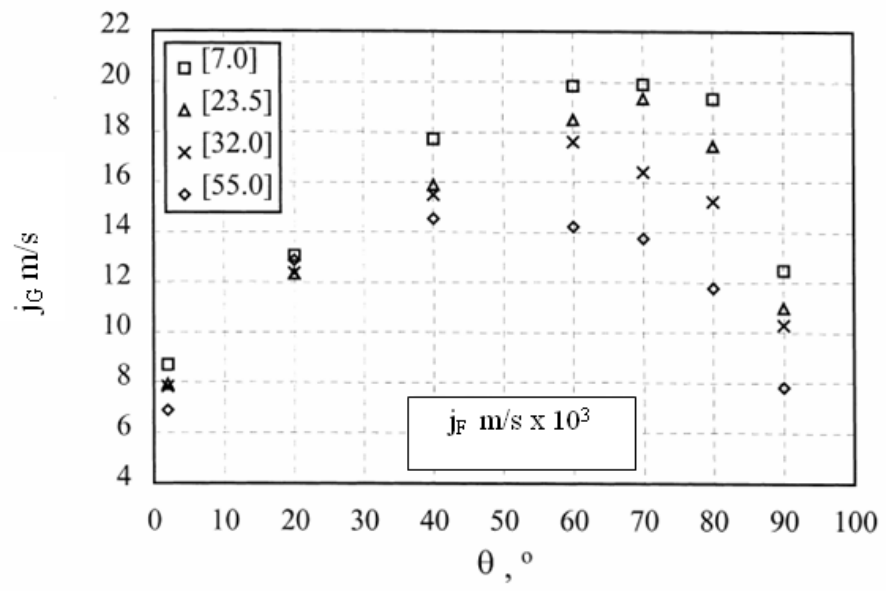

Figure 3.45 Optimum Channel Inclination for Gas Venting in Zapke's Experiments [15]

The analytical model starts with expressing the gas superficial velocity upon occurrence of flooding in inclined channels as a function of the channel inclination and liquid film thickness by using the criterion for the Kelvin-Helmholtz instability. Then the liquid film thickness is again derived as a function of the channel inclination by a laminar flow analysis. Upon combining the above two steps, the gas superficial velocity reduces to a concave function of the channel inclination. By maximizing this function with respect to the inclination angle, the optimum channel inclination for the maximum gas superficial velocity at the onset of flooding can be obtained.

The model was developed with the following simplified assumptions: the liquid velocity is much less than the gas velocity; the liquid flow can be analyzed by using laminar flow assumptions; the liquid film thickness is much less than the channel height.

Consider a stratified countercurrent flow system in figure 3.46, where the gas phase flows upward and the liquid phase flows downward. The channel cross section is rectangular with a height of $\mathrm{H}$ and a width of $\mathrm{W}$. The coordinate $\mathrm{z}$ is along the liquid flow direction and $\mathrm{y}$ is perpendicular to the flow direction. Now focus on a wave existing on the interface. As the gas accelerates, the pressure in the gas phase over the wave decreases owing to the Bernoulli effect so that the wave tends to grow. On the other hand, the gravity component normal to the interface stabilizes the wave and inhibits the wave growth. If the dynamic pressure effect is greater than the gravity effect, the wave amplitude will continue to increase and eventually the wave will be swept upward in the gas direction. Thus the onset of flooding occurs as a result of the Kelvin-Helmholtz instability.

Taitel and Dukler [28] firstly proposed a theoretical model to predict the flow regime transition by using the criterion for the Kelvin-Helmholtz instability. The Taitel and Dukler model has been used as the criterion for the onset of flooding in an inclined channel by other researchers $[2,30]$ :

$$
V_{G}=\left(1-\frac{h_{L}}{H}\right) \sqrt{\frac{A_{G}\left(\rho_{L}-\rho_{G}\right) g \cos \theta}{\rho_{G}\left(d A_{L} / d h_{L}\right)}}
$$

For a rectangular channel, equation (3.40) can be simplified by using $A_{G}=\left(1-h_{L} / H\right) A$ and $d A_{L} / d h_{L}=A / H$, and reduced to 


$$
V_{G}=\left(1-h_{L} / H\right)^{3 / 2} \sqrt{\frac{\left(\rho_{L}-\rho_{G}\right) g H \cos \theta}{\rho_{G}}}
$$

Using $j_{G}=\alpha V_{G}$ and $\alpha=1-h_{L} / H$, equation (3.41) can be recast as

$$
j_{G}^{2}=\left(1-h_{L} / H\right)^{5} \frac{\left(\rho_{L}-\rho_{G}\right) g H \cos \theta}{\rho_{G}}
$$

In most CCFL experiments inside inclined channels, the gas superficial velocity is much larger than that of the liquid phase and thus the film thickness is much less than the channel height. Therefore, the right hand side of equation (3.42) can be simplified by using the Taylor series expansion and the first order approximation on the film thickness

$$
j_{G}^{2}=\left(1-5 h_{L} / H\right) \frac{\left(\rho_{L}-\rho_{G}\right) g H \cos \theta}{\rho_{G}}
$$

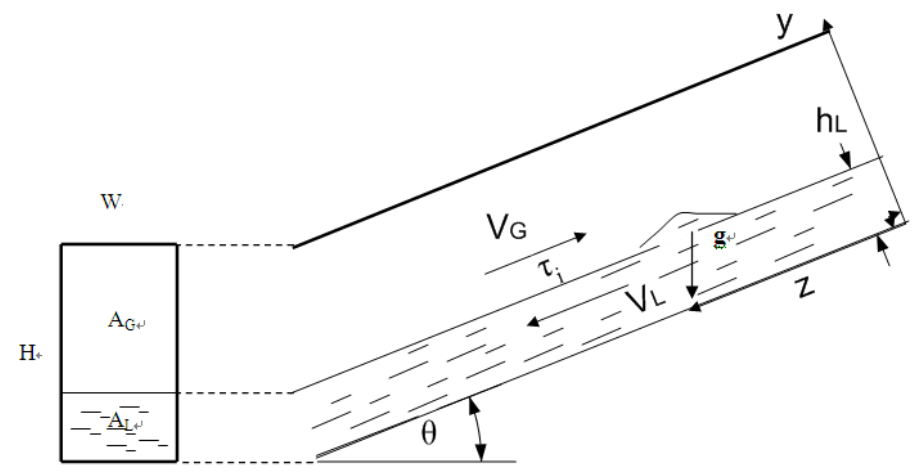

Figure 3.46 Coordinate System for Countercurrent Flow in a Rectangular Inclined Channel

The liquid film thickness in Equation (3.43) may be approximated by using the laminar flow analysis. As shown later, the liquid Reynolds number for the test data in figure 3.45 falls into the laminar range, which justifies using the laminar liquid flow assumptions to analyze the data in figure 3.45. A solution for the liquid velocity profile can be obtained by using the steady state momentum balance on the liquid phase

$$
0=-\frac{d p}{d z}+\mu_{L} \frac{d^{2} V_{L}(y)}{d y^{2}}+\rho_{L} g \sin \theta
$$

with the boundary conditions

$$
\begin{aligned}
& y=0, V_{L}=0 ; \\
& y=h_{L}, \mu_{L} \frac{d V_{L}}{d y}=-\tau_{i}
\end{aligned}
$$

The solution of equation (3.44) subject to the boundary conditions in equation (3.45) is 


$$
V_{L}(y)=\frac{\rho_{L} g \sin \theta-d p / d z}{\mu_{L}} y\left(h_{L}-y / 2\right)-\frac{\tau_{i}}{\mu_{L}} y
$$

The average liquid mass flux through the film thickness can be obtained by using equation (3.46)

$$
\begin{aligned}
& m_{L}=\frac{\rho_{L}}{h_{L}} \int_{0}^{h_{L}} V_{L}(y) d y \\
& =\frac{\rho_{L}\left(\rho_{L} g \sin \theta-d p / d z\right) h_{L}^{2}}{3 \mu_{L}}-\frac{\rho_{L} \tau_{i} h_{L}}{2 \mu_{L}}
\end{aligned}
$$

At the onset of flooding, the average liquid mass flux can be assumed zero. Setting the right hand side of equation (3.47) to zero, one obtains the liquid film thickness at the onset of flooding

$$
h_{L}=\frac{3 \tau_{i}}{2\left(\rho_{L} g \sin \theta-d p / d z\right)}
$$

The pressure gradient in equation (3.48) is typically much less than the liquid gravity head for flows in a smooth channel, therefore it can be neglected if the optimum channel inclination is not very close to the horizontal. Inserting equation (3.48) into equation (3.43), one obtains

$$
j_{G}^{2}=\left(1-\frac{7.5 \tau_{i}}{\rho_{L} g H \sin \theta}\right) \cos \theta \frac{\left(\rho_{L}-\rho_{G}\right) g H}{\rho_{G}}
$$

Now the gas superficial velocity at the onset of flooding has been expressed as a concave function of the channel inclination. The optimum channel inclination is obtained from maximizing the gas superficial velocity with respect to the channel inclination angle

$$
\frac{d\left(j_{G}^{2}\right)}{d \theta}=\left(-\sin \theta+\frac{7.5 \tau_{i}}{\rho_{L} g H(\sin \theta)^{2}}\right) \frac{\left(\rho_{L}-\rho_{G}\right) g H}{\rho_{G}}
$$

Setting the right hand side to zero, one obtains the optimum channel inclination

$$
\sin \theta^{*}=\left(7.5 \tau_{i} / \rho_{L} g H\right)^{1 / 3}
$$

The existence of the optimum channel inclination is the combined effects of conflicting mechanisms that govern the onset of flooding inside inclined channels. As the channel inclination varies from horizontal to vertical, the liquid film thickness in equation (3.48) becomes smaller. Consequently, the interfacial shear stress also decreases since the roughness of the interface decreases with a smaller film thickness. These effects result in increasing gas superficial velocity at the onset of flooding. The gas superficial velocity also increases due to the increasing gravity component tangent to the interface which has to be overcome in the direction of the gas flow. On the other hand, the gravity component normal to the interface diminishes, therefore the interfacial waves tend to be more unstable and the tendency for the onset of flooding is enhanced as the 
channel inclination varies from horizontal to vertical. Consequently, the gas flooding velocity tends to decrease.

The relative importance of these mechanisms determines the optimum channel inclination. As a result shown in equation (3.51), the optimum channel inclination varies with the interfacial shear stress, channel geometries, and fluid properties. The interfacial shear stress can be calculated by closure equations introduced in the next section.

\section{CLOSURE EQUATIONS}

The interfacial shear stress for countercurrent flow is evaluated in a conventional manner

$$
\tau_{i}=\frac{f_{i} \rho_{G}\left(V_{G}-V_{L}\right)^{2}}{2}
$$

Barnea el al. [30] applied an empirical correlation proposed by Wallis et al. [64] for the interfacial friction factor to the analysis of countercurrent flows in an inclined channel

$$
f_{i}=0.005+24(1-\alpha)^{2.04}
$$

The next step is to use a CCFL compatible drift-flux model developed by Ohkawa and Lahey [65] to calculate the gas void fraction

$$
\begin{aligned}
& V_{G j}=\frac{V_{0} C_{0}\left(1-C_{0} \alpha\right)}{m^{2}\left(1-C_{0} \alpha\right)+C_{0} \alpha \sqrt{\rho_{G} / \rho_{L}}} \\
& V_{0}=K u_{c r i t} \sqrt[4]{g \sigma\left(\rho_{L}-\rho_{G}\right) / \rho_{L}^{2}}
\end{aligned}
$$

where $C_{0}$ is approximately equal to 1.2 for a round pipe and 1.35 for a rectangular channel [66]; $\mathrm{m}$ and $K u_{\text {crit }}$ satisfy the Kutateladze type CCFL correlation

$$
\sqrt{K u_{G}^{*}}+m \sqrt{K u_{L}^{*}}=\sqrt{K u_{c r i t}}
$$

$\mathrm{m}$ is generally correlated from experiment data and $K u_{\text {crit }}$ was given in Table 3.8 [67]. Without loss of generality, $m$ is chosen to be 1 in this analysis.

Table $3.8 K u_{c r i t}$ as a Function of $\mathrm{D}^{*}$

\begin{tabular}{|c|r|r|r|r|r|r|r|}
\hline $\mathrm{D}^{*}$ & $<2$ & 4 & 10 & 14 & 20 & 28 & $>50$ \\
\hline $\mathrm{Ku}_{\text {crit }}$ & 0 & 1 & 2.1 & 2.5 & 2.8 & 3 & 3.2 \\
\hline
\end{tabular}

Upon defining $C_{1}=C_{0}\left(1-\sqrt{\rho_{G} / \rho_{L}}\right)$ and using the definition $V_{G j}=V_{G}-j=j_{G} / \alpha-\left(j_{G}+j_{L}\right)$ for the drift-flux parameter, equation (3.54) can be rewritten as 


$$
\left(C_{1} \alpha-1\right) j_{G}=\left(V_{0} C_{0}^{2}+C_{1} j\right) \alpha^{2}-\left(V_{0} C_{0}+j\right) \alpha
$$

For a given value of $\alpha$, the locus of possible values of $j_{G}$ and $j_{L}$ determined by equation (3.56) form a straight line, referred to as a drift flux line. The boundary of the region formed by the envelope of the drift-flux lines is called the flooding curve, and defines the limit of quasi-steady countercurrent flow. The corresponding gas superficial velocity at the flooding point was given parametrically as a function of $\alpha$ by the equation (3.58)

$$
j_{G}=j_{G L}-a \frac{\mathbb{I} j_{G L}}{\mathbb{I} a}
$$

Upon using the definition, $j_{G L}=j_{G}-a j$, and equation (3.56) the locus of flooding points also satisfy [68]

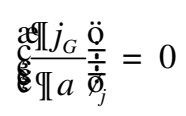

Carrying out derivatives on both sides of equation (3.56) with respective to $\alpha$, and combining equation (3.58), one obtains the void fraction at the flooding point

$$
\alpha=\frac{V_{0} C_{0}+j_{G} C_{1}+j}{2\left(V_{0} C_{0}^{2}+C_{1} j\right)}
$$

\subsubsection{Model Validation against Experimental Data}

The model for predicting optimum venting angle in air-water systems was validated against experimental data. The optimum channel inclination can be predicted by using Eqns. (3.51), (3.52), (3.53) and (3.59), as well as flooding curves with gas and liquid superficial velocities obtained from experiments as shown in figure 3.45. Since the channel geometries and fluid properties are available from experimental data, the parameters $V_{0}, C_{0}$ and $C_{1}$ in equation (3.59) can be easily calculated and the void fraction follows. The interfacial shear stress can be calculated by equation (3.52) with the help of equation (3.53). Finally, the theoretically predicted optimum channel inclination can be found by using equation (3.51).

The optimum channel inclination inferred from experimental data can be obtained by reading the flooding curves. In Zapke's experimental data [15] shown in figure 3.45, for instance, corresponding to a $7.0 \mathrm{E}-3 \mathrm{~m} / \mathrm{s}$ liquid superficial velocity, the optimum channel inclination inferred from the experiment data is 70 degrees, at which the gas superficial velocity attains a maximum value equal to $20.0 \mathrm{~m} / \mathrm{s}$. It is noted that the liquid superficial velocity is much less than that of the gas, which was assumed in the model development. The optimum channel inclinations for other flooding curves in figure 3.45 could be inferred with a similar way. Table 3.9 lists the optimum channel inclinations inferred from experimental data in figure 3.45, as well as the gas and liquid superficial velocities occurred at the optimum channel inclination. Liquid phase Reynolds numbers are calculated by $\operatorname{Re}_{L}=\rho_{L} j_{L} D_{h} / \mu_{L}$.

It is noted from Table 3.9 that the liquid Reynolds number falls into the laminar range, which justifies the assumption in deriving the film thickness in the current model development. Upon using the procedure described in the first paragraph of this section, the optimum channel 
inclination was predicted and listed in Table 3.10. The predictions compare favorably with experimental data.

Table 3.9 Comparison of Optimum Channel Inclinations in the theory and Zapke's data [15]

\begin{tabular}{|c|c|c|c|c|}
\hline $\operatorname{Re}_{\mathrm{L}}$ & $\begin{array}{c}\mathrm{j}_{\mathrm{F}} \\
(\mathrm{m} / \mathrm{s})\end{array}$ & $\begin{array}{c}\mathrm{j}_{\mathrm{G}} \\
(\mathrm{m} / \mathrm{s})\end{array}$ & $\begin{array}{c}\theta^{*} \text { (degree), } \\
\text { Experiment }\end{array}$ & $\begin{array}{c}\theta^{*} \\
(\text { degree), } \\
\text { Theory }\end{array}$ \\
\hline 149 & 0.007 & 20.0 & 70 & 70.5 \\
\hline 500 & 0.024 & 19.5 & 70 & 67.8 \\
\hline 681 & 0.032 & 17.5 & 60 & 59.9 \\
\hline 1170 & 0.055 & 14.5 & 40 & 50.2 \\
\hline
\end{tabular}

The other two experiments conducted for a full range of inclinations from 0 to 90 degrees were performed by Hewitt [50] and Barnea et al. [30]. These experiments were also performed with air-water fluids under ambient conditions, but in a pipe with a circular cross section. Some of the liquid Reynolds numbers in these two experiments fall into the turbulent range, which invalidates the assumption of laminar flow. However, to test the robustness of the analytical model, the optimum channel inclinations in these two experiments were also used to compare with the analytical predictions.

Figure 3.47 shows the comparisons of predictions and experimental data with results grouped by the experiment author. Figure 3.48 shows the comparison results grouped by the liquid Reynolds number. Apparently, the analytical model works better for the liquid Reynolds numbers in the laminar range. The analytical model works best for the Zapke's experimental data [15], since in this experiment all liquid Reynolds numbers were in the laminar range and the channel had a roughly rectangular cross section, which is consistent with the assumptions used in the theoretical model development. Greater data scattering are observed for comparing with Hewitt's [50] and Barnea's [30] experimental data. One possible reason for this greater data scattering is the assumption of a rectangular cross section in the analytical model, while the channel had a circular cross section in both Hewitt's [50] and Barnea's experiments. Another reason is some of the liquid Reynolds numbers in these experiments were above the laminar range.

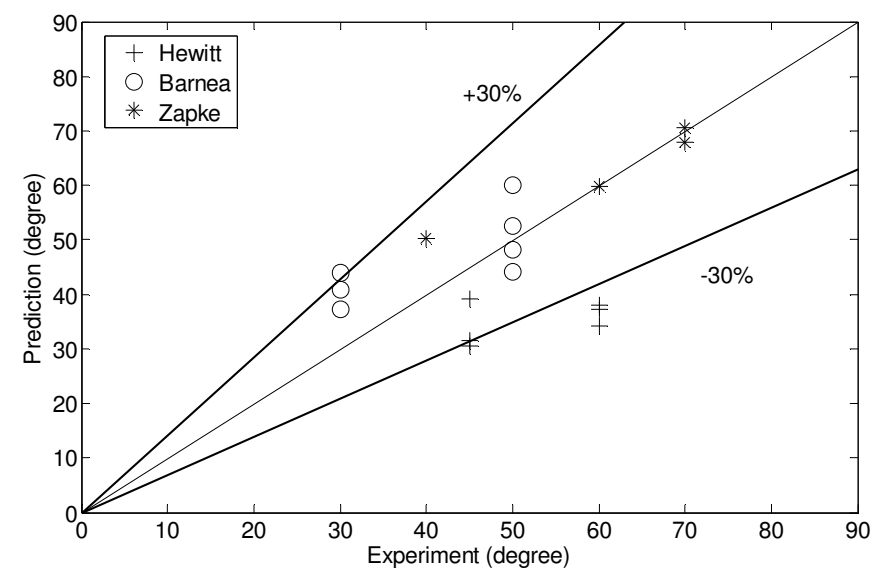

Figure 3.47 Comparison Results: Data Grouped by Experiment Author 


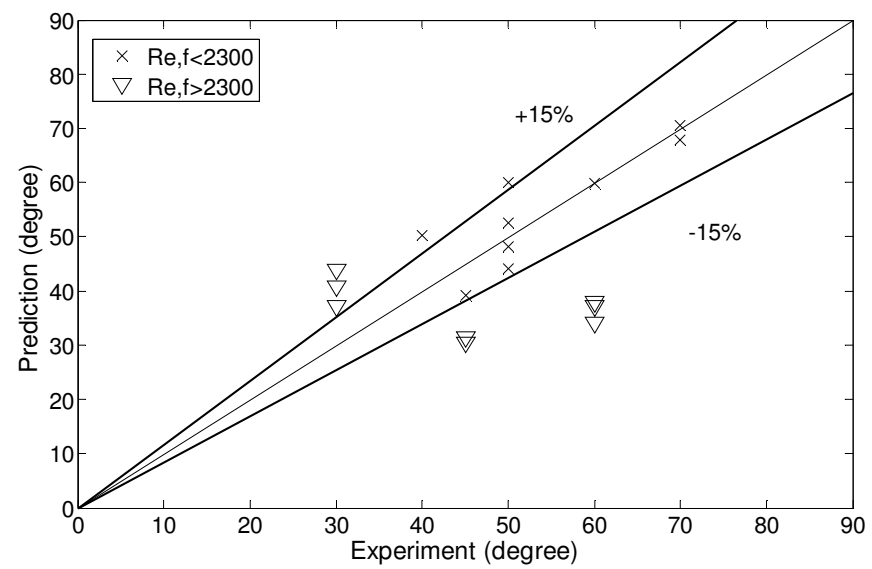

Figure 3.48 Comparison Results: Data Grouped by Liquid Reynolds Number

Comparison results show that the model can predict published experimental data satisfactorily, and the model behaviors in a consistent way with its underlying assumptions. The model may be used for the design of an inclined countercurrent flow system such as the pressurizer surge line, where gas venting and liquid draining are crucial for the functionality of Emergency Core Cooling Systems.

\subsubsection{Mechanistic Model for Steam-Water Systems - Effect of Condensation}

The current experimental program results for large diameter tubes are consistent with those of Wallis [84], who performed complementary air-water and steam-water tests. Specifically, the two sets of data show many similarities. Further, the steam-water data indicates that once the steam has transferred enough energy to raise the water temperature to saturation, the flooding phenomena is hydrodynamically controlled.

As a first approach, the dimensionless Wallis and Kutateladze parameters may be used, with a modified steam flooding velocity to account for the decrease of steam flow rate by condensation. However the constants in these correlations are known to lack general applicability. Secondary effects such as material properties and geometry are also not included [84].

The general considerations mentioned above for mechanistic models must be followed, with the addition of formulations for determining where the water has achieved saturation, and to account for the effect of water temperature when subcooling persists. In the steam-water experiments, the wall surface thermocouple nearest to the steam inlet approached the saturation temperature just prior to flooding. Therefore, flooding is hypothesized to be occurring near the steam entrance to the test section.

\subsubsection{Additional Considerations for Flooding in the Surge Line}

Prediction of flooding in the pressurizer surge line involves additional factors not included in the current study, namely:

- the complex geometry of the surge line

- various possible configurations for water entrance into the surge line

- high temperature and pressure condition during severe accidents, where the fluid properties and two-phase interactions are different from those at experimental conditions. 
Rothe and Crowley [69] addressed pressure scaling issues. They concluded that for saturated water behavior in small-scale facilities, the dimensionless Wallis $j *$ parameters properly scale the effect of system pressure.

Siddiqui and Banerjee [70] and Ardron and Banerjee [71] investigated the location of flooding when the piping system is not a straight tube. They concluded the flooding will preferentially occur downstream of bends in the piping. A hydraulic jump that formed downstream of an elbow resulted in unstable wave formation that induced flooding in air-water systems. The gas flow rates for flooding were lower than those expected in straight vertical tubes. The flooding velocity depended on tube diameter, length, inclination and elbow radius Siddiqui and Banerjee [70]. Ardron and Banerjee [71] developed a theoretical model to predict flooding as a function of dimensionless parameters including void fraction, dimensionless volumetric fluxes of each phase, Reynolds number and property ratios. 


\section{Conclusions}

All of the goals and objectives of the project except for testing at various tube inclinations were successfully completed. The primary technical goals of the work were:

1. to investigate the effects of condensation and tube inclination on countercurrent flow limitation for geometries and conditions applicable to the pressurizer surge line

2. to advance the understanding of flooding mechanisms

3. to develop modeling methods for use in nuclear reactor safety codes

Unique data sets in large diameter, vertical tubes which represent a scaled down pressurizer surge line were obtained. Steam-water experimental results indicate that, as for smaller diameter tubes, the flooding phenomenon is predominantly driven by the hydrodynamics. The tests were run with an inlet water subcooling of about $30^{\circ} \mathrm{C}$, compared to the predicted $25^{\circ} \mathrm{C}$ for a station blackout event in a PWR. For certain combinations of liquid flow rate and steam flow rate, flooding was not observed until the test section heated up and the water temperatures reached the saturation temperature. Once saturation was achieved, the steam no longer condensed and flooding was observed. As long as enough condensation occurred to reduce the steam momentum, flooding was not observed.

The three sets of data, air-water in the acrylic facility, air-water in the stainless steel facility, and steam-water in the stainless steel facility, formed the bases for empirical correlations to predict the occurrence of flooding. The correlations are functions of the traditional Wallis parameters, the Kutateladze numbers and dimensionless parameters which better represent the phenomena than the earlier methods of correlating.

The methods for developing a mechanistic model for the onset of flooding are discussed in this report, along with the applicability of the new data under expected surge line conditions.

Tests with the test sections inclined were attempted but the annular film was easily disrupted. In part because the steam-water facility is opaque and minimal data could be obtained, further testing under inclined conditions was not pursued. However, a mechanistic model for gas venting in inclined tubes was proposed and validated against air-water data in smaller diameter tubes.

The applicability of this data to surge line conditions and geometries is discussed. The test facilities have been scaled down to reproduce most aspects of expected behavior except the fluid density ratio and tube bends. Flooding has been shown by other researchers to occur downstream of tube bends. This aspect of flooding was not studied herein. 


\section{References}

[1] Y. Liao and K. Vierow. Optimum channel inclination for gas venting under countercurrent flow limitations. in International Conference on Nuclear Engineering 14, number 14-89665, Miami, FL 2006.

[2] K Takeuchi, Young M.Y., and Gagon A.F. Flooding in the pressurizer surge line of ap600 plant and analyses of apex data. Nucl. Eng. Des., 192:(1999)45-58.

[3] N.E. Todreas and M.S. Kazimi. Nuclear Systems I: Thermal Hydraulic Fundamentals, volume 2. Taylor \& Francis, 1993.

[4] J.R. Lamarsh and A.J. Baratta. Introduction to Nuclear Engineering. Prentice Hall, 2001.

[5] Y. Liao and K. Vierow. Melcor analysis of steam generator tube creep rupture in station blackout severe accident. Nuclear Technology, 152(2005):302-313.

[6] K.W. McQuillan and P.B. Whalley. Comparison between flooding correlations and experimental flooding data for gas-liquid flow in vertical circular tubes. Chem. Eng. Sci., 40(1985):1425-40.

[7] G.B. Wallis. Flooding velocities for air and water in vertical tubes. Technical report, AEEWR-123, United Kingdom Atomic Energy Authority. Reactor Group. Atomic Energy Establishment, Winfrith, Dorset, 1961.

[8] T.K. Sherwood, G.H. Shipley, and F.A.L. Holloway. Flooding velocities in packed columns. Industrial and Engineering Chemistry, 30(1938):765-769.

[9] R. Clift, C.L. Pritchard, and R.M. Nedderman. The effect of viscosity on the flooding conditions in wetted wall columns. Chem. Eng. Sci., 21(1966):87-95.

[10] M. Vijayan, S. Jayanti, and A.R. Balakrishnan. Effect of tube diameter on flooding. Int. J. Multiphase Flow, 27(2001):797-816.

[11] G.B. Wallis and J.T. Kuo. The behavior of gas-liquid interfaces in vertical tubes. Int. J. Multiphase Flow, 2(1976):521-536.

[12] S.S. Kutateladze. Elements of the hydrodynamics of gas-liquid systems. Fluid Mechanics Soviet Research, 1(4), 1972.

[13] D.L. Tien. A simple analytical model for counter-current flow limiting phenomena with vapor condensation. Letters in Heat and Mass Transfer, 4(1977):231-238.

[14] O.L. Pushkina and Y.L. Sorokin. Breakdown of liquid _lm motion in vertical tubes. Heat Transfer Sov. Res., 1(1969):56-64.

[15] A. Zapke and D.G. Kroger. Countercurrent gas-liquid flow in inclined and vertical ducts II: The validity of the Froude-Ohnesorge number correlation for flooding. Int. J. Multiphase Flow, 26(2000):1457-1468. 
[16] A. Zapke and D.G. Kroger. Countercurrent gas-liquid flow in inclined and vertical ducts II: Flow patterns, pressure drop characteristics and flooding. Int. J.Multiphase Flow, 26(2000):1439-1455.

[17] S.G. Bankoff and S.C. Lee. A critical review of the flooding literature. Technical report, NUREG/CR-3060, Dept. Chem. Eng., Northwestern U., Evanston, IL,1983.

[18] H.J. Richter, G.B. Wallis, and M.S. Speers. Effect of scale on two-phase countercurrent flow flooding. Technical report, NUREG/CR-0312, Dartmouth Coll.,Hanover, NH (USA). Thayer School of Engineering, 1979.

[19] S.G. Bankoff and S.C. Lee. A critical review of the flooding literature. Technical report, NUREG/CR-3060, Northwesting Univ., Evanston, IL, 1983.

[20] S. Levy. Two-Phase Flow in Complex Systems. Wiley-IEEE, 1999.

[21] G.B. Wallis. One Dimensional Two Phase Flow. McGraw-Hill, 1969.

[22] K. Ohkawa and R.T. Lahey. The analysis of CCFL using drift-flux models. Nucl. Eng. Des., 61(1980):245-255.

[23] H. Imura, H. Kusuda, and S. Funatsu. Flooding velocity in a countercurrent annular twophase flow. Chem. Eng. Sci., 32(1977):79-87.

[24] G. Karimi and M. Kawaji. Flooding in vertical counter-current annular flow.Nucl. Eng. Des., 200(2000):95-105.

[25] A.A. Mouza, S.V. Paras, and A.J. Karabelas. Incipient flooding in inclined tubes of small diameter. Int. J. Multiphase Flow, 29(2003):1395-1412.

[26] S.K. Chung, L.P. Liu, and C.L. Tien. Flooding in two-phase counter current flows-II experimental investigation. Physicochem. Hydrodyn., 1(1980):209-220.

[27] A.G. Cetinbudaklar and G.J. Jameson. The mechanism of flooding in vertical countercurrent two-phase flow. Chemical Engineering Science, 24(1969):1669-1680.

[28] Y. Taitel, D. Barnea, and A.E. Dukler. A _lm model for the prediction of flooding and flow reversal for gas-liquid flow in vertical tubes. Int. J. Multiphase Flow, 8(1982):1-10.

[29] A.E. Dukler, L. Smith, and A. Chopra. Flooding and upward film flow in tubes I: Experimental studies. Int. J. Multiphase Flow, 10(1984):585-597.

[30] D. Barnea, B. Yoseph, and Y. Taitel. Flooding in inclined pipes-effect of entrance section. Can. J. Chem. Eng., 64(1986):177-184.

[31] D. Moalem Maron and A.E. Dukler. Flooding and upward film flow in vertical tubes II: Speculations on film flow mechanisms. Int. J. Multiphase Flow,10(1984):599-621.

[32] Y. Taitel, D. Barnea, and A.E. Dukler. Modelling flow pattern transitions for steady upward gas-liquid flow in vertical tubes. AIChE Journal, 26(1980):345-354.

[33] H. Richter. Flooding in tubes and annuli. Int J. Multiphase Flow, 7(1981):647-658. 
[34] A.H. Govan, G.F. Hewitt, H.J. Richter, and A. Scott. Flooding and churn flow in vertical pipes. International J. Multiphase Flow, 17(1991):27-44.

[35] S. Jayanti, A. Tokarz, and G.F. Hewitt. Theoretical investigation of the diameter effect on flooding in countercurrent flow. Int. J. Multiphase Flow, 22(1996):307-324.

[36] H.H. Belkin, A.A. MacLeod, C.C. Monrad, and R.R. Rothfus. Turbulent liquid flow down vertical walls. AIChE journal, 5(1959):245-248.

[37] J.R.F. Guedes de Carvalho, M.A.R. Talaia, and M.J.F. Ferreira. Flooding instability of highdensity gas slugs rising in vertical tubes filled with water. Chem.Eng. Sci., 55(2000):37853802 .

[38] R.W. Fox and A.T. McDonald. Introduction to Fluid Mechanics. John Wiley \& Sons New York, 1985.

[39] A. Zapke and D.G. Kroger. The influence of fluid properties and inlet geometry on flooding in vertical and inclined tubes. Int. J. Multiphase Flow, 22(1996):461-472.

[40] J.H. Jeong and H.C. No. Experimental study of the effect of pipe length and pipe-end geometry on flooding. Int. J. Multiphase Flow, 22:(1996)499-514.

[41] A. Deendarlianto, A. Ousaka, A. Kariyasaki, T. Fukano, and M. Konishi. The effects of surface tension no the flow pattern and counter-current flow limitation (CCFL) in gasliquid two-phase flow in an inclined pipe. Japanese Journal of Multiphase Flow, 18(2004)337-350.

[42] J.R.F. Guedes de Carvalho and M.A.R. Talaia. Interfacial shear stress as a criterion for flooding in counter current film flow along vertical surfaces. Chem.Eng. Sci., 53(1998):2041-2051.

[43] N. Tsoulfanidis. Measurement and Detection of Radiation. Taylor-Fancis, 1995.

[44] C.E. Lacy and A.E. Dukler. Flooding in vertical tubes I: Experimental studies of the entry region. Int. J. Multiphase Flow, 20(1994):219-233.

[45] Idaho National Engineering and Environmental Laboratory (1999). RELAP5/MOD3 Code Manual Vol. I: Code Structure, System Models, and Solution Methods (NUREG /CR-5535, Vol. I).

[46] Los Alamos National Laboratory and Pennsylvania State University (2000). TRAC-M /FORTRAN 90 (V 3.0) Theory Manual (LA-UR-00-910).

[47] Vierow, K., T. Nagae, T. Wu, "Experimental Investigation of Reflux Condensation Heat Transfer in PWR Steam Generator Tubes in the Presence of Noncondensible Gases", 10th International Topical Meeting on Nuclear Reactor Thermal Hydraulics (NURETH-10), Seoul, Korea, Oct. 2003.

[48] Vierow, K., Liao, Y., Johnson, J., Kenton, M. and Gauntt, R. (2004). Severe Accident Analysis of a PWR Station Blackout with the MELCOR, MAAP4 and SCDAP/RELAP5 Codes, Nuclear Engineering and Design, Vol. 234, p129-145. 
[49] Burns, C., Liao, Y., Vierow, K. (2005). MELCOR Code Assessment by Simulation of TMI2, Proc. of 11th International Topical Meeting on Nuclear Reactor Thermal Hydraulics (NURETH-11), Avignon, France, (18 pp.).

[50] Hewitt, G. F. (1996). In search of two-phase flow. Transactions of the ASME, Journal of Heat Transfer, Vol. 118, p518-27.

[51] Mouza, A.A., Paras, S.V., and Karabelas, A.J. (2003). Incipient flooding in inclined tubes of small diameter. International Journal of Multiphase Flow, Vol.29, p1395-1412.

[52] Zapke, A. and Kroger, D.G. (1996). The Influence of Fluid Properties and Inlet Geometry on Flooding in Vertical and Inclined Tubes. Int. J. Multiphase Flow, Vol. 22, No. 3, p 461472.

[53] Wongwises, S. (1998). Effect of inclination angles and upper end conditions on the countercurrent flow limitation in straight circular pipes. Int. Commun. Heat Mass Transfer, Vol. 25, p117-125.

[54] Lee, S.C. and Bankoff, S.G. (1983). Stability of steam-water countercurrent flow in an inclined channel. Journal of Heat Transfer, Vol.105, p713-718.

[55] Choi, K.Y. and No, H.C. (1995). Experimental Studies of Flooding in nealy Horizontal Pipes. Int. J. Multiphase Flow, Vol. 21, p 419-436.

[56] Girard, R. and Chang J.S. (1992). Reflux condensation phenomena in single vertical tubes. International Journal of Heat Mass Transfer, Vol.35, p2203-2218.

[57] Jeong, J.H. and No, H.C. (1996). Experimental Study of the Effect of Pipe Length and Pipeend Geometry on Flooding. Int. J. Multiphase Flow, Vol. 22, p 499-514.

[58] Vijayan, M., Jayanti, S. and Balakrishnan, A.R. (2001). Effect of tube diameter on flooding. International Journal of Multiphase Flow, Vol. 27, p 797-816.

[59] Gauntt, R. O. et al., MELCOR Computer Code Manuals, Vol. 2: Reference Manuals, Version 1.8.6, Prepared by Sandia National Laboratories for the U.S. Nuclear Regulatory Commission, Office of Nuclear Regulatory Research, NUREG/CR-6119, Vol. 2, Rev. 3, SAND 2005-5713, Sept. 2005.

[60] Belkin, H. H., MacLeod, A.A., Monrad, C.C., and Rothfus, R.R. (1959). Turbulent liquid flow down vertical walls. AIChE Journal, Vol. 5, p245-248.

[61] Rothe, P. H., C. J. Crowley, (1978). Scaling Pressure and Subcooling for Countercurrent Flow, prepared by Creare, Inc. for U. S. Nuclear Regulatory Commission, NUREG/CR0464, CREARE-TN-285.

[61] Tien, C.L., Chung, K.S., and Liu, C.P. (1980) Flooding in two-phase countercurrent flows I. analytic modeling, Physiochemical Hydrodynamics, 1, 195-207.

[62] Yao, L.S. and Sun, K.H. (1981) On the prediction of the hydrodynamic flooding criterion, 20th Annual Heat Transfer Conference, Milwaukee, WI. 
[63] Shibata, Y and Kaminaga, F. (2001) Instability of interfacial waves on countercurrent twophase Flow in a vertical tube, JSME International Journal Series B, 44(3), 352-360.

[64] Wallis, G.B., Richter, H.J. and Bharathan, D., 1978. Air-water Countercurrent Annular Flow in Vertical Tubes. Electric Power Research Institute Report, EPRI NP-786.

[65] Ohkawa, K. and Lahey, R.T., 1980. The Analysis of CCFL Using Drift-flux Models. Nuclear Engineering and Design, Vol. 61, pp. 245-255.

[66] Ishii, M., 1977. One-dimensional drift-flux model and constitutive equations for relative motion between phases in various two-phase flow regimes. Argonne National Lab, ANL77-47, Argonne, Illinois.

[67] Wallis, G.B. and Makkenchey, S., 1974. The Hanging Film Phenomenon in Vertical Annular Two-Phase Flow. Transactions ASME, Series I, 96, p. 297.

[68] Sandia National Laboratories, 2000. NUREG/CR-6119, Vol. 2, Rev. 2, MELCOR Computer Code Manuals, Vol. 2: Reference Manuals, Thermal Hydraulic (CVH and FL) Packages Reference Manual, Version 1.8.5, Prepared by Sandia National Laboratories for the U.S. Nuclear Regulatory Commission, Office of Nuclear Regulatory Research.

[69] Rothe, P.H. and Crowley, C.J., Scaling pressure and subcooling for countercurrent flow. Quarterly progress report, April 1, 1978--June 30, 1978

[70] Siddiqui, H., S. Banerjee, K.N. Ardron, "Flooding in an Elbow between a Vertical and a Horizontal or Near-Horizontal Pipe, Part 1: Experiments," International Journal of Multiphase Flow, Vol. 12, No. 4, pp 531-541, 1986.

[71] Ardron, K. N., S. Banerjee, "Flooding in an Elbow between a Vertical and a Horizontal or Near Horizontal Pipe, Part II: Theory," International Journal of Multiphase Flow, Vol. 12, No. 4, pp. 543-558, 1986.

[72] G.P. Celata, M. Cumo and T. Setaro, Flooding in inclined pipes with obstructions. Exp. Thermal Fluid Sci. 5, pp. 18-25, 1992.

[73] Fletcher, D, (2005). ISL Inc., email to K. Vierow.

[84] Wallis, G. B., D. C. deSieyes, R. J. Rosselli, J. Lacombe, (1980). Countercurrent Annular Flow Regimes for Steam and Subcooled Water in a Vertical Tube. Prepared by Dartmouth College for Electric Power Research Institute, NP-1336, Research Project 443-2.

[85] Wallis, G. B., C. J. Crowley, J. A. Block, (1975). ECC Bypass Studies. AICHE Symposium on Light Water Reactor Safety, Boston, Massachusetts. 


\section{Publications Arising from this Award}

\section{Journal Publications in preparation}

"Air-water and steam-water tests for flooding in large diameter tubes", to be submitted to Nuclear Engineering Design.

"Effect of water temperature on flooding in counter-current steam-water flow", to be submitted to Nuclear Engineering Design.

\section{Conference Papers}

M. Solmos, K. J. Hogan and K. Vierow, "Flooding Experiments and Modeling for Improved Reactor Safety", sponsored by NSF, hosted by UCLA, proc. of US Japan Two Phase Flow Seminar, Santa Monica, CA, Sept. 2008. 